\title{
AVALIAÇÃO DE CARACTERÍSTICAS AGRONÔMICAS E NUTRICIONAIS DE HÍBRIDOS DE MILHO PARA SILAGEM
}

\author{
Luís Felipe Prada e SILVA \\ Engenheiro Agrônomo
}

Orientador: Prof.Dr. PAULO FERNANDO MACHADO

\begin{abstract}
Dissertação apresentada à Escola Superior de Agricultura "Luiz de Queiroz", Universidade de São Paulo, para obtenção do título de Mestre em Agronomia, Área de Concentração: Ciência Animal e Pastagens.
\end{abstract}

\section{PIRACICABA}

Estado de São Paulo - Brasil

Novembro - 1997 
Dados Internacionais de Catalogação na Publicação (CIP)

DIVISÃO DE BIBLIOTECA E DOCUMENTAC̣ÃO - Campus "Luiz de Queiroz"/USP

Silva, Luis Felipe Prada e

Avaliação de caracteristicas agronômicas e nutricionais de hibridos de milho para

silagem / Luis Felipe Prada e Silva. - - Piracicaba, 1997.

$98 \mathrm{p}$.

Dissertação (mestrado) - Escola Superior de Agricultura Luiz de Queiroz, 1997. Bibliografia.

1. Digestibilidade 2. Forragem 3. Nutrição animal 4. Silagem de milho hibrido I. Título

CDD 636.08552 


\title{
AVALIAÇÃO DE CARACTERISTICAS AGRONÔMICAS E NUTRICIONAIS DE HÍBRIDOS DE MILHO PARA SILAGEM
}

\author{
LUÍS FELIPE PRADA E SILVA
}

Aprovada em: 21.05.1998

Comissão julgadora:

Prof. Dr. Paulo Fernando Machado

ESALQ/USP

Prof. Dr. Carlos de Souza Lucci

FZEA/USP

Prof. Dr. Antonio Luiz Fancelli

ESALQ/USP

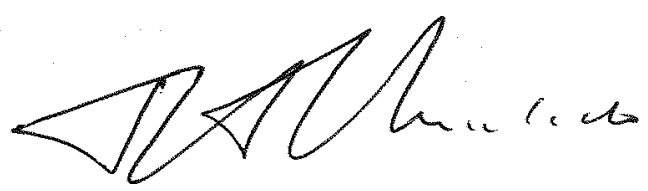

Prof. Dr. PAULO FERNANDO MACHADO

Orientador 


\section{Dedico}

Aos meus pais, Martha e Alexandre,

Aos meus irmãos João Miguel e Carolina

\section{Ofereço}

À Andréa Maria Silveira, pela presença e inspiração. 


\section{AGRADECIMENTOS}

A ESALQ/USP, pela formação pessoal e profissional, A FAPESP, pela concessão da bolsa de estudo.

A Usina Nova América (em especial, Pedro Henrique e Melchiades Donizzeti), pela realização do trabalho.

Ao Prof. Dr. Paulo Fernando Machado, pela orientação e formação profissional.

Aos colegas de pós-graduação, pela amizade e apoio.

Aos amigos do Departamento de Zoologia da ESALQ (em especial, Júnior, Lázaro, Elaine, Alfredo, Giovana), a todo seu corpo técnico e de pesquisadores, por esses anos de convivência.

A todos os professores do Curso de Ciência Animal e Pastagens, pelos ensinamentos recebidos.

A Prof.a. Dr.a. Maria Cristina Stolf Nogueira, pelo auxílio nas análises estatísticas.

Aos estagiários Kátia, Carol, Knalha, Cocho, Gigo, Nariz, Enxada, Jaqueline e Cristiane, pela ajuda na realização do experimento.

Aos colegas da república Curral, pelo apoio cultural nas horas de folga.

A todos os que me apoiaram, e desejaram que eu atingisse o meu objetivo, 


\section{SUMÁRIO}

Página

LISTA DE FIGURAS ................................................................. vi

LISTA DE TABELAS ..................................................................... vii

LISTA DE ABREVIATURAS ......................................................... xii

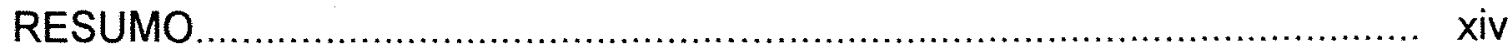

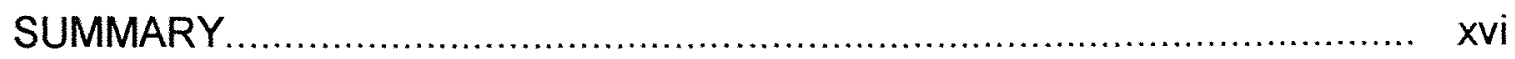

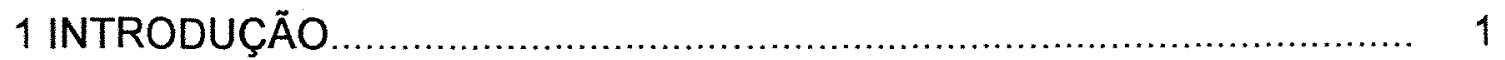

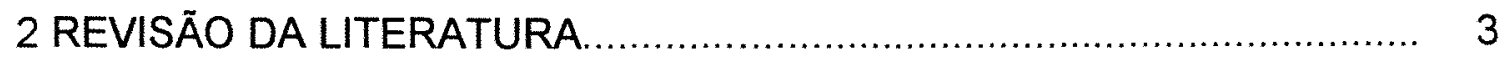

2.1 Relação entre a composição da planta de milho e sua qualidade

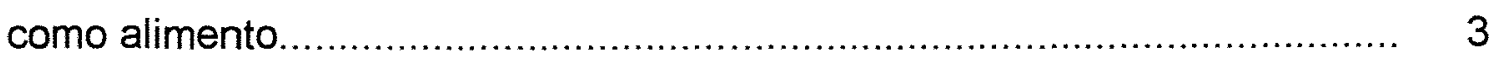

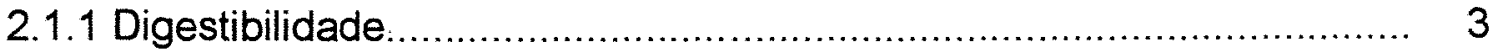

2.1.2 Digestibilidade vs. Consumo.................................................... 12

2.2 Fatores ambientais que afetam a qualidade da forragem................... 19

2.2.1 Défice hídrico..................................................................... 19

2.2.2 Temperatura e luminosidade ................................................. 22

2.2.3 Efeito ambiental vs. efeito genético .............................................. 22

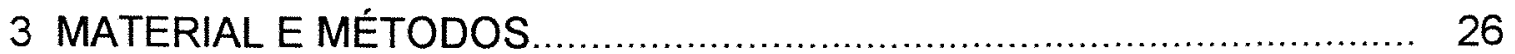

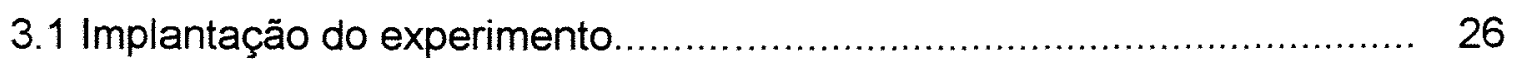

3.2 Colheita e preparo das amostras............................................... 29

3.3 Confecção das silagens de milho................................................ 30

3.4 Análises laboratoriais............................................................... 30

3.5 Determinação da degradabilidade "in situ" ...................................... 30

3.5.1 Períodos de coleta.................................................................. 32

3.5.2 Modelos matemáticos........................................................ 33

3.6 Análise estatística..................................................................... 35

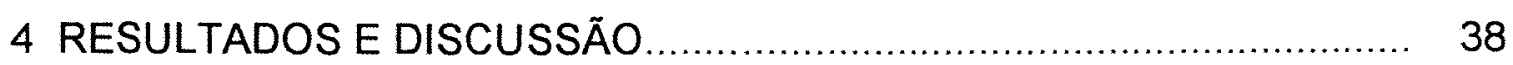


Página

4.1 Características agronômicas, composição química, digestibilidade "in situ" e cinética da degradação da fração volumosa (haste+folhas) dos híbridos de milho cultivadas nos anos de 1996 e 1997 38

4.1.1 Características agronômicas.................................................. 38

4.1.2 Composição química............................................................. 41

4.1.3 Digestibilidade "in situ" ....................................................... 43

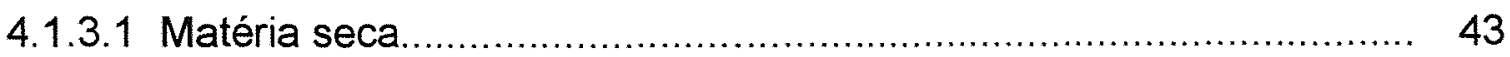

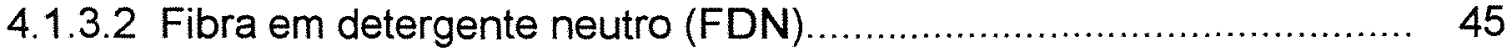

4.1.4 Cinética da degradação............................................................ 47

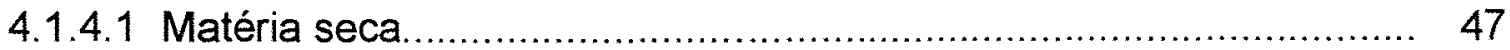

4.1.4.2 Fibra em detergente neutro (FDN) ..................................... 49

4.2 Efeito do ciclo fenológico ....................................................... 51

4.3 Relação entre as variáveis analisadas............................................ 53

4.3.1 Características agronômicas vs. composição química da fração volumosa.

4.3.2 Características agronômicas vs. digestibilidade "in situ" da MS da fração volumosa.

4.3.3 Características agronômicas vs. digestibilidade "in situ" do FDN da fração volumosa.

4.3.4 Análises químicas vs. digestibilidade "in situ" da MS da fração volumosa 64

4.3.5 Análises químicas vs. digestibilidade "in situ" do FDN da fração volumosa.

4.3.6 Composição química e digestibilidade da fração volumosa vs.

composição química das silagens em 1996.

Efeito do ambiente sobre as características agronômicas, composição

química e digestibilidade da fração volumosa de híbridos de milho.

5 CONCLUSÕES.

REFERÊNCIAS BIBLIOGRÁFICAS 


\section{LISTA DE FIGURAS}

Página

1 Relação entre a \% de grãos e a digestibilidade de silagens de milho... 09

2 Relação entre a porcentagem de grãos na MS e o teor de FDA de silagens de milho

3 Relação entre o teor de FDA de silagens de milho e sua digestibilidade "in situ"

4 Cinética da degradação de duas forrageiras.

5 Relação entre o teor de FDA e a digestibilidade "in situ" da porção volumosa de híbridos de milho. 


\section{LISTA DE TABELAS}

Página

1 Correlações entre medidas agronômicas e qualitativas de 23 silagens de milho oferecidas a carneiros

6

2 Efeito do ambiente sobre a qualidade de plantas de milho 21

3 Influência de fatores ambientais sobre a composição e digestibilidade de forragens.

4 Análise química do solo onde foi implementado o experimento. 26

5 Precipitação pluvial ocorrida nos dois anos experimentais 27

6 Caracterização dos híbridos de milho utilizados no experimento. 28

7 Composição química dos alimentos utilizados na dieta do animal. 31

8 Composição bromatológica do feno de aveia utilizado como padrão .... 32

9 Análise de variância do experimento 1 ano a ano. 35

10 Análise de variância dos dois anos experimentais em conjunto do experimento 1 .

11 Análise de variância ano a ano do experimento 2

12 Análise de variância dos dois anos experimentais em conjunto do experimento 2 
Página

13 Características agronômicas dos híbridos de milho em 1996

39

14 Características agronômicas dos híbridos de milho em 1997

15 Composição bromatológica da fração volumosa (haste+folha) de hibridos de milho em 1996

16 Composição bromatológica da fração volumosa (haste+folha) de híbridos de milho 1997.

17 Digestibilidade "in situ" da MS da fração volumosa dos híbridos de milho em 1996

18 Digestibilidade "in situ" da MS da fração volumosa dos híbridos de milho em 1997.

19 Digestibilidade "in situ" do FDN da fração volumosa dos híbridos de milho em 1996

20 Digestibilidade "in situ" do FDN da fração volumosa dos híbridos de milho em 1997

21 Cinética da degradação ruminal da MS da fração volumosa dos híbridos de milho em 1996.

22 Cinética da degradação ruminal da MS da fração volumosa dos híbridos de milho em 1997. 
Página

23 Cinética da degradação ruminal do FDN da fração volumosa de hibridos de milho em 1996.

50

24 Cinética da degradação ruminal do FDN da fração volumosa de híbridos de milho em 1997.

25 Efeito do ciclo fenológico dos híbridos sobre as variáveis estudadas.... 52

26 Correlação entre as características de produção e a composição bromatológica da fração volumosa em 1996. 55

27 Correlação entre as características de produção e a composição bromatológica da fração volumosa em 1997.

28 Correlação entre as características de produção e a composição bromatológica da fração volumosa $(1996+1997)$. 58

29 Correlação entre as características agronômicas e a digestibilidade "in situ" da MS da fração volumosa em 1996.

30 Correlação entre as características agronômicas e a digestibilidade "in situ" da MS da fração volumosa em 1997.

31 Correlação entre a digestibilidade "in situ" do FDN da fração volumosa e as características agronômicas de híbridos de milho em 1996.

62

32 Correlação entre a digestibilidade "in situ" do FDN e as características agronômicas de híbridos de milho em 1997 
Página

33 Correlação entre a degradação "in situ" da MS e as análises bromatológicas da fração volumosa em 1996 .................................. 65

34 Correlação entre a degradação "in situ" da MS e as análises bromatológicas e da fração volumosa em 1997.

35 Correlação entre a degradação "in situ" da MS e as análises bromatológicas da fração volumosa (1996 e 1997).

36 Correlação entre a digestibilidade "in situ" do FDN e composição bromatológica da fração volumosa em 1996

37 Correlação entre a digestibilidade "in situ" do FDN e composição bromatológica da fração volumosa em 1997

38 Composição bromatológica das silagens de milho de 1996.

72

39 Correlação entre a composição química das silagens de milho dos hibridos de 1996

40 Correlação entre a composição química das silagens e da fração volumosa de hibridos de milho de 1996.

41 Correlação entre a composição química das silagens de milho e as características de produção dos híbridos de milho em 1996.

42 Correlação entre a composição química das silagens de milho e a digestibilidade da fração volumosa em 1996 
Página

43 Efeito do ano agrícola sobre a composição bromatológica dos híbridos de milho.................................................................... 78

44 Efeito do ano agrícola sobre as características agronômicas dos hibridos de milho. 78

45 Efeito do ano agrícola sobre a digestibilidade da MS da fração volumosa dos híbridos de milho

46 Correlação entre as características agronômicas e a digestibilidade "in situ" da MS da fração volumosa (1996 e 1997).

47 Degradabilidade da MS do feno de aveia (padrão) nos dois anos experimentais.

48 Efeito do ano agrícola sobre a digestibilidade do FDN da fração volumosa dos híbridos de milho.

49 Correlação entre a digestibilidade "in situ" do FDN e as características agronômicas de híbridos de milho dos dois anos experimentais (1996 e 1997). 82

50 Correlação entre a digestibilidade "in situ" do FDN e composição bromatológica da fração volumosa dos dois anos experimentais (1996 e 1997) 


\section{LISTA DE ABREVIATURAS}

\%ESPIGA = porcentagem de espigas na MS

$\mathrm{CEL}=$ celulose

CELFDN $=$ porcentagem de celulose do FDN

$C E L s=C E L$ da silagem

Deg.ef. = degradabilidade efetiva

Dry-down = diferença entre o teor de MS das espigas e da fração volumosa

FDA = fibra em detergente ácido

FDAs = FDA da silagem

FDN = fibra em detergente neutro

FDNs $=$ FDN da silagem

Fill = tempo de retenção ruminal

HEM = hemicelulose

HEMFDN = porcentagem de hemicelulose no FDN

HEMs = HEM da silagem

Lag = tempo de colonização

$\mathrm{LIG}=$ lignina

LIGFDN = porcentagem de lignina no FDN

LIGs = LIG da silagem

$\mathrm{MM}=$ matéria mineral

$\mathrm{MMs}=\mathrm{MM}$ da silagem

$M S$ = matéria seca

MS espigas = teor de MS das espigas

$M S P L=$ teor de MS da planta inteira

MSs = MS da silagem

$\mathrm{N}-\mathrm{FDA}=$ nitrogênio ligado ao FDA

$\mathrm{N}-\mathrm{NH}_{3}=$ nitrogênio na forma amoniacal

$\mathrm{PB}=$ proteína bruta

$\mathrm{PBs}=\mathrm{PB}$ da silagem 
PESP = produção de espigas

$\mathrm{PFIB}=$ produção da porção volumosa

PTOT = produção total de MS 


\title{
AVALIAÇÃO DE CARACTERISTIICAS AGRONÔMICAS E NUTRICIONAIS DE HÍBRIDOS DE MILHO PARA SILAGEM
}

\author{
Autor: LUÍS FELIPE PRADA E SILVA \\ Orientador: Prof. Dr.: PAULO FERNANDO MACHADO
}

\section{RESUMO}

Estudou-se as características agronômicas, composição química da fração volumosa ( haste+folhas) e da silagem, e a digestibilidade "in situ" da matéria seca e da fibra em detergente neutro da fração volumosa de 28 híbridos de milho em 1996, e de 21 híbridos de milho em 1997, com o objetivo de se estabelecer as relações existentes entre os parâmetros analisados. Dos 21 híbridos de milho selecionados em 1997, 13 fizeram parte do experimento em 1996. Em 1996, foram confeccionadas silagens em tambores de $200 \mathrm{~L}$ dos híbridos estudados. Foi utilizado o modelo de McDonald (1981) para se avaliar a cinética de degradação "in situ" da MS, e o modelo descrito por Mertens \& Loften (1980) para se analisar a cinética de degradação "in situ" do FDN. No experimento de campo (características agronômicas e composição química), o delineamento experimental utilizado foi o de blocos ao acaso com 3 repetições. No experimento de digestibilidade "in situ", o delineamento utilizado foi o de parcelas subdivididas, onde os períodos constituiam os blocos (3 periodos), os tempos de incubação ruminal as parcelas e os hibridos de milho as subparcelas. Os dois anos experimentais foram analisados em conjunto para se determinar o efeito ambiental (ano) e a interação efeito genético (híbrido) e ambiental (ano) sobre os parâmetros analisados. Observou-se a existência de variabilidade genética para todos os parâmetros analisados. A produção total e a porcentagem de grãos não se mostraram correlacionadas com a digestibilidade da porção volumosa, indicando a possibilidade de um programa de seleção conjunto para produção e digestibilidade. Os constituintes da parede 
celular (FDN, FDA, lignina, celulose e hemicelulose) se mostraram negativamente correlacionados com a digestibilidade da MS da porção fibrosa, sendo que dentre eles, o FDA foi o parâmetro que melhor se relacionou com a degradabilidade efetiva da MS durante os dois anos experimentais, indicando que doravante, deva ser utilizado como indicador da digestibilidade da fração volumosa usando-se a equação desenvolvida: Deg.ef $=100,6077-1,4085$ * FDA $\left(R^{2}=0,86\right)$. A porcentagem de espigas na $M S$ se mostrou positivamente correlacionada com o teor de FDN e FDA da fração volumosa em 1996, e com o teor de FDA em 1997, indicando um possível efeito de translocação de carboidratos da planta para os grãos. Houve grande efeito ambiental sobre os parâmetros de qualidade dos híbridos de milho. A interação híbridoXano experimental foi significativa para as características agronômicas, bem como para a digestibilidade da fração volumosa, indicando que o efeito ambiental exerceu grande influência sobre a expressão genética dos híbridos, porém a interação não foi significativa para o teor de FDA da fração volumosa. A ocorrência de estresse hídrico (1996) diminuiu a produção total de MS e a participação das espigas na MS, porém aumentou a digestibilidade "in situ" da MS da fração volumosa dos híbridos. 


\title{
EVALUATION OF NUTRITIONAL AND AGRONOMIC CHARACTERISTICS OF CORN HYBRIDS FOR SILAGE
}

\author{
Author: LUIS FELIPE PRADA E SILVA \\ Adviser: Prof. Dr. PAULO FERNANDO MACHADO
}

\section{SUMMARY}

The agronomic characteristics, stover and silage chemical composition, and the dry matter (DM) and neutral detergent fiber (NDF) "in situ" digestibility of 28 corn hybrids in 1996, and 21 corn hybrids in 1997, was measured with the objective of establishing relationships among this analyzed variables. From the 21 corn hybrids selected in 1997, 13 were hybrids already tested in 1996. In 1996, silages were made with the selected hybrids in $200 \mathrm{~L}$ plastic barrels. The mathematic model described by McDonald (1981) was used to describe the DM "in situ" digestibility kinetics, and the model described by Mertens \& Loften (1980) to analyze the digestibility kinetics of the NDF fraction. The experimental design utilized in the agronomic experiment was the randomized blocks with 3 plots. In the digestibility trial, the split-plot design was utilized, where the periods were the blocks ( 3 periods), the ruminal incubation times were the plots, and the corn hybrids were the split-plots. Both the years were analyzed together to determine the environmental effect (year) and the environmental (year) $x$ genetic (hybrids) interactions over the analyzed variables. The occurrence of genetic variability was observed for all the analyzed variables. The total DM production and the cob percentage were not correlated with the stover digestibility, showing the possibility for a selection program based on productivity and digestibility. The cell wall constituents (NDF, ADF, lignin, cellulose and hemicellulose) were negatively correlated with the stover DM digestibility, and among them, ADF was the variable best correlated with effective DM degradability (Deg.ef) during both 
experimental years, showing that from now on should be utilized as a stover digestibility indicator using this equation: Deg.ef $=100,6077-1,4085^{*} \mathrm{ADF}$ $\left(R^{2}=0,86\right)$. The cobs $D M$ percentage were positively correlated with the stover NDF and ADF content in 1996, and with the stover ADF content in 1997; possibly a reflection of a soluble carbohydrates translocation from the stover to the grains. There was a greatest environmental effect over the corn hybrid quality variables. The hybrid $X$ year interaction was significant for the agronomic characteristics, as well as for the stover digestibility, showing that the environment had great influence upon the genetic behavior of the corn hybrids, however the interaction were not significant for the stover ADF content. The occurrence of water stress (1996) reduced the DM total production and the percentage of cobs, however improved the corn hybrids stover digestibility. 


\section{INTRODUÇÃO}

Apesar das elevadas quantidades de concentrado utilizadas nas dietas para produção de leite e carne, a forragem permanece como principal fonte de nutrientes para o animal ruminante, uma vez que, além de fornecer nutrientes, estimula a ruminação e a salivação, importantes para o tamponamento e saúde do rúmen. $E$ é, normalmente, mais barata que os alimentos concentrados.

No entanto, o valor nutritivo das forragens é, via de regra, mais baixo do que o dos concentrados. Como valor nutritivo entende-se o efeito do alimento sobre o seu consumo e a sua digestibilidade, o que determinará a produtividade do animal.

Visando maximizar a produtividade, deve-se procurar fornecer alimentos volumosos que possuam a maior digestibilidade, desta maneira sendo atendidos os requisitos por fibra na dieta ao mesmo tempo que será aumentado o fornecimento de nutrientes para maior produção.

A silagem de milho compõe grande parte da alimentação de bovinos leiteiros em nosso país, sendo utilizada como principal ou único volumoso da dieta, e portanto, é imperativo que se conheça o seu valor nutritivo.

Apesar de utilizada como volumoso, o fator mais enfatizado para a avaliação da qualidade de uma silagem de milho é a porcentagem de grãos na matéria seca. Isto porque trabalhos desenvolvidos até a década de 70 (Morrison, 1956; Daynard \& Hunter, 1975; Roth et al., 1970) demonstraram que os grãos de milho são mais digestíveis do que as folhas e hastes da planta $e$, sendo assim, aumentando-se a proporção de grãos na MS, aumentar-se-ia a qualidade do volumoso 
Esta afirmação parece óbvia, e pode ser traduzida no seguinte: aumentando-se a proporção de concentrado aumenta-se a digestibilidade da dieta, o que é verdade.

No entanto, outros trabalhos (Deinum \& Bakker, 1981; Coors, 1996; Oliveira et al., 1997) mostram não haver correlação entre a porcentagem de grãos e a digestibilidade da porção volumosa (haste+folhas) da silagem de milho, enfatizando que grande parte dos trabalhos de seleção de híbridos foi conduzido de forma errônea, quando se pensa em qualidade de volumoso.

Isto não quer dizer que a porcentagem de grãos não seja importante, é, no entanto, a digestibilidade da porção volumosa deve ser avaliada se pretende-se determinar a qualidade do material.

Este trabalho tem como objetivos verificar a relação entre características agronômicas (produção de MS, produção e proporção de espigas na MS), composição química da porção volumosa e da silagem, e ambiente com a qualidade da fração volumosa medida através da sua digestibilidade "in situ". 


\section{REVISÃO DE LITERATURA}

\subsection{Relação entre a composição da planta de milho e sua qualidade como alimento}

\subsubsection{Digestibilidade}

As pesquisas realizadas nas décadas de 60 e 70, (Morrison, 1959; Daynard \& Hunter, 1975; Roth et al., 1970) levaram à crença geral que a qualidade da silagem de milho estaria intimamente relacionada com a porcentagem de grãos na matéria seca total.

Morrison (1959) relatou digestibilidade "in vitro" de $85,8 \%$ para os grãos de milho, $61,2 \%$ para as folhas e $48,2 \%$ para as hastes da planta de milho.

Daynard \& Hunter (1975), estudando 4 híbridos comerciais por dois anos, também demonstraram a maior digestibilidade "in vitro" dos grãos de milho sobre o restante da planta. Quando colhido com um teor de MS de 33,2\%, a digestibilidade "in vitro" foi de $83,4 \%$ para os grãos, $57 \%$ para a fração volumosa (haste e folhas), $67,4 \%$ para as brácteas e $54,5 \%$ para o sabugo. A digestibilidade da planta inteira foi de $70,0 \%$. Os autores relatam que com 0 avanço da maturidade da planta, não houve mudança na digestibilidade da planta inteira, porém, a digestibilidade da fração volumosa (haste e folhas) passou de $61,8 \%$ com $24 \%$ de MS para $54,2 \%$ com $39,6 \%$ de MS, enquanto que a digestibilidade dos grãos passou de 86,3 a $84,6 \%$. Ou seja, o avanço da maturidade aumentou a participação dos grãos na MS e diminuiu a 
digestibilidade da porção volumosa, mantendo a digestibilidade da planta inteira.

Trabalhando com carneiros, Gordon et al. (1968) avaliaram dois materiais oriundos de silagens no ponto normal de corte ( $26 \%$ de MS), com pequena participação de grãos na MS, ou de silagens confeccionadas com plantas no estádio de maturidade fisiológica dos grãos ( $56 \% \mathrm{MS}$ ), com maior participação de grãos no total de MS ensilado. Não encontraram diferença no consumo das silagens pelos carneiros, sendo que a digestibilidade "in vivo" da MS das duas silagens foi de 70,3 e $68,8 \%$ para as silagens com baixo e alto teor de MS, respectivamente.

Outros trabalhos, como o de Johnson \& McClure (1968), mostraram pequena variação na digestibilidade "in vivo" de silagens de milho cortadas em diferentes estágios de maturidade. No entanto, a digestibilidade da celulose decresceu significativamente com o avanço da maturidade, passando de $74 \%$ para $48 \%$ quando o teor de MS passou de $20 \%$ para $71 \%$.

A literatura demonstra que ocorre pequena variação entre os materiais quanto a digestibilidade dos grãos. No entanto, ocorre grandes variações na digestibilidade da porção volumosa, como evidenciado no trabalho de Johnson et al. (1985). Os autores estudaram a digestibilidade "in vitro" de 13 híbridos de milho e encontraram uma variação de 85,8 a $89,0 \%$ e de 61,6 a $69,5 \%$ para a digestibilidade dos grãos e da haste, respectivamente.

Penati (1995) reporta uma variação na digestibilidade "in vitro" da haste de híbridos de milho de 40 a 59,73\%; enquanto a digestibilidade da planta inteira variou de 58,3 a $66,9 \%$.

Roth et al. (1970) analisaram a digestibilidade "in vitro" da MS, FDA, FDN, lignina e PB de 36 híbridos de milho para silagem. Os resultados apontam uma grande variação genética quanto a digestibilidade das diferentes frações. A porcentagem de espigas na MS apresentou correlação negativa com a produção total de MS $(r=-0,43)$ e correlação positiva com a digestibilidade da MS $(r=0,51)$. A correlação negativa entre a produção total e a digestibilidade "in 
vitro" $(r=-0,51)$ demostra a dificuldade de se selecionar um híbrido produtivo e com elevada qualidade nutritiva.

Resultados semelhantes foram observados por Wolf et al. (1993), onde a porcentagem de grãos se mostrou correlacionada com a digestibilidade verdadeira "in vitro" da MS, porém não se mostrou correlacionada com a digestibilidade da parede celular. A produção total de MS não se mostrou correlacionada com a produção de grãos $(r=0,15)$ ou com a porcentagem de grãos na MS $(r=-0,16)$, mas se mostrou correlacionada com a produção da fração volumosa $(r=0,90)$.

Schmid et al. (1976) avaliaram 23 silagens feitas de 11 híbridos de milho para determinar a importância da composição da planta e digestibilidade sobre a performance de carneiros. Os resultados obtidos podem ser visualizados na tabela 1. A porcentagem de grãos apresentou correlação positiva com a digestibilidade "in vivo" da MS, consumo de MS e ganho médio diário; enquanto os outros componentes apresentaram correlações negativas. A porcentagem de grãos na MS não apresentou correlação com a produção total. É interessante notar que a silagem que apresentava elevada porcentagem de grãos (64\%) e com maior digestibilidade e consumo se mostrava com $55,8 \%$ de MS, enquanto a silagem com menor digestibilidade, menor ganho médio diário e baixa porcentagem de grãos (16\%) se mostrava com $22,8 \%$ de MS.

Owen (1967) observou que aumentando a porcentagem de grãos na MS aumenta o teor de MS da planta inteira, que por sua vez afeta o consumo de MS pelo animal. O autor não foi capaz de concluir se a mudança na performance do animal foi devido a maior concentração de grãos ou ao maior teor de MS da dieta. O efeito do teor de MS de silagens sobre o consumo de MS foi demonstrado por Huber et al. (1965), onde vacas de leite consumindo silagens com 25, 30 ou 35 \% MS apresentaram um consumo de 1,95; 2,13 e $2,31 \mathrm{~kg} \mathrm{MS} .100 \mathrm{~kg}^{-1} \mathrm{PV}$, respectivamente. 
Tabela 1. Correlações entre medidas agronômicas e qualitativas de 23 silagens de milho oferecidas a carneiros.

\begin{tabular}{|c|c|c|c|c|c|c|c|c|}
\hline \multirow[b]{2}{*}{$\begin{array}{l}\text { Medidas } \\
\text { Agronômicas }\end{array}$} & \multicolumn{4}{|c|}{ Medidas de qualidade * } & \multicolumn{4}{|c|}{ Medidas Agronômicas } \\
\hline & ADF & DMS & CMS & GMD & Folhas & Hastes & Grãos & Altura \\
\hline & & & & & - & $\%$ & - & \\
\hline Folhas(\%) & 0,78 & $-0,63$ & $-0,73$ & $-0,68$ & & & & \\
\hline Hastes(\%) & 0,90 & $-0,67$ & $-0,71$ & $-0,65$ & 0,89 & & & \\
\hline Grãos(\%) & $-0,87$ & 0,67 & 0,73 & 0,68 & $-0,97$ & $-0,97$ & & \\
\hline Altura & 0,35 & $-0,11$ & $-0,26$ & $-0,34$ & 0,20 & 0,47 & $-0,35$ & \\
\hline Produção & 0,1 & $-0,11$ & $-0,15$ & $-0,26$ & $-0,08$ & 0,15 & $-0,04$ & 0,76 \\
\hline
\end{tabular}

* Correlação significativa com $P<0,05= \pm 0,39$.

$\mathrm{ADF}=$ Fibra em detergente neutro, $\mathrm{DMS}$ = digestibilidade da matéria seca, CMS = consumo de matéria seca, GMD = ganho médio diário.

Fonte: Adaptado de Schmid et al. (1976).

A linha de pensamento que vem sendo defendida, qual seja, o aumento na porcentagem de grãos corresponde ao aumento da qualidade da silagem, ficou claramente demonstrada no trabalho de Sonon et al. (1993). Os autores retiraram a espiga da planta no momento da ensilagem e ensilaram o material reconstituído com a espiga triturada em proporções que variaram de 0 a $65 \%$ de grãos na MS. Quando as silagens foram fornecidas a carneiros para a avaliação de consumo e digestibilidade, pode-se notar o efeito benéfico da maior proporção de grãos na MS sobre o desempenho animal, uma vez que o consumo voluntário passou de 39,4 para 59,3 g MS . kg-1 de peso metabólico e a digestibilidade da MS passou de 55,7 para $69,1 \%$. A digestibilidade da fibra (FDA) diminuiu com $\circ$ aumento da concentração de grãos, passando de 45,9 para $35,1 \%$.

Trabalho semelhante foi desenvolvido por Fischer et al. (1968) em ensaio 
de produção para avaliação de silagens feitas com ou sem grãos.

Contrastando com os resultados apresentados, que levam a conclusão que silagens com maior porcentagem de grãos na MS apresentam maiores desempenhos animais, McCullough et al. (1964) forneceu aos animais silagens feitas com linhagens macho estéreis ou regulares e não observou diferença na produção de leite dos animais.

Deinum \& Bakker (1981) testaram, na Holanda, 27 híbridos em 1976 e 29 híbridos em 1978, em três locais. Os resultados mostraram pequena correlação entre porcentagem de grãos e digestibilidade da planta inteira $(r=0,48$ e 0,49 para os anos de 1976 e 1978) e uma elevada correlaçăo entre digestibilidade da fração volumosa (hastetfolhas) com a digestibilidade da planta inteira $(r=0,66$ e 0,78$)$. A porcentagem de grãos na MS se mostrou positivamente correlacionada com o teor de FDN da fração volumosa ( $r=0,55$ e 0,68 ), demonstrando um possível efeito de translocação de carboidratos solúveis da fração volumosa para os grãos, como sugerido por Russel et al. (1992).

Neste estudo de Deinum \& Bakker (1981), a digestibilidade do FDN da fração volumosa não se mostrou correlacionada com a porcentagem de grãos na MS, demonstrando que os híbridos com maior enchimento de gräos não necessariamente se apresentam mais lignificados e com menor digestibilidade da parede celular. Os autores sugerem que a seleção de híbridos para silagem se dê sobre a maior digestibilidade da fração volumosa.

No experimento de Lundvall et al. (1994) a produção de grãos não foi associada com a digestibilidade "in vitro" da fração volumosa, se correlacionando fracamente com o teor de FDN da mesma $(r=0,32)$.

Pequena correlação entre a porcentagem de grãos na MS e digestibilidade da planta inteira $(r=0,48)$, e elevada correlação entre a digestibilidade da fração volumosa e da planta inteira também foram os resultados obtidos por Vattikonda \& Hunter (1983). Os autores conduziram a avaliação de híbridos de milho para silagem por dois anos (1978 e 1979) em duas localidades do Canadá. Estes autores demonstraram ainda, que a digestibilidade da fração 
volumosa (haste+folhas) apresenta maior variação na digestibilidade do que a planta inteira ou somente os grãos, semelhante ao encontrado por Wolf et al. (1993) e por Coors (1996).

No estudo de Deinum (1988), a correlação entre \% de grãos e digestibilidade da MS da planta inteira foi baixa, bem como a relação entre FDA, FDN e lignina com a digestibilidade. No entanto, a digestibilidade da MS da planta inteira e digestibilidade do FDN da haste foi elevada $(r=0,60$ a 0,96$)$.

Isto indica que a variação genética na digestibilidade da MS de plantas de milho seria principalmente influenciada pela variação genética da digestibilidade do FDN e não tanto pela produção e composição da parede celular.

Sanderson et al. (1995) não encontraram correlação entre a porcentagem de espigas na MS e a digestibilidade da planta inteira, mesmo resultado obtido por Coors (1996).

Neste trabalho, Coors (1996) estudou 33 hibridos de milho e encontrou uma correlação positiva entre a porcentagem de grãos na MS e o teor de FDN da fração volumosa ( $r=0,57$ para híbridos precoces e $r=0,81$ para híbridos tardios), apesar da correlação negativa entre porcentagem de grãos e o teor de FDN da planta inteira ( $r=-0,69$ para híbridos precoces e $r=-0,46$ para híbridos tardios). $O$ autor não encontrou nenhuma correlação entre produção de MS e digestibilidade da MS ou FDN.

Ferret et al. (1997) estudando 11 silagens de milho na Espanha, encontraram uma correlação positiva $(r=0,69)$ entre o teor de FDA da fração volumosa e a porcentagem de grãos da silagem.

Resultados semelhantes demonstrando o efeito de translocação de carboidratos, foi encontrado por pesquisadores brasileiros. Oliveira et al. (1997) estudaram 11 cultivares de milho em Coronel Pacheco (MG) quanto a digestibilidade "in situ" de suas diversas frações e a correlação com a composição botânica da planta. A correlação entre a digestibilidade "in situ" da planta inteira e a porcentagem de grãos foi extremamente baixa $\left(R^{2}=0,009\right)$ e pode ser visualizado na figura 1. 
Penati (1995) analisando 19 híbridos de milho para silagem, encontrou correlação baixa entre \% de grãos e digestibilidade verdadeira in vitro da MS . As maiores correlações com a digestibilidade foram encontradas com os constituintes da parede celular, sendo que a porcentagem de lignina respondeu por $31,09 \%$ da variação, enquanto ADF e FDN por 27,19 e 24,35\% da variação, respectivamente. $O$ autor observou que a produção total de MS pode ser obtida com diferentes participações dos componentes da planta, sendo produção de folha o maior responsável pela produção de $M S$ total $\left(R^{2}=60,59\right)$.

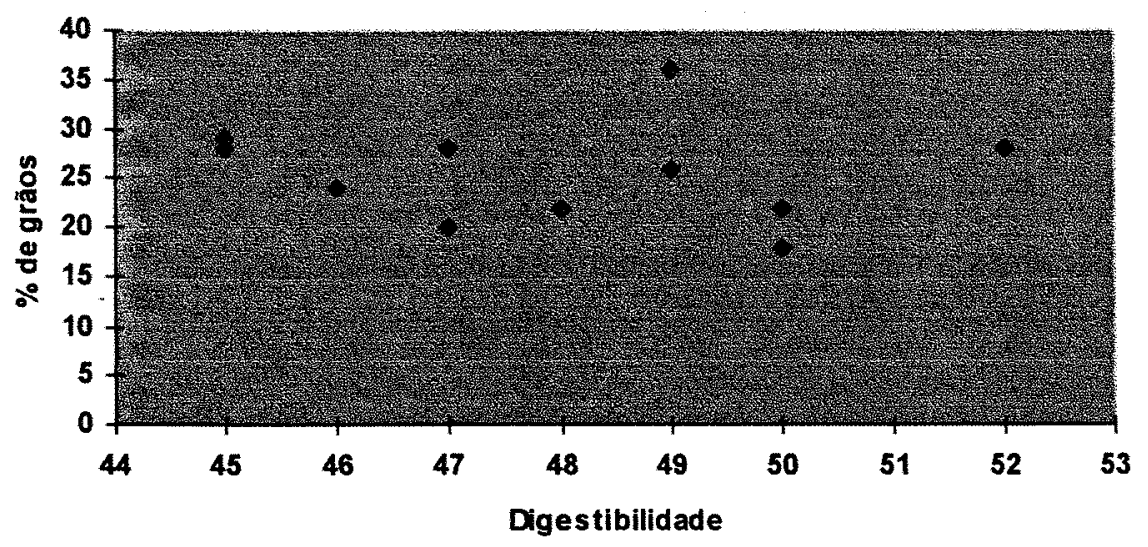

Figura 1. Relação entre \% de grãos e a digestibilidade de silagens de milho. Fonte: adaptado de Oliveira et al. (1997).

Nussio et al. (1992) em avaliação de 18 híbridos de milho colhidos no mesmo ponto de maturação (média de $36,37 \% \mathrm{MS}$ ) concluíram que a porcentagem de grãos se correlaciona negativamente com a produção de MS e que híbridos com maior proporção de grãos tendem a apresentar maiores teores de FDN da haste, porém FDN da planta inteira e a digestibilidade verdadeira in vitro da matéria seca da planta foi semelhante aos demais híbridos. 
Estes trabalhos mostram que o teor de carboidratos não estruturais da fração volumosa é normalmente inversamente relacionado com a porcentagem de grãos do material, por serem translocados da haste, para os grãos em desenvolvimento. Sendo assim, a digestibilidade da fraçäo volumosa estaria negativamente correlacionada com a porcentagem de grãos, e a digestibilidade da planta inteira seria minimamente afetada pela porcentagem de grãos.

A variação genética existente na digestibilidade da fração volumosa foi demonstrada em vários trabalhos (Buxton \& Casler, 1993; Lundvall et al., 1994; Leask \& Daynard, 1973; Flachowsky et al., 1993; Coors et al., 1992; Roth, 1992; Hintz et al., 1992).

Allen et al. (1990) encontraram uma variação de 29 unidades percentuais na digestibilidade do FDN de híbridos de milho.

Allen et al. (1997) salienta que qualidade de silagem é um termo complexo, e que somente fatores de qualidade que possuem repetibilidade das diferenças entre híbridos devem ser utilizados para seleção dos mesmos. Estes fatores incluem, segundo os autores: conteúdo de fibra, proteína e gordura e digestibilidade da fibra e do amido. Estes autores também destacam o maior retorno financeiro oriundo de um híbrido de alta digestibilidade da fibra quando comparado a um hibrido de elevada produção de MS por área.

As seguintes características desejáveis em um híbrido ideal para silagem, são apontadas por Roth \& Lauer (1997): elevada produção de silagem, elevada qualidade de forragem, resistência a doenças e a acamamento, textura macia dos grãos e relação entre produção total e umidade.

Os autores demonstram que produção e qualidade não são variáveis antagônicas, e afirmam que, considerando-se o retorno econômico da propriedade agrícola, um híbrido de alta qualidade e baixa produção é superior a um híbrido de elevada produção e baixa qualidade.

A problemática de definição do que seria qualidade de silagem é abordada no trabalho de Undersander (1997). O autor demonstra a falta de correlação entre a porcentagem de grãos na MS e o teor de FDA das silagens (figura 2), e 
também para a falta de correlação entre o teor de FDA das silagens e sua digestibilidade "in vitro" (figura 3).

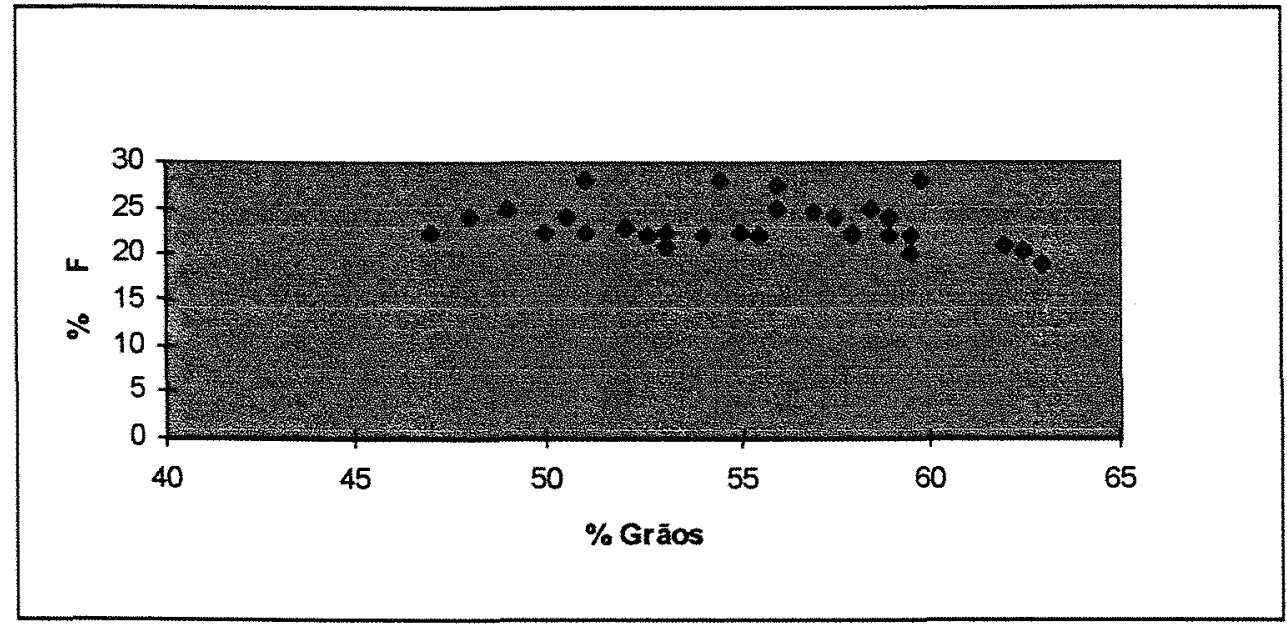

Figura 2. Relação entre a porcentagem de grãos na MS e o teor de FDA de silagens de milho.

Fonte: Adaptado de Undersander (1997).

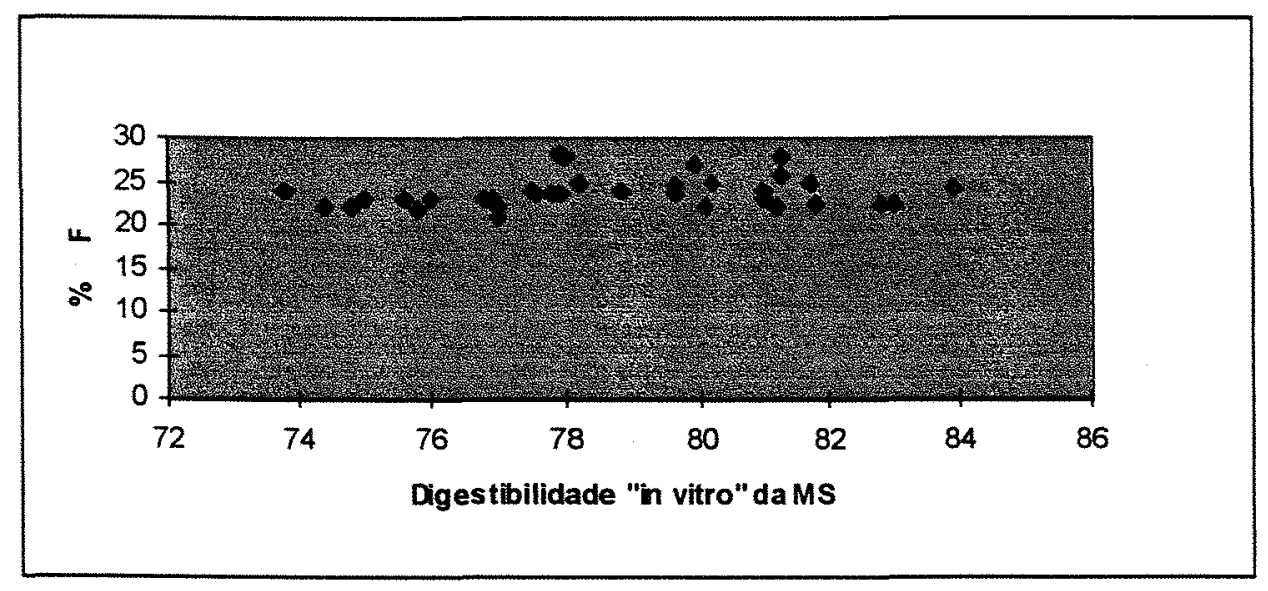

Figura 3. Relação entre o teor de FDA de silagens de milho e sua digestibilidade "in situ".

Fonte: Adaptado de Undersander (1997). 
Outro ponto levantado pelo autor é o tempo de incubação "in vitro" para determinação da digestibilidade. O uso da digestibilidade "in vitro" pode levar a erros na avaliação de silagens, uma vez que está baseada em somente um ponto da curva de degradação do alimento (normalmente 30 ou 48 horas). 0 autor sugere a obtenção de toda a curva de degradação ( "in situ" ou "in vitro") para melhor avaliação dos alimentos (figura 4).

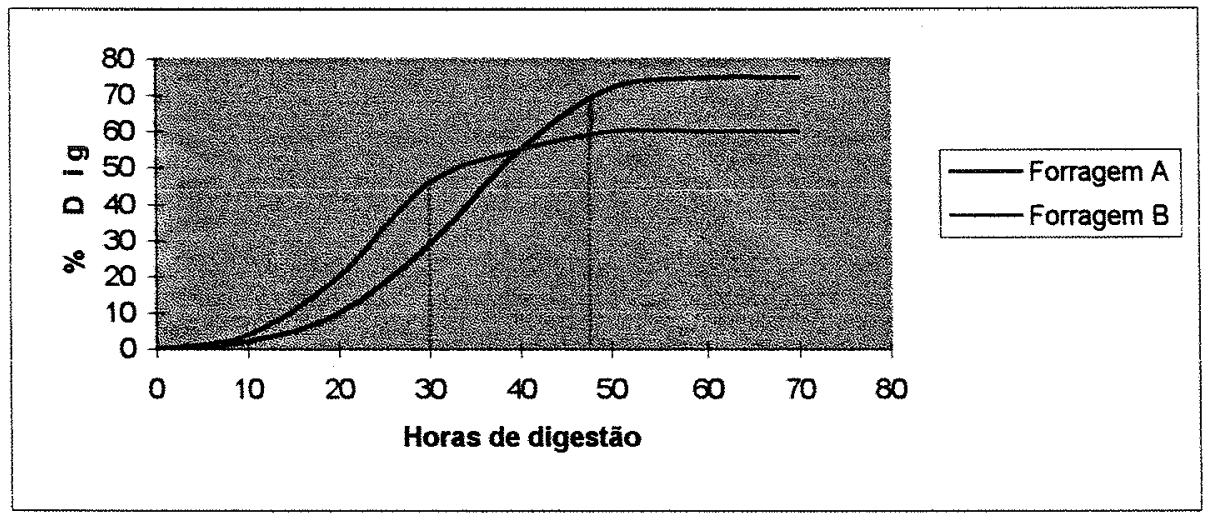

Figura 4. Cinética da degradação de duas forrageiras.

Fonte: Adaptado de Undersander (1997).

\subsubsection{Digestibilidade vs. Consumo}

O valor de uma forragem para atender as necessidades de um animal ruminante, é basicamente uma função da quantidade de alimento consumida e sua digestibilidade. Estes fatores estão interligados e dependem em grande parte da composição química da forragem (Lechtenberg et al., 1974).

O consumo de um alimento estaria, de acordo com Waldo et al., (1972), relacionado com a sua composição química bem como com a taxa de digestão e passagem da fibra.

Van Soest (1965) classificou os alimentos de acordo com os efeitos da composição química da forragem sobre o seu valor nutritivo, em três classes 
distintas : (1) o fator afeta o consumo mas não tem nenhum efeito direto sobre a digestibilidade, (2) ○ fator promove uma relação positiva entre consumo e digestibilidade e (3) o fator promove uma relação negativa entre digestibilidade e consumo. A primeira classe seria composta por silagens de alta umidade onde o suco parece conter alguma substância que inibe o consumo, exemplos da segunda classe seria os fatores associados com a maturidade da planta, como conteúdo de fibra. A terceira classe envolveria as forragens de elevada qualidade com pequena fração volumosa onde o seu consumo estaria limitado pelas exigências do animal.

Essa diferença de relações entre digestibilidade e consumo ficou demonstrado no trabalho de Wilkins et al. (1971). Os autores estudaram o consumo voluntário de 70 silagens feitas com diversas espécies de leguminosas e gramíneas. A correlação entre consumo e digestibilidade "in vivo" da MS foi significativa e negativa para silagens feita com gramíneas ( $r=-$ 58,1 ), a não ser as confeccionadas com azevém. Para o grupo das leguminosas a relação entre digestibilidade e consumo voluntário foi significativa e positiva $(r=30,9)$. As silagens de gramíneas apresentaram uma digestibilidade média de $70,3 \%$, enquanto as leguminosas apresentaram uma digestibilidade média de $62,5 \%$.

As características de fermentação (teor e proporção de ácidos graxos voláteis) apresentaram maiores correlações com consumo do que a digestibilidade "in vivo" da MS, tanto para o grupo das gramíneas, quanto para as leguminosas.

$O$ efeito dos produtos finais de fermentação e o consumo de silagens, foi demonstrado no trabalho de Anil et al. (1993). Os autores estudaram o efeito da infusão de acetato de sódio, propionato de sódio, da tonicidade do fluido ruminal e da distensão ruminal sobre o consumo de fenos e silagens por vacas de leite. Verificaram que a infusão de acetato de sódio ou propionato de sódio no rúmen causou uma depressão no consumo de fenos e silagens de uma maneira dose dependente. No entanto, os autores salientam que as doses mais 
baixas de acetato e propionato utilizadas $\left(1,8\right.$ e $2,0 \mathrm{~mol}^{-3 \mathrm{~h}^{-1}}$, respectivamente) estavam dentro da variação fisiológica encontrada nos animais $\left(2,3 \mathrm{~mol} \cdot \mathrm{h}^{-1}\right)$, e não causaram efeito sobre o consumo. O decréscimo do consumo somente ocorreu com a infusão de doses acima do limite fisiológico encontrado nos animais.

Encontramos na literatura, diversos trabalhos demonstrando a relação entre a digestibilidade da forragem e o desempenho animal.

Marten et al. (1976) estudaram a relação entre a digestibilidade "in vivo" e o consumo de 49 silagens de sorgo e de milho. A dieta dos carneiros era composta somente pelas silagens e uma mistura de sal, uréia e $110 \mathrm{~g}$ de milho moído por animal. Os resultados mostraram uma correlação positiva entre o consumo voluntário ( $\left(\mathrm{PV}^{-0,75}\right.$ ) e a digestibilidade "in vivo" das silagens de milho e sorgo ( $r=0,40$ e 0,66 respectivamente). A análise química que apresentou a maior correlação $(r=-0,59)$ com o consumo voluntário de silagens de milho, foi o teor de celulose. A determinação da digestibilidade verdadeira "in vitro" apresentou uma correlação de $r=0,64$ e $r=0,60$ com o consumo das silagens de milho e sorgo, respectivamente.

O uso de resultados de sacolinhas de náilon para previsão do consumo foi introduzido por Chenost et al. (1970). Estes autores notaram que o consumo voluntário apresentava uma grande correlação $(r=0,82)$ com a degradação após 12 horas de incubação "in situ".

Poppi et al. (1981) estudando a consumo de folhas e hastes de forragens secas, demostraram a relação entre o enchimento ruminal e o consumo animal. O tempo de retenção ruminal explicou $92,5 \%$ da variação no consumo de forragens por bovinos adultos. O maior consumo de folhas de gramíneas comparado com o de hastes não pode ser explicado pela digestibilidade "in vivo" do animal, mas sim pelo seu menor tempo de retenção ruminal. Poppi et al., (1981b) concluíram que o maior consumo de folhas em relação a hastes seria devido a maior taxa de digestão "in vivo" do FDN, maior taxa de passagem do FDN pelo rúmen e pela maior digestibilidade potencial "in situ" da folha. 
Uma maior correlação entre o consumo de MS de forragens e a digestibilidade determinada "in situ" do que com a digestibilidade determinada "in vivo", também ficou demonstrada no trabalho de Hovell et al. (1986), enfatizando a fermentação ruminal como ponto limitante ao consumo.

Anil et al. (1993) verificaram que a presença de um balão inflado no rúmen, diminuiu o consumo de fenos e silagens linearmente com o volume do balão utilizado $\left(R^{2}=0,99\right.$ para silagens), mostrando que mesmo com o uso de pequenos volumes, houve efeito negativo sobre o consumo. Os volumes dos balões utilizados no experimento com silagem foi de $0,15,20$ e 25 litros.

Keyserlingk \& Mathison (1989) utilizaram a técnica da sacolinha de náilon (in situ) para predizer o consumo voluntário e digestibilidade "in vivo" de novilhos em crescimento. O tempo de incubação de 36 horas apresentou a maior relação com o consumo de MS de forragem por $\mathrm{kg}$ de peso vivo $\left(R^{2}=0,86\right)$. Os tempos de incubação "in situ" de 24 e 36 horas também apresentaram alta relação com a digestibilidade aparente determinada "in vivo" $\left(R^{2}=0,92\right.$ e 0,89 respectivamente). Os autores salientam o fato de que o uso das análises químicas (FDN, FDA) explicaram $85 \%$ da variação no consumo de forragens, índice semelhante ao obtido com a incubação "in situ".

Ferret et al. (1997) estudaram a relação entre a digestibilidade "in situ", análises químicas, características da fermentação e digestibilidade "in vivo" com o consumo voluntário de 11 silagens de milho por carneiros. A degradação da MS "in situ" apresentou a maior correlação com o consumo de MS pelos animais, sendo que a fração solúvel (a) e a fração insolúvel potencialmente degradável (b) explicaram $93,2 \%$ da variação no consumo $\left(\mathrm{gMS}^{\mathrm{kg}} \mathrm{kg}^{-1} \mathrm{PM}=\right.$ $81,21+0,12(a)+0,22$ (b) ). As características da fermentação explicaram $80,2 \%$ da variação no consumo, enquanto as análises bromatológicas explicaram $75,7 \%$.

A previsão do consumo animal somente com a composição química do alimento tem sido criticado, uma vez o consumo e a digestibilidade de alimentos são influenciados não somente pela composição química, como também pelo 
animal e o meio ambiente (Mertens, 1987).

O decréscimo do tamanho de partícula de forragens pela moagem ou peletização geralmente aumenta o consumo voluntário (Minson, 1963), como resultado da redução do volume inicial e tempo de retenção no retículo-rúmen (Moore, 1964). Minson (1963) mostra que o benefício da peletização sobre o consumo de forragens é maior para forragens de menor qualidade, porque 0 consumo voluntário dessas forragens estaria mais prejudicado pelo efeito de enchimento ruminal.

Muller et al., (1972) e Lechtenberg et al. (1974) estudaram a relação entre a digestibilidade da fibra e o consumo de duas silagens feitas somente com a fração volumosa da planta de milho (haste+folhas). A silagem que apresentou o maior consumo voluntário por carneiros $(2,43$ contra $1,88 \% \mathrm{PV})$, apresentava o mesmo teor de FDN $(56,6$ contra 57,2$)$ porém com maior digestibilidade do FDN em 72 horas $(61,5$ contra $47,7 \%)$. Os autores concluíram que a quantidade de fibra indigestivel (lignina) seria responsável pela variação no consumo, uma vez que a taxa de degradação (\% por hora) foi semelhante entre as silagens.

A digestibilidade da fibra é uma função da fração potencialmente degradável e da taxa de digestão. Apesar do conteúdo de lignina estar relacionado com a fração potencialmente degradável da fibra, nenhuma análise química está relacionada com a taxa de degradação. Entretanto, o conteúdo energético das forragens é rotineiramente predito pela composição química dos alimentos (FDA e FDN). A acurácia dessas equações é baixa, respondendo geralmente por menos de $60 \%$ da variação no conteúdo energético de forragens. Uma diferença de 20 unidades percentuais na digestibilidade da fibra irá afetar o consumo de energia de uma vaca consumindo $22,7 \mathrm{~kg}$ de MS e 5,5 $\mathrm{kg}$ de fibra de forragens em aproximadamente 2,4 Mcal; suficiente para produzir $3,6 \mathrm{~kg}$ de leite (Allen, 1993). Além de aumentar o consumo de energia, o aumento na digestibilidade da fibra pode aumentar a produção de proteína bacteriana, uma vez que para cada $\mathrm{kg}$ de MS fermentada temos $150 \mathrm{~g}$ de proteína bacteriana produzida. 
Segundo VanSoest \& Allen (1993), a energia do alimento para os micróbios ruminais é dependente da fermentabilidade de suas frações, particularmente dos carboidratos. O erro dos procedimentos atuais para avaliação de silagens seria a previsão da digestibilidade pelo FDA, e a suposição que os carboidratos solúveis (FDN - (PB+CINZA+EE)), e nitrogênio solúvel possuem a mesma qualidade dessas frações em alimentos não fermentados.

Em todos os experimentos citados acima, a forragem em teste era o único ou principal componente da dieta dos animais, com pequena participação de alimentos concentrados na dieta.

Animais que são alimentados com dietas de silagem de milho com mínima suplementação com concentrados, possuem diferentes fatores que afetam a produção, do que animais que são alimentados com dietas balanceadas para o máximo desempenho. Para ruminantes consumindo dietas altas em forragem, a silagem de milho com menor teor de FDN e com FDN de elevada digestibilidade irá aumentar o consumo de MS e de energia, uma vez que a fibra toma espaço no rúmen e limita o consumo.

Para vacas consumindo dieta com elevado teor de concentrados, o teor de FDN da forragem é de pouca importância, uma vez que não tem nenhuma ou pouca influência sobre o consumo de MS. Em muitos casos, como no início da lactação, o consumo ainda está limitado pelo efeito físico de enchimento, e a digestibilidade da fibra será o principal fator determinando o consumo, além de aumentar a densidade energética da dieta.

Quando a dieta é formulada para atender as exigências mínimas de fibra do animal, como em vacas de leite de elevada produção, o conteúdo de FDN da silagem de milho afeta a relação concentrado:volumoso da dieta, e consequentemente, afeta o custo da alimentação. Silagem com menor teor de FDN pode ser incluída em maiores niveis na dieta. A importância relativa desse fator depende do preço dos ingredientes disponiveis (Allen et al., 1997).

A variação de teor de FDN, digestibilidade do FDN e digestibilidade do 
amido de silagens de milho, podem afetar a performance do animal. A importância relativa de cada um desses fatores depende do animal a ser alimentado.

Allen \& Oba (1996) analisaram os dados da literatura e concluíram que a digestibilidade do FDN está positivamente relacionada com o consumo de MS, produção de leite e mudança no peso corporal para vacas no início da lactação ( $<100$ dias pós-parto).

Cinco unidades percentuais de aumento na digestibilidade do FDN em animais com até 100 dias pós-parto, responde por um aumento no consumo de $1,2 \mathrm{~kg} \cdot \mathrm{dia}^{-1}$ de MS, resultando em 1,2 kg. dia ${ }^{-1}$ a mais de leite, e $25 \mathrm{~g}$ a mais de peso vivo. dia ${ }^{-1}$. Em animais no meio da lactação, um aumento na digestibilidade da fibra, está relacionado com menores aumentos na produção de leite e não se mostra relacionado com o consumo de MS, devido ao menor efeito negativo do enchimento ruminal nesta fase.

Segundo VanSoest \& Allen, (1993), a disponibilidade de nutrientes em silagens de milho é determinada principalmente por fatores pré colheita. A qualidade da fibra é determinada pela lignificação da haste e folhas, enquanto a quantidade de fibra é determinada pelo conteúdo de grãos na massa.

Hunt et al. (1993) cita que a identificação de características da planta inteira do milho que estejam relacionadas com a digestibilidade e performance animal tem sido difícil. Apesar de alguns trabalhos mostrarem boa correlação entre conteúdo da fibra da silagem e digestibilidade, a variação na proporção de grãos na MS total provavelmente obscurece essa relação.

Estudando dois materiais (P3377 e P3389) com porcentagem similar de grãos na MS (41 e $44 \%$ respectivamente), os autores encontraram que 0 híbrido com menor teor de fibra $(42,7 \%$ contra $48,1 \%$ de FDN) e com maior digestibilidade da MS e do FDN, manteve essas características após a ensilagem, indicando que os parâmetros selecionados com a planta fresca, se mantiveram após a ensilagem.

Os teores de FDN, FDA e lignina do colmo eram menores para o híbrido 
P3377 comparado ao P3389, sendo que as diferenças eram maiores do que as diferenças da planta inteira. Os autores sugerem que o uso do teor de fibra da fração volumosa seria superior a seleção pelo teor de fibra da planta inteira.

Quando as silagens dos dois materiais foram fornecidas a novilhos em crescimento ( $65 \%$ da MS da dieta), não foi observada diferença no consumo animal, apesar da maior digestibilidade da MS e PB do híbrido P3377.

No ensaio de crescimento, houve uma tendência do híbrido P3377 apresentar menor consumo $(p<0,09)$, apesar de manter um maior ganho de peso $(p<0,02)$ dos animais, traduzindo em maior eficiência alimentar $(6,75$ contra 7,49$)$. Os resultados apontam que outros fatores que não o enchimento ruminal, como a exigência do animal, estaria limitando o consumo da dieta.

Resultados semelhantes foram obtidos por Mahanna (1993). O autor indica que pesquisas feitas pela Pioneer dos Estados Unidos encontraram dois híbridos com a mesma produção de silagem diferindo quanto a digestibilidade da fração volumosa em 15\%. Quando essas silagens foram oferecidas a bovinos em crescimento compondo $65 \%$ da dieta, o híbrido mais digestível resultou em uma melhora de $11 \%$ na eficiência de alimentação e um ganho médio diário $7 \%$ maior.

\subsection{Fatores ambientais que afetam a qualidade da forragem}

A qualidade da forragem no momento da colheita, é o resultado da somatória do crescimento da planta com os fatores ambientais que influenciam a distribuição de nutrientes e da energia gerada pela fotossíntese (VanSoest, 1978). Genericamente, os fatores que retardam o crescimento da planta irão promover a manutenção da qualidade da forragem por um tempo maior.

\subsubsection{Défice hídrico}

O estresse hídrico, retarda o desenvolvimento da planta e aumenta a sua 
digestibilidade, enquanto que tempo nublado, reduz a luminosidade $e$, consequentemente, a digestibilidade. Estes fatores combinados, acentuam as diferenças entre áreas áridas e úmidas (Van Soest et al., 1978). O tempo nublado afeta a fotossíntese, enquanto a disponibilidade de água promove a mobilização de açúcar para proteína, parede celular e lignina (VanSoest, 1993).

Diversos autores apontam o efeito negativo do estresse hídrico sobre a produção de grãos, salientando o período compreendido por 15 dias antes e 15 dias após a polinização como crítico para ocorrência de estresse hídrico (Fancelli \& Lima, 1990; Jama \& Ottman, 1993; Gordon et al., 1995). No trabalho de Jama \& Ottman (1993), os autores obtiveram uma redução de $37,2 \%$ na produção de grãos quando da não irrigação durante a antése, sendo que a produção da fração volumosa não foi afetada.

0 efeito de estresse hídrico sobre a qualidade de forragem ficou evidenciada no trabalho de Snaydon (1972), onde o autor observou o decréscimo da digestibilidade de hastes e folhas de alfafa com a aplicação de água, sendo que a digestibilidade da planta inteira diminuiu de $65 \%$ para $55 \%$ com a aplicação de água.

Loomis (1937) reportou que plantas de milho que passaram por um período de estresse hídrico, apresentavam a mesma proporção de folhas:haste que plantas normais. A característica dessas plantas seria o baixo ou nulo conteúdo de grãos. $O$ autor relata que o teor de nutrientes digestiveis totais (NDT) das silagens confeccionadas com as plantas de milho que passaram por um estresse hídrico, se mostrava semelhante ao NDT das silagens normais, demonstrando a maior digestibilidade da fração volumosa da população que passou por um estresse hidrico.

Segundo Roth (1993), estresses ambientais no final da estação de desenvolvimento (enchimento de grãos), causariam a translocação de carboidratos do colmo para os grãos, afetando negativamente a digestibilidade do colmo e a qualidade total da forragem. Similarmente, estresses no início da estação de crescimento, seguido por boas condições de crescimento, pode 
resultar em menor rendimento de grãos, porém com maior qualidade da forragem.

Allen', citado por Van Soest (1996), plantou 32 híbridos de milho em 4 localidades de Michigan em 1988 e 1989. No ano de 1988, que se mostrou quente e seco, a digestibilidade da MS foi maior do que no ano de 1989, que se mostrou frio e úmido.

Os autores apontam que o efeito do estresse hídrico é mais importante do que temperatura (graus dias) sobre a qualidade da forragem. Os autores esperavam que o ano mais quente, com um maior acúmulo de graus dia, promovesse um milho mais lignificado e menos digestivel. Entretanto, o oposto foi o caso. Os autores concluíram que o efeito do estresse hídrico é de 5 a 8 vezes superior ao efeito do acúmulo de graus dias sobre a digestibilidade da forragem.

A tabela 2 mostra a correlação entre fatores ambientais e qualidade da plantas de milho.

Tabela 2. Efeito do ambiente sobre a qualidade nutricional de plantas de milho para silagem.

\begin{tabular}{lcccc}
\hline Fator & Chuva & Défice hídrico & Graus dia & Graus dia - resíduo* \\
\hline Produção & $+0,51$ & $-0,78$ & $+0,28$ & $+0,83$ \\
Digestibilidade MS & -0.62 & $+0,88$ & $-0,27$ & $+0,81$ \\
FDN & $+0,66$ & $-0,78$ & $-0,09$ & $+0,84$ \\
Dig. FDN & $-0,56$ & $+0,88$ & $-0,27$ & $-0,66$ \\
Lignina/FDN & $+0,63$ & $-0,83$ & $+0,40$ & $+0,70$ \\
\hline
\end{tabular}

* Variação da deficiência hídrica eliminada.

Fonte: Allen ${ }^{1}$, citado por Van Soest (1996).

\footnotetext{
${ }^{1}$ ALLEN, M.S. Predicting energy content of forages: variation in digestibility of fiber. /Presented at the Northwest (Blaine, WA) and Lower Columbia (Portland, OR) Shortcourses, 1994/

${ }^{1}$ ALLEN, M.S. Predicting energy content of forages: variation in digestibility of fiber. /Presented at the Northwest (Blaine, WA) and Lower Columbia (Portland, OR) Shortcourses, 1994/
} 


\subsubsection{Temperatura e luminosidade}

Os estudos ambientais sugerem que o aumento da intensidade luminosa, tende a aumentar o conteúdo de carboidratos solúveis $e$ a digestibilidade das gramíneas através do acúmulo de carboidratos pela fotossíntese, enquanto que o aumento da temperatura favorece a conversão dos produtos fotossintéticos em matéria estrutural (celulose e lignina).

Os efeitos ambientais foram sumarizados por VanSoest et al. (1978) e podem ser vistos na tabela 3 .

Tabela 3. Influência de fatores ambientais sobre a composição e digestibilidade de forragens.

\begin{tabular}{lccccc}
\hline & Temperatura & Luminosidade & Nitrogênio & Água & Predação \\
\hline Produção & + & + & + & + & - \\
Carboidratos solúveis & - & + & - & - & + \\
Parede celular & + & - & \pm & + & - \\
Lignina & + & - & + & + & - \\
Digestibilidade & - & + & \pm & - & + \\
\hline
\end{tabular}

Fonte: Adaptado de VanSoest et al. (1978).

\subsubsection{Efeito ambiental $X$ efeito genético.}

As diferentes condições ambientais durante 0 crescimento $e$ desenvolvimento da cultura são responsáveis pela ocorrência de interação híbrido $x$ local e híbrido $x$ ano nos experimentos de seleção de híbridos.

Fairey (1980) encontrou uma variação significativa entre três locais de semeadura para os parâmetros de qualidade de plantas de milho. Os ambientes diferiram quanto ao acúmulo de graus dias, sendo que não foi verificado sintoma visual de estresse hídrico em nenhuma das três localidades. 
O ambiente que proporcionou a menor somatória de graus dia durante a estação de crescimento (2150 contra 2630 e $2570^{\circ} \mathrm{C}$.dia) apresentou semelhante produção total por área, porém menor produção de grãos. Os autores concluem que menores temperaturas diárias, reduzem 0 desenvolvimento da planta prolongando a fase vegetativa.

Os efeitos do ambiente sobre a produção e digestibilidade de plantas de milho, e a variação existente entre locais de semeadura, foram estudados por Deinum \& Bakker (1981). Os autores testaram 27 híbridos em 1976 e 29 híbridos em 1978, em três localidades diferentes. O ano de 1976 foi um ano extremamente quente e seco, enquanto que 1978 foi um ano com temperaturas baixas.

No ano quente e seco (1976), os híbridos produziram menos MS por área, e foi encontrada uma grande variação entre locais quanto a produção de MS e porcentagem de grãos na MS total. Não houve diferença na digestibilidade da MS entre os dois anos, porém o ano de 1976 (quente e seco) apresentou maior digestibilidade "in vitro" do FDN. Apesar da grande variação entre cultivares, não houve interação cultivar $x$ ano ou cultivar $x$ local para a digestibilidade da MS e do FDN, mostrando que os híbridos mais digestíveis em um ano ou local também o foram no outro ano ou local.

Semelhante ao observado por Deinum \& Bakker (1981), Vattikonda e Hunter (1983) demonstraram a interação significativa entre híbrido $x$ ano quanto a produção de MS e de grãos. No entanto não encontraram interação significativa entre híbrido $x$ ano para digestibilidade "in vitro" da fração volumosa de plantas de milho (haste+folhas), apesar da grande diferença entre híbridos.

Deinum (1988) relata o resultado de 24 ensaios de variedades de milho distribuidos por regiões de milho da Europa. O objetivo do estudo foi investigar as diferenças no valor nutritivo entre híbridos e localidades e as causas básicas desses diferenças. As diferenças ambientais provocaram uma grande variação na produção total de MS. O conteúdo de grãos variou de 41 a $55 \%$ e a digestibilidade "in vitro" da MS variou de 64,7 a $81,4 \%$. 
$O$ autor relata que não houve interação entre locais $x$ híbridos ou ano $x$ híbridos para a digestibilidade da MS. Os resultados obtidos não apontaram para a ocorrência de menor digestibilidade em latitudes menores ou com temperaturas diárias maiores, sugerindo que a digestibilidade de plantas de milho pode ser tão alta em ambientes quentes como em ambientes mais frios.

Cox et al. (1994) estudaram o comportamento de 12 híbridos de milho em dois locais por dois anos (1991 e 1992). O ano de 1991 foi excepcionalmente quente e seco (1592 ${ }^{\circ} \mathrm{C}$.dia e $304 \mathrm{~mm}$ durante a condução da cultura), enquanto 1992 foi frio e úmido $\left(1247^{\circ} \mathrm{C}\right.$.dia e $595 \mathrm{~mm}$ durante a condução da cultura), garantindo um periodo vegetativo 3 semanas mais prolongado que em 1991, e um período de enchimento de grãos, 1 semana mais prolongado. Os híbridos apresentaram menor teor de fibra e maior digestibilidade no ano quente e seco (1991) comparado com o ano frio e úmido. Não houve diferença na porcentagem de grãos.

Houve interação significativa entre ano $x$ híbrido para o teor de FDN, somente na localidade onde ocorreu uma geada, causando interrupção no desenvolvimento dos grãos. Os resultados mostraram que o teor de FDN de um híbrido pode ser consistente mesmo com grande variação de ambientes. Não existiu nenhuma interação entre ano $x$ híbrido ou entre local $x$ híbrido para a digestibilidade "in vitro" da MS, apesar da ocorrência de interação significativa ano $x$ híbrido $x$ local para a porcentagem de grãos na MS.

Estudando somente a fração volumosa de plantas de milho, Lundvall et al. (1994) encontraram uma interação significativa ano $X$ híbrido para a digestibilidade "in vitro" e teor de FDN de hastes e folhas de hibridos de milho.

Roth (1993) relata que a digestiblidade do colmo é menos consistente do que a digestibilidade da planta inteira, em diferentes ambientes, devido provavelmente aos efeitos do estresse sobre o nivel de carboidratos do colmo.

Sanderson et al. (1995) encontraram resultados diversos quanto ao efeito da irrigação sobre a digestibilidade das frações de plantas de milho, e interação significativa da irrigação com a adubação nitrogenada. A adubação 
nitrogenada, diminuiu a digestibilidade "in vitro" de lâminas foliares e colmo em parcelas irrigadas, enquanto em parcelas não irrigadas, a adubação nitrogenada não teve efeito.

A irrigação não teve efeito significativo sobre a digestibilidade de lâminas foliares e colmo.

Geralmente, a maioria dos estudos tem demonstrado pequena interação híbrido $X$ ambiente, indicando estabilidade dos híbridos. No entanto, a maioria dos estudos foram conduzidos em ambientes com pequena variação climática (Roth, 1993). 


\section{MATERIAL E MÉTODOS}

\subsection{Implantação do experimento}

O experimento de campo foi realizado na Companhia Agrícola Nova América, localizada no município de Assis-SP. O experimento foi realizado por dois anos consecutivos, 1996 e 1997. Para facilidade de entendimento, o ano experimental que começou em 1995 foi denominado de ano 1996, e o ano experimental iniciado em 1996, de ano 1997. O resultado da análise química do solo é apresentado na tabela 4.

Tabela 4. Análise química do solo onde foi implementado o experimento.

\begin{tabular}{|c|c|c|c|c|c|c|c|c|}
\hline $\begin{array}{c}\mathrm{pH} \\
\mathrm{CaCl}_{2}\end{array}$ & $\begin{array}{l}\text { M.O. } \\
\text { g. dm }\end{array}$ & $\begin{array}{l}\text { P resina } \\
\text { mg.dm }\end{array}$ & $\bar{K}$ & $\mathrm{Ca}$ & $\begin{array}{l}\mathrm{Mg} \mathrm{Al}+\mathrm{H} \\
\mathrm{cmol}_{\mathrm{c}} \cdot \mathrm{dm}^{-3}\end{array}$ & $S$ & $\bar{T}$ & V\% \\
\hline 5,5 & 2,6 & 29 & 0,82 & 3,2 & 1,2 & 5,22 & 9,02 & 57,9 \\
\hline
\end{tabular}

O clima de Assis se caracteriza como aw' (classificação de Koeppen) e sua altitude média é de $500 \mathrm{~m}$. O município está localizado na latitude $22^{\circ} 37^{\prime} \mathrm{S}$ e longitude $50^{\circ} 25^{\prime} \mathrm{W}$. A região possui precipitação anual média de 1200 a 1300 $\mathrm{mm}$ (1941 a 1970).

O local de semeadura da cultura de milho foi uma área de reforma de canavial, e a correção do solo e adubações realizadas foram as seguintes:

Antes da semeadura foram aplicados $2,2 \mathrm{tha}^{-1}$ de calcário no solo para correção da acidez. No momento da semeadura, foram aplicados $220 \mathrm{~kg}^{\text {ha }}{ }^{-1}$ 
de MAP. Trinta dias após a semeadura foi realizado adubação de cobertura com $150 \mathrm{~kg} \cdot \mathrm{ha}^{-1}$ de uréia. Com 45 dias após semeadura, foi realizada outra aplicação aérea de uréia na dose de $100 \mathrm{~kg} \cdot \mathrm{ha}^{-1}$.

No ano experimental de 1996, foram semeados 47 híbridos de milho no dia 5 de outubro de 1995. Cada parcela foi composta por 6 linhas de 10 metros de comprimento. As duas linhas externas de cada parcela foram consideradas como bordadura. O espaçamento utilizado foi de 0,9 metros entre linhas e a densidade após desbaste foi de 5 plantas por metro (55.555 pl.ha ${ }^{-1}$ ). Foram semeadas 3 repetições de cada hibrido, compondo 3 blocos experimentais.

A localização dos híbridos dentro de cada bloco foi determinado por sorteio. Dos 47 híbridos semeados em 1996, foram escolhidos $28 \mathrm{com}$ as melhores características agronômicas (sanidade, porte da planta e produção total 'de MS) para fazerem parte do experimento.

No ano experimental de 1997, foram semeados 36 híbridos de milho no dia 08 de novembro, de maneira idêntica ao descrito para 1996. Dos 36 híbridos de milho, 21 foram selecionados de acordo com sua sanidade, porte da planta e produção total de MS, para fazerem parte do experimento. Dos 21 híbridos selecionados, 13 hibridos haviam sido previamente avaliados no ano anterior.

A precipitação pluvial ocorrida durante os dois anos experimentais pode ser visualizada na tabela 5. Na tabela 6 é apresentada a descrição dos híbridos de milho utilizados.

Tabela 5. Precipitação pluvial ocorrida nos dois anos experimentais.

\begin{tabular}{|c|c|c|c|c|c|c|c|c|}
\hline Semanas & Out/95 & Nov/95 & Dez/95 & $\operatorname{Jan} / 96$ & Nov/96 & Dez/96 & $\operatorname{Jan} / 97$ & Fev/97 \\
\hline 1 & 46,0 & 14,7 & 17,0 & 40,3 & - & 39,0 & 0 & 70,2 \\
\hline 2 & 11,3 & 37,7 & 16,7 & 35,7 & 4,4 & 140,4 & 112,6 & 87,2 \\
\hline 3 & 131,3 & 0 & 9,0 & - & 66,9 & 62,4 & 20,9 & 87,5 \\
\hline 4 & 5,0 & 3,3 & 42,0 & - & 0 & 113,6 & 108,4 & - \\
\hline & \multicolumn{4}{|c|}{1996} & \multicolumn{4}{|c|}{1997} \\
\hline Total & \multicolumn{4}{|c|}{$410,0 \mathrm{~mm}$} & \multicolumn{4}{|c|}{$913.5 \mathrm{~mm}$} \\
\hline
\end{tabular}


Tabela 6. Caracterização dos híbridos de milho utilizados no experimento.

\begin{tabular}{|c|c|c|c|c|c|}
\hline Híbrido & Ano & Tipo de hibrido & $\begin{array}{c}\text { Ciclo } \\
\text { fenológico }\end{array}$ & $\begin{array}{c}\text { Soma } \\
\text { calórica * }\end{array}$ & Tipo de grão \\
\hline Agroceres 122 & 96 & Duplo & Precoce & 865 & Semi-dentado amarelo \\
\hline Agromen 2012 & 96 & Duplo & Super precoce & & $\begin{array}{l}\text { Semi-dentado amarelo } \\
\text { laranja }\end{array}$ \\
\hline BR 3123 & 96 & Triplo & Precoce & 850 & $\begin{array}{l}\text { Semi-flint laranja } \\
\text { avermelhado }\end{array}$ \\
\hline Cargill 969 & 96 & Simples & Super precoce & 800 & Semi-dentado amarelo \\
\hline Cargill 425 & 96 & Duplo & Precoce & 900 & Semi-duro alaranjado \\
\hline Cargill 505 & 96 & Triplo & Precoce & 915 & Semi-duro amarelo \\
\hline Cargill 701 & 96 & Duplo & Precoce & 860 & Semi-duro alaranjado \\
\hline Cargill 805 & 96 & Triplo & Super precoce & 810 & $\begin{array}{l}\text { Semi-duro amarelo } \\
\text { alaranjado }\end{array}$ \\
\hline Cargill 806 & 96 & Triplo & Super precoce & 810 & $\begin{array}{l}\text { Semi-duro amarelo } \\
\text { alaranjado }\end{array}$ \\
\hline Cargill 808 & 96 & Triplo & Super precoce & 815 & Semi-dentado amarelo \\
\hline Dina 887 & 96 & Simples modificado & Super precoce & 779 & Semi-duro alaranjado \\
\hline Pioneer 3072 & 96 & Simples modificado & Super precoce & 807 & Duro alaranjado \\
\hline XI 220 & 96 & Simples & Super precoce & 815 & Semi-dentado amarelado \\
\hline $\mathrm{XL} 370$ & 96 & Triplo & Semi precoce & 860 & Semi-duro amarelado \\
\hline XL 660 & 96 & Duplo & Normal & 915 & Semi-duro alaranjado \\
\hline Agroceres 1043 & 97 & Duplo & Normal & 925 & Semi-dentados amarelos \\
\hline Agroceres 1051 & 97 & Duplo & Normal & 910 & Dentados amarelos \\
\hline Agroceres 9014 & 97 & Simples modificado & Super precoce & 820 & Duro avermelhado \\
\hline Colorado 42 & 97 & Duplo & Precoce & 853 & $\begin{array}{c}\text { Semi-duro amarelo } \\
\text { alaranjado }\end{array}$ \\
\hline Dina 556 & 97 & Simples modificado & Precoce & 844 & Semi-dentado avermelhado \\
\hline Exceler & 97 & Triplo & Precoce & & Duro alaranjado \\
\hline Master & 97 & Triplo & Semi precoce & & Duro alaranjado \\
\hline XL 360 & 97 & Triplo & Precoce & 850 & Semi-duro alaranjado \\
\hline Agroceres 5011 & $96-97$ & Triplo & Precoce & 865 & Semi-dentados amarelos \\
\hline Cargill 333 & $96-97$ & Simples modificado & Normal & 950 & $\begin{array}{l}\text { Semi-duro amarelo } \\
\text { alaranjado }\end{array}$ \\
\hline Cargill 435 & $96-97$ & Duplo & Precoce & 910 & $\begin{array}{l}\text { Semi-duro amarelo } \\
\text { alaranjado }\end{array}$ \\
\hline Cargill 909 & $96-97$ & Simples & Super precoce & 810 & Flint moderno alaranjado \\
\hline Colorado F0-01 & $96-97$ & Triplo & Normal & 898 & - \\
\hline Dina 657 & $96-97$ & Simples modificado & Precoce & 841 & Semi-duro alaranjado \\
\hline Dina 766 & $96-97$ & Simples modificado & Super precoce & 795 & Semi-duro alaranjado \\
\hline Dina 769 & $96-97$ & Triplo & Super precoce & 820 & Duro alaranjado \\
\hline Pioneer 3027 & $96-97$ & Triplo & Semi precoce & 874 & Duro alaranjado \\
\hline Pioneer 3041 & $96-97$ & Triplo & Precoce & 851 & Duro alaranjado \\
\hline Zeneca 8392 & $96-97$ & Simples & Precoce & & Semi-duro alaranjado \\
\hline Zeneca 8452 & $96-97$ & Simples & Precoce & & Semi-duro alaranjado \\
\hline Zeneca 8501 & $96-97$ & Triplo & Semi-precoce & & Semi-duro alaranjado \\
\hline
\end{tabular}

* Unidades de calor necessárias para o florescimento 
No ano experimental de 1996 notamos a ocorrência de défice hídrico no período entre 15/11/95 a 21/12/95, com uma precipitação pluvial de apenas 46 $\mathrm{mm}$ em 36 dias. Este periodo de défice, iniciado 55 dias antes da colheita, correspondeu ao período reprodutivo da cultura, durante a fase de polinização das plantas.

Já o ano experimental de 1997, apresentou uma elevada precipitação pluvial, sem a ocorrência de periodos de défice hídrico prolongado.

\subsection{Colheita e preparo das amostras}

No ano experimental de 1996, as parcelas foram colhidas do dia 6 ao dia 13 de janeiro de 1996. O ponto de colheita foi determinado amostrando-se 2 plantas das bordaduras, por parcela, para determinação do teor de $\mathrm{MS}$ a $60^{\circ} \mathrm{C}$ em estufa de ventilação forçada. As parcelas foram colhidas quando o teor de MS das plantas amostradas era superior a $28 \%$ e inferior a $35 \%$.

Foram colhidos 1 metro linear central ( 5 a 6 plantas) das duas linhas centrais de cada parcela, a uma altura de $20 \mathrm{~cm}$ acima do solo. Após o corte, as espigas foram separadas do restante da planta e as duas frações foram pesadas (espigas e fração volumosa). Em seguida foram trituradas e armazenadas em sacos plásticos para posterior determinação da MS e realização das análises.

Em 1997, as parcelas foram colhidas entre 19 e 24 de fevereiro de 1997, quando os grãos se apresentavam no estágio visual farináceo-duro. Foram colhidas as duas linhas centrais de cada parcela ( 10 metros) a uma altura de 20 $\mathrm{cm}$ acima do solo. As frações espiga e fração volumosa foram separadas e pesadas. Em seguida foram trituradas para facilitar a homogeneização e a retirada de uma amostra de aproximadamente $2 \mathrm{~kg}$ para determinação da MS e realização das análises. 


\subsection{Confecção das silagens de milho}

Em 1996, o restante das 2 linhas centrais de cada parcela foi colhido, adicionado com as outras parcelas do mesmo híbrido, e ensilado em tambores plásticos de $200 \mathrm{~L}$. As silagens permaneceram armazenadas por um período de 7 meses, quando foram abertas e amostradas para a realização das análises químicas.

\subsection{Análises laboratoriais.}

Nas amostras da fração volumosa (haste+folhas) foram analisados os seguintes itens: matéria seca (MS), proteína bruta (PB), fibra em detergente neutro (FDN), fibra em detergente ácido (FDA), lignina e matéria mineral (MM).

O FDN, FDA e lignina foram determinados de acordo com Goering \& VanSoest (1970); e a MS e PB segundo métodos da A.O.A.C. (1984).

As amostras das espigas foram analisadas somente quanto ao teor de MS.

Em 1996, as amostras de silagens foram analisadas para: $\mathrm{pH}, \mathrm{MS}, \mathrm{PB}$, FDA, FDN, lignina, MM, segundo metodologia já descrita; nitrogênio ligado ao FDA (N-FDA), segundo VanSoest (1991) e nitrogênio na forma amoniacal (N$\mathrm{NH}_{3}$ ) segundo A.O.A.C. (1984).

\subsection{Determinação da degradabilidade "in situ".}

Determinou-se para todos os híbrịdos, a degradabilidade "in situ" da fração volumosa (haste+folhas). As amostras das três parcelas de cada hibrido, foram secas por 72 horas em estufa de ventilação forçada a $60^{\circ} \mathrm{C}$, e moidas em peneira de $5 \mathrm{~mm}$. Foi retirado uma sub-amostra de $200 \mathrm{~g}$ de cada parcela, e combinadas as três parcelas para formar uma amostra composta de cada híbrido para determinação da degradabilidade "in situ". 
As sacolas foram confeccionadas em náilon monofilamentoso com abertura de poro aproximada de $50 \mu$ e com uma área de $182 \mathrm{~cm}^{2}(7 \times 13 \mathrm{~cm})$.

Foram colocadas $3 \mathrm{~g}$ de amostra em cada sacola, correspondendo a uma relação de $16,5 \mathrm{mg} . \mathrm{cm}^{-2}$.

Trabalhos anteriores realizados por Castro (1989) com duas vacas e Medeiros (1992) com quatro vacas, demonstraram a inexistência de diferenças significativas entre os animais quanto a digestibilidade "in situ" de diferentes alimentos. O mesmo foi relatado por Nocek (1985); Weakley et al. (1983) e Wilkerson et al. (1995). Estes trabalhos demonstraram ainda, a maior variação existente entre repetições feitas no mesmo animal em relação a repetições feitas com diferentes animais.

Baseado nestes resultados, foi utilizada somente uma vaca da raça holandesa, seca, fistulada no rúmen, com idade aproximada de 48 meses, pertencente ao departamento de Zoologia - ESALQ para determinação da digestibilidade "in situ" no presente experimento.

A dieta fornecida ao animal consistia de silagem de milho como volumoso mais concentrado na proporção 40:60 de volumoso:concentrado com base na MS.

A dieta foi fornecida a vontade de modo a se manter uma sobra aproximada de 5 a $10 \%$ do fornecido. Na tabela 7 é apresentada a composição química das silagens e concentrado utilizados.

Tabela 7. Composição química dos alimentos utilizados na dieta do animal.

\begin{tabular}{cccccccc}
\hline & Alimentos & MS & FDN & FDA & lignina & PB & N-FDA \\
\hline \multirow{3}{*}{ silagens } & 1996 & 30,5 & 46,0 & 27,5 & 3,57 & 7,19 & 8,22 \\
& 1997 & 34,9 & 48,3 & 23,6 & 2,06 & 7,00 & - \\
\hline & Concentrado & 87,7 & 26,8 & 19,9 & - & 24,4 & - \\
\hline
\end{tabular}


O consumo do animal se manteve na média de $17 \mathrm{~kg}$ de silagem mais 10 $\mathrm{kg}$ de concentrado em 1996, e $15 \mathrm{~kg}$ de silagem mais $9 \mathrm{~kg}$ de concentrado em 1997 com base na matéria original.

Os tempos de incubação das sacolas no rúmen do animal foram: $0,3,6$, $12,24,48$ e 72 horas.

\subsubsection{Períodos de coleta}

Foram realizados três períodos de incubação "in situ", observando-se um período de 14 dias antes do início do experimento para adaptação da microfauna ruminal a dieta experimental.

Como padrão de degradação "in situ", foi utilizado um feno de aveia cuja composição química pode ser observada na tabela 8.

Em cada tempo de incubação, havia no rúmen do animal, 58 sacolas de náilon em 1996 e 44 sacolas de náilon em 1997, correspondendo a duas sacolas para cada híbrido de milho mais o padrão utilizado. Assim, todos os hibridos testados estavam sujeitos ao mesmo ambiente ruminal em cada tempo de incubação.

Tabela 8. Composição bromatológica do feno de aveia utilizado como padrão.

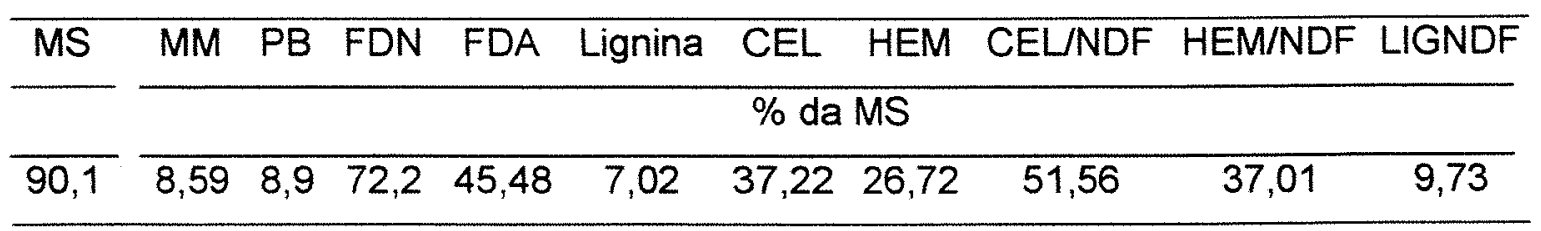

As sacolas foram incubadas no animal sempre no mesmo horário (7:30 h) e retiradas após o tempo determinado. Entre cada tempo de incubação, esperou-se um dia para lavagem das sacolas e preparo das amostras.

Antes da incubação ruminal, as sacolas de náilon contendo as amostras, 
foram enxaguados em água morna por 10 minutos, visando imitar a salivação removendo a fração solúvel e diminuindo o tempo de colonização das partículas do alimento pelos microorganismos ruminais.

As sacolas referentes ao tempo zero foram somente enxaguadas em água morna e em seguida passaram pelo processo de lavagem.

Após serem retiradas do rúmen, as sacolas eram imediatamente colocadas em água com gelo para paralisar a fermentação e, em seguida, lavadas em máquina de lavar com agitação e fluxo de água constante. O ponto final da lavagem era visual, observando-se, com o uso de um becker, o momento em que a coloração da água atingia o ponto de água limpa. As sacolas foram secas a $60^{\circ} \mathrm{C}$ em estufa com ventilação forçada por 48 horas e o resíduo analisado para o teor de FDN.

A determinação das degradabilidades foi obtida pela diferença entre as quantidades de amostra incubadas $(3 \mathrm{~g})$ e o resíduo após incubação.

$O$ conjunto dos 7 tempos de incubação $(0,3,6,12,24,48$ e 72 horas) constituiu um periodo experimental, sendo cada período experimental considerado como um bloco, os tempos de incubação no animal como parcelas e os híbridos como sub-parcelas.

\subsubsection{Modelos matemáticos}

Para o ajuste da curva de degradação da MS foi utilizado o modelo matemático proposto por McDonald (1981):

$$
\begin{gathered}
\operatorname{deg}=a+\left[b^{*}\left(1-e^{-c^{*}}\right)\right] \text { quando } t>\operatorname{lag} e \\
\operatorname{deg}=\text { A quando } t<\text { lag sendo: }
\end{gathered}
$$

deg = degradabilidade no tempo $t(\%)$;

$\mathrm{a}$ = parâmetro da equação; interseção do modelo exponencial quando $\mathrm{t}=0$, correspondendo a fração imediatamente solúvel se não houvesse lag-time;

$b$ = parâmetro da equação; seria a fração potencialmente degradável se não houvesse lag-time; 


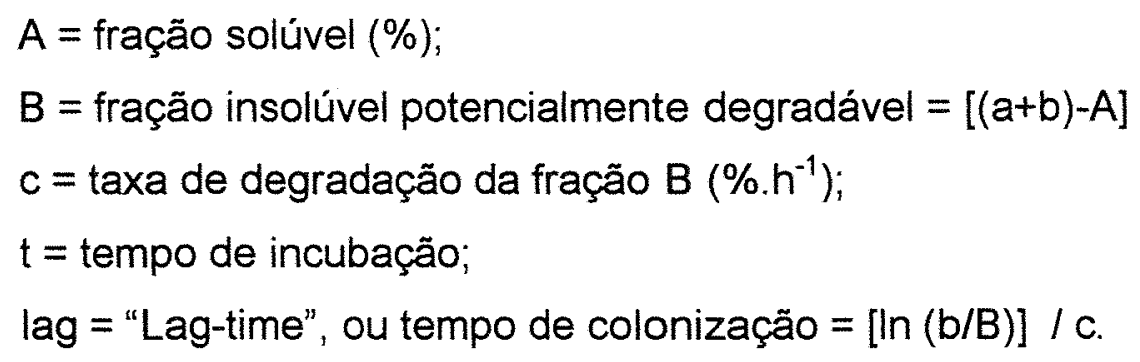

A degradabilidade efetiva da MS (Deg.ef) foi calculada supondo-se uma taxa de passagem ruminal de $5 \% \cdot \mathrm{h}^{-1}$ como:

$$
\text { Deg.ef }=A+\left[\left(b^{*} c\right) /(c+0,05)^{*} e^{-(c+0,05)^{*} \operatorname{lag}}\right]
$$

Rossi Júnior (1994) encontrou em seu trabalho, uma taxa de passagem ruminal média de dietas com $60 \%$ volumoso (silagem de milho) de $4,64 \% \cdot h^{-1}$.

Para a modelagem dos dados de degradação do FDN foi utilizado o modelo proposto por Mertens (1973) e descrito por Mertens \& Loften (1980):

$$
\begin{gathered}
\text { Resíduo FDN }=\left[B * e^{-c^{*}(t-a g)}\right]+U \text { quando } t>\operatorname{lag} e ; \\
\text { Resíduo } F D N=B+U \text { quando } t<\text { lag sendo: }
\end{gathered}
$$

Resíduo FDN = resíduo de parede celular após a incubação no tempo t;

$B=$ fração digestivel do FDN;

$C=$ taxa de degradação da fração $B$;

lag = "Lag-time" ou tempo de colonização;

$\mathrm{U}=$ fração indigestivel.

O efeito de enchimento (Fill) do FDN, ou tempo de retenção ruminal, foi calculado supondo-se uma taxa de passagem do FDN de $5 \% \cdot \mathrm{h}^{-1}$ utilizando a equação descrita por VanSoest (1994) onde:

$$
\text { Fill }=[B /(c+0,05)]+\text { lag }+(U / 0,05)
$$

Para o ajuste dos modelos utilizou-se o procedimento PROC NLIN do pacote estatístico SAS, sendo escolhido o método de secante (DUD). 


\subsection{Análise estatística}

O delineamento experimental utilizado para análise das caracteristicas agronômicas e da composição química (experimento 1) foi 0 de blocos casualizados com 3 repetições e 28 tratamentos por bloco em 1996 e 21 tratamentos em 1997. O esquema da análise de variância pode ser observado na tabela 9.

Tabela 9. Análise de variância do experimento 1 ano a ano.

\begin{tabular}{lcc}
\hline Causa de variação & Graus de liberdade & Graus de liberdade \\
\cline { 2 - 2 } Blocos & 1996 & 1997 \\
Híbridos & 2 & 2 \\
Resíduo & 27 & 20 \\
\hline Total & 54 & 40 \\
\hline
\end{tabular}

Os dois anos experimentais foram analisados em conjunto para verificar 0 efeito do ano e da interação ano $x$ híbrido. O esquema da análise de variância em conjunto pode ser visto na tabela 10.

Tabela 10. Análise de variância dos dois anos experimentais em conjunto do experimento 1 .

\begin{tabular}{lc}
\hline \multicolumn{1}{c}{ Causa de variação } & Graus de liberdade \\
\hline Ano & 1 \\
Blocos (ano) & 4 \\
Híbridos comuns & $(12)$ \\
Híbridos regulares & $(22)$ \\
Híbridos comuns * híbridos regulares & $(1)$ \\
Híbridos & $12+22+1=35$ \\
Ano*Hibridos comuns & 12 \\
\hline Resíduo & 94 \\
\hline Total & 146 \\
\hline
\end{tabular}

A análise estatística foi realizada utilizando-se o procedimento "GLM" do 
pacote estatístico SAS (1990). Para a comparação das médias dos híbridos foi aplicado o teste de Tukey.

Para o experimento de degradabilidade ruminal (experimento 2), o delineamento experimental utilizado foi o de parcelas subdivididas onde os periodos experimentais foram considerados blocos, os tempos de incubação as parcelas e os híbridos de milho as sub-parcelas. O esquema da análise de variância ano a ano pode ser observado na tabela 11. A tabela 12 apresenta o esquema da análise de variância dos dois anos em conjunto.

Tabela 11. Análise de variância ano a ano do experimento 2 .

\begin{tabular}{lccc}
\hline Causa de variação & Graus de liberdade & Graus de liberdade \\
\cline { 2 - 2 } Bloco & 1996 & 1997 \\
Hora & 2 & 2 \\
\hline Resíduo (a) & 6 & 6 \\
\hline Hibrido & 12 & 12 \\
\hline Hibrido * hora & 27 & 20 \\
\hline Resíduo (b) & 162 & 120 \\
\hline Total & 378 & 280 \\
\hline
\end{tabular}

A análise estatística foi feita utilizando-se o procedimento "MIXED" do pacote estatístico SAS (1990). Foi realizado o teste de Tukey para comparação das médias de degradação dentro de cada ano. 
Tabela 12. Análise de variância dos dois anos experimentais em conjunto do experimento 2 .

\begin{tabular}{lc}
\hline \multicolumn{1}{c}{ Causa de variação } & Graus de liberdade \\
\hline Ano & 1 \\
Bloco(ano) & 4 \\
Hora & 6 \\
Ano * hora & 6 \\
\hline Resíduo (a) & 24 \\
\hline Hibridos comuns & 12 \\
Hibridos comuns * Hora & 72 \\
Híbridos comuns * Ano & 12 \\
Híbrido comuns * Hora * ano & 72 \\
\hline Resíduo (b) & 336 \\
\hline Total & 545 \\
\hline
\end{tabular}




\section{RESULTADOS E DISCUSSÃO}

4.1 Características agronômicas, composição química, digestibilidade "in situ" e cinética da degradação da fração volumosa (haste+folhas) dos hibridos de milho cultivadas nos anos de 1996 e 1997.

\subsubsection{Características agronômicas}

Houve um efeito significativo do híbrido sobre todos os parâmetros estudados em 1996 (tabela 13). Apesar dos esforços para se colher todas as parcelas no mesmo teor de MS, foi verificado diferenças significativas entre os híbridos, sendo que o teor de $\mathrm{MS}\left(105^{\circ} \mathrm{C}\right)$ no momento do corte variou de 23 a 32\% em 1996 (Tabela 13).

Em 1997, devido as condições climáticas mais favoráveis a condução da cultura, foi possivel a colheita de todas as parcelas com um grau homogêneo de umidade (31 a $36 \% \mathrm{MS}$ ), não sendo encontrado variação significativa entre os híbridos (tabela 14).

Apesar do grau uniforme de umidade da planta inteira dos híbridos em 1997, houve efeito do híbrido sobre o teor de MS da fração volumosa (haste+folhas)e da espiga (tabelas 16 e 14), levando a grandes diferenças entre o teor de MS das espigas e da fração volumosa (dry-down) (tabela 14). 
Tabela 13. Características agronômicas dos hibridos de milho em 1996.

\begin{tabular}{|c|c|c|c|c|c|c|c|}
\hline híbrido & PESP & $\begin{array}{c}\text { PFIB } \\
- \text { tha }^{-1}\end{array}$ & PTOT & espigas & $\begin{array}{c}\text { MS } \\
\text { planta }\end{array}$ & $\begin{array}{c}\text { MS } \\
\text { espigas }\end{array}$ & $\begin{array}{l}\text { Dry- } \\
\text { down }\end{array}$ \\
\hline C701 & 3876,25 & 11226,95 & 15103,19 & 25,65 & 29,40 & 43,04 & 19,15 \\
\hline P3027 & 5179,57 & 8774,87 & 14280,56 & 36,25 & 25,21 & 35,40 & 15,19 \\
\hline XL220 & 4556,22 & 9387,46 & 13943,68 & 33,08 & 32,35 & 45,00 & 21,14 \\
\hline AG122 & 5032,32 & 8847,41 & 13879,73 & 36,20 & 31,04 & 41,64 & 16,94 \\
\hline C333 & 6831,78 & 6996,46 & 13828,24 & 48,77 & 29,86 & 38,81 & 17,01 \\
\hline DINA766 & 5688,18 & 8043,98 & 13732,16 & 41,49 & 29,53 & 46,67 & 24,75 \\
\hline AG5011 & 4775,46 & 8539,34 & 13683,44 & 35,03 & 28,06 & 41,11 & 19,63 \\
\hline XL660 & 5974,82 & 8338,89 & 13613,25 & 43,89 & 26,59 & 36,86 & 16,41 \\
\hline C & 4729,87 & 8412,55 & 13142,42 & 35 & 26,00 & 72 & 16,49 \\
\hline C909 & 5930,71 & 6957,49 & 13103,12 & 45,26 & 29,48 & 43,88 & 23,81 \\
\hline ZEN8501 & 3670,70 & 9402,27 & 13072,97 & 27,95 & 31,09 & 40,75 & 15,70 \\
\hline P3041 & 5624,99 & 7076,29 & 12701,28 & 44,55 & 26,31 & 36,44 & 17,40 \\
\hline XL370 & 5463,25 & 7066,35 & 12529,60 & 43,28 & 26,59 & 36,20 & 16,81 \\
\hline C505 & 4607,58 & 7860,57 & 12468,15 & 36,55 & 27,75 & 38,41 & 16,51 \\
\hline DINA657 & 4193,23 & 8255,75 & 12448,97 & 33,78 & 28,23 & 34,87 & 11,70 \\
\hline AGROMEN & 5098,66 & 7209,42 & 12308,08 & 40,82 & 26,68 & 40,06 & 20,68 \\
\hline F001 & 3536,47 & 8675,64 & 12212,12 & 28,94 & 28,20 & 41,08 & 18,04 \\
\hline C969 & 4602,30 & 7339,75 & 11942,05 & 38,64 & 28,06 & 38,31 & 17,15 \\
\hline ZEN8452 & 4438,42 & 7459,46 & 11897,88 & 37,10 & 26,81 & 38,39 & 18,42 \\
\hline DINA769 & 4514,60 & 7114,29 & 11628,89 & 39,06 & 25,75 & 34,64 & 14,51 \\
\hline BR3123 & 4475,03 & 6829,13 & 10934,46 & 40,68 & 24,47 & 33,97 & 15,91 \\
\hline DINA887 & 4957,34 & 4745,77 & 9703,12 & 51,63 & 27,82 & 35,93 & 15,52 \\
\hline ZEN8392 & 3066,25 & 6603,86 & 9670,11 & 31,57 & 24,41 & 25,17 & 4,49 \\
\hline P3072 & 3485,35 & 5828,32 & 9611,01 & 36,12 & 23,06 & 29,79 & 11,93 \\
\hline C806 & 3400,37 & 6150,44 & 9550,80 & 34,55 & 25,52 & 32,36 & 12,40 \\
\hline C808 & 3340,37 & 6187,26 & 9527,63 & 35,10 & 23,68 & 29,73 & 10,99 \\
\hline C805 & 3963,81 & 5377,82 & 9341,63 & 42,02 & 26,22 & 35,97 & 16,36 \\
\hline C435 & 3357,16 & 5247,43 & 8475,50 & 38,22 & 24,79 & 32,03 & 13,03 \\
\hline Híbrido* & 0,0484 & 0,0001 & 0,0001 & 0,0269 & 0,0001 & 0,0001 & 0,0024 \\
\hline C.V. & 27,9 & 21,0 & 17,0 & 22,0 & 10,0 & 15,0 & 31,0 \\
\hline
\end{tabular}

PESP = produção de espigas

$P F I B=$ produção da fração volumosa

PTOT $=$ produção total

MS planta = teor de MS da planta inteira

MS espiga = teor de MS das espigas

${ }^{1}$ (MS espiga - MS fração volumosa).

* Probabilidade de o efeito dos híbridos ser nulo. 
Tabela 14. Características agronômicas dos hibridos de milho em 1997.

\begin{tabular}{|c|c|c|c|c|c|c|c|}
\hline & PESP & PFIB & PTOT & espigas & $\begin{array}{c}\text { MS } \\
\text { planta }\end{array}$ & $\begin{array}{c}\text { MS } \\
\text { espigas }\end{array}$ & $\begin{array}{l}\text { Dry- } \\
\text { down }\end{array}$ \\
\hline C333 & 10884,27 & 10940,09 & 21824,36 & 50,06 & 35,50 & 52,21 & 28,71 \\
\hline P3027 & 10712,39 & 11081,33 & 21793,73 & 49,24 & 32,56 & 48,63 & 26,67 \\
\hline FO01 & 10058 & 116 & 7,24 & 46,42 & 36,22 & 34 & 31,47 \\
\hline AG1051 & 10352 & 105 & 20869,06 & 49,72 & 32,12 & 50,21 & 28,60 \\
\hline AG1043 & 10915,84 & 9832,59 & 8,43 & 0 & 33,47 & 25 & 26,44 \\
\hline ZEN8452 & 10733,06 & 9812,63 & 20545,69 & 52,10 & 34,82 & 53,20 & 30,60 \\
\hline COL4 & 10613,41 & 9629,09 & 20242,50 & 52,42 & 35,82 & 55,80 & 32,78 \\
\hline C435 & 9967,85 & 10090,29 & 20058,15 & 49,66 & 33,96 & 51,70 & 29,07 \\
\hline XL360 & 10250,41 & 9668,46 & 19918,87 & 51,91 & 35,13 & 54,35 & 31,49 \\
\hline DINA657 & 11467,88 & 8418,62 & 19886,50 & 57,70 & 34,99 & 55,21 & 33,97 \\
\hline ZEN8392 & 10929,26 & 8831,75 & 19761,00 & 55,31 & 34,50 & 56,34 & 35,65 \\
\hline ZEN8501 & 9338,88 & 10401,34 & 19740,22 & 47,46 & 33,35 & 50,12 & 28,58 \\
\hline EXCELER & 9400,77 & 9994,46 & 19395,24 & 48,43 & 34,65 & 51,45 & 27,98 \\
\hline DINA766 & 10202,07 & 9100,41 & 19302,48 & 52,77 & 32,95 & 53,77 & 33,10 \\
\hline MASTER & 10130,56 & 9146,33 & 19276,89 & 52,66 & 35,55 & 53,48 & 29,62 \\
\hline C909 & 9385,77 & 9597,80 & 18983,57 & 49,28 & 34,79 & 49,40 & 25,59 \\
\hline DINA556 & 10142,50 & 8621,95 & 18764,45 & 54,19 & 34,46 & 51,16 & 28,40 \\
\hline P3041 & 10161,71 & 8428,87 & 18590,57 & 54,61 & 33,36 & 52,27 & 1,20 \\
\hline DINA769 & 9342,32 & 8514,00 & 17856,32 & 52,14 & 33,46 & 52,45 & 30,82 \\
\hline AG5011 & 8944,49 & 7495,48 & 16439,97 & 54,42 & 31,45 & 53,70 & 34,56 \\
\hline AG9014 & 8083,45 & 7454,89 & 15538,33 & 52,10 & 34,56 & 48,92 & 24,94 \\
\hline Hibrido* & 0,0098 & 0,0006 & 0,0008 & 0,0119 & 0,2801 & 0,0100 & 0,0155 \\
\hline C.V. & 10,0 & 14,0 & 10,0 & 7,0 & 8,0 & 7,0 & 13,0 \\
\hline
\end{tabular}

$\mathrm{PESP}=$ produção de espigas

$P F I B=$ produção da fração volumosa

PTOT = produção total

MS planta = teor de MS da planta inteira

MS espiga = teor de MS das espigas

${ }^{1}$ MS espiga - MS fração volumosa.

* Probabilidade de o efeito dos híbridos ser nulo.

Uma acentuada diferença de umidade entre as espigas e a fração volumosa não é desejável para a confecção de silagens de elevado valor nutritivo ( Allen 1997; Roth, 1993), uma vez que os grãos de milho presentes na silagem devem possuir alta umidade e serem de textura macia, de modo a aumentar a 
digestibilidade do amido. Um híbrido que apresente uma grande diferença entre a umidade da planta (haste+folhas) e do grão no momento de ensilagem, fornecerá uma silagem cujo grão estará muito seco e duro para ser quebrado e a planta ainda úmida. A consequência será um menor consumo de energia digestível, devido a menor digestibilidade do amido no rúmen do animal.

Em ambos os anos, foi verificado uma grande variação entre os genótipos quanto a produção de matéria seca total, bem como na composição da planta. A produção total de MS variou de $8.475,5$ a $15.103,2$ t.ha $^{-1}$ em 1996, sendo que a porcentagem de espigas na MS variou de 25,6 a $51,63 \%$ (tabela 13). Em 1997, a produção de MS total variou de $15.538,3$ a $21.824,3$ tha $^{-1}$ e a porcentagem de espigas na MS de 46,4 a $57,7 \%$ (tabela 14).

\subsubsection{Composição química}

Vemos na tabela 15 que em 1996 houve um efeito significativo do híbrido sobre os parâmetros de composição química estudados.

Em 1997, houve novamente uma grande variação entre os genótipos em todos os parâmetros, com exceção do teor de FDA, lignina, celulose e hemicelulose da fração volumosa (haste+folhas) (tabela 16). 
Tabela 15. Composição bromatológica da fração volumosa (haste+folhas) de hibridos de milho em 1996.

\begin{tabular}{ccccccccc}
\hline híbrido & MS & M.M. & P.B. & FDN & FDA & LIG & CEL & HEM \\
C435 & 19,00 & 8,49 & 9,02 & 67,42 & 36,84 & 7,14 & 28,78 & 30,59 \\
C333 & 21,80 & 7,42 & 9,37 & 66,56 & 36,75 & 5,84 & 29,94 & 29,81 \\
C805 & 19,61 & 7,39 & 8,51 & 66,51 & 38,37 & 7,44 & 30,10 & 28,14 \\
DINA887 & 20,41 & 7,81 & 7,77 & 65,90 & 37,48 & 5,50 & 31,33 & 28,42 \\
BR3123 & 18,06 & 9,72 & 9,08 & 64,26 & 35,30 & 4,11 & 29,97 & 28,95 \\
C969 & 21,16 & 7,52 & 8,50 & 63,55 & 36,07 & 3,71 & 31,16 & 27,48 \\
C808 & 18,74 & 7,74 & 9,33 & 63,49 & 32,73 & 4,02 & 27,83 & 30,76 \\
C909 & 20,07 & 6,82 & 8,12 & 63,07 & 36,57 & 3,69 & 32,14 & 26,50 \\
DINA657 & 23,17 & 7,87 & 8,76 & 62,23 & 36,51 & 6,09 & 28,72 & 25,72 \\
C806 & 19,96 & 7,12 & 9,13 & 60,92 & 34,92 & 5,49 & 28,73 & 26,00 \\
DINA769 & 20,13 & 8,02 & 9,51 & 60,65 & 34,13 & 4,50 & 28,19 & 26,53 \\
C425 & 20,23 & 6,93 & 8,36 & 60,60 & 35,89 & 4,08 & 30,62 & 24,70 \\
P3027 & 20,21 & 7,08 & 8,88 & 60,53 & 37,19 & 4,43 & 32,33 & 23,34 \\
ZEN8452 & 19,97 & 8,15 & 9,27 & 60,38 & 34,96 & 5,26 & 27,85 & 25,42 \\
C505 & 21,90 & 8,77 & 9,12 & 60,23 & 35,10 & 4,58 & 28,60 & 25,13 \\
C701 & 23,90 & 6,19 & 8,54 & 60,20 & 34,50 & 4,87 & 29,07 & 25,70 \\
FO01 & 23,05 & 7,52 & 9,05 & 60,03 & 37,87 & 4,59 & 32,28 & 22,15 \\
XL370 & 19,38 & 8,34 & 8,78 & 60,01 & 34,60 & 4,45 & 29,04 & 25,41 \\
ZEN8501 & 25,05 & 7,47 & 9,39 & 59,86 & 33,79 & 4,51 & 27,87 & 26,07 \\
P3041 & 19,04 & 8,06 & 8,42 & 59,56 & 36,39 & 4,98 & 30,93 & 23,17 \\
P3072 & 17,86 & 8,26 & 8,55 & 59,46 & 35,20 & 4,16 & 30,41 & 24,26 \\
XL660 & 20,45 & 7,44 & 8,61 & 59,31 & 36,06 & 4,27 & 30,79 & 23,25 \\
AGROMEN & 19,38 & 7,85 & 8,99 & 59,17 & 33,49 & 4,35 & 27,95 & 25,68 \\
AG122 & 24,70 & 6,31 & 8,55 & 59,15 & 33,61 & 4,06 & 28,57 & 25,55 \\
XL220 & 23,86 & 7,39 & 9,61 & 57,85 & 31,74 & 3,93 & 26,61 & 26,11 \\
ZEN8392 & 20,67 & 6,00 & 7,32 & 57,09 & 31,19 & 7,00 & 23,51 & 25,91 \\
AG5011 & 21,48 & 7,42 & 8,79 & 56,92 & 33,69 & 4,39 & 28,33 & 23,23 \\
DINA766 & 21,92 & 7,39 & 9,02 & 55,03 & 32,86 & 3,03 & 28,55 & 22,17 \\
\hline Hibrido* & 0,0001 & 0,0001 & 0,012 & 0,0001 & 0,0001 & 0,002 & 0,0001 & 0,0001 \\
C.V. & 10,1 & 11,0 & 8,0 & 5,9 & 6,46 & 30,0 & 8,0 & 11,0 \\
\hline
\end{tabular}

* Probabilidade de o efeito dos híbridos ser nulo 
Tabela 16. Composição bromatológica da fração volumosa (haste+folhas) de híbridos de milho 1997.

\begin{tabular}{ccccccccc}
\hline Híbrido & MS & M.M. & P.B. & FDN & FDA & LIG & CEL & HEM \\
MASTER & 23,86 & 7,17 & 7,79 & 71,18 & 43,94 & 6,64 & 35,55 & 27,24 \\
DINA657 & 21,24 & 8,41 & 7,36 & 70,63 & 43,87 & 4,90 & 36,91 & 26,76 \\
COL4 & 23,02 & 7,18 & 7,27 & 69,80 & 43,18 & 6,63 & 34,48 & 26,63 \\
AG9014 & 23,98 & 9,27 & 8,34 & 68,78 & 41,56 & 6,46 & 32,96 & 27,22 \\
FO01 & 24,86 & 7,57 & 7,22 & 68,34 & 43,66 & 7,48 & 34,77 & 24,68 \\
AG1043 & 21,81 & 8,32 & 8,17 & 67,30 & 40,25 & 5,74 & 32,25 & 27,05 \\
DINA766 & 20,67 & 9,52 & 7,97 & 67,26 & 42,20 & 5,57 & 34,19 & 25,06 \\
AG1051 & 21,61 & 7,66 & 8,26 & 67,16 & 41,40 & 6,10 & 33,33 & 25,76 \\
DINA769 & 21,62 & 7,74 & 8,05 & 67,07 & 42,06 & 6,80 & 33,67 & 25,01 \\
P3027 & 21,96 & 7,63 & 7,63 & 66,43 & 41,98 & 5,35 & 34,24 & 24,45 \\
DINA556 & 22,75 & 8,29 & 7,80 & 66,18 & 43,05 & 6,41 & 34,12 & 23,13 \\
ZEN8452 & 22,59 & 10,02 & 7,34 & 65,47 & 42,64 & 6,85 & 33,85 & 22,82 \\
ZEN8501 & 21,54 & 7,14 & 7,81 & 65,46 & 42,08 & 6,72 & 31,30 & 23,38 \\
P3041 & 21,07 & 8,81 & 7,89 & 65,34 & 41,25 & 6,43 & 33,11 & 24,09 \\
C435 & 22,63 & 7,37 & 7,85 & 65,25 & 40,54 & 6,63 & 31,96 & 24,71 \\
XL360 & 23,96 & 6,52 & 6,07 & 64,53 & 37,47 & 5,05 & 30,47 & 27,06 \\
AG5011 & 19,14 & 9,62 & 9,02 & 64,41 & 40,86 & 6,36 & 31,51 & 23,55 \\
C333 & 23,50 & 7,84 & 8,02 & 64,14 & 39,36 & 5,69 & 31,47 & 24,78 \\
EXCELER & 23,46 & 7,22 & 6,46 & 62,83 & 39,08 & 6,96 & 30,71 & 23,75 \\
ZEN8392 & 20,68 & 7,95 & 6,96 & 62,24 & 38,12 & 5,23 & 30,71 & 24,11 \\
C909 & 23,82 & 6,23 & 6,96 & 61,05 & 38,11 & 5,13 & 31,15 & 22,94 \\
\hline hibrido* & 0,0386 & 0,0191 & 0,0427 & 0,0125 & 0,2153 & 0,3209 & 0,0535 & 0,5128 \\
C.V. & 11,0 & 18,0 & 11,0 & 5,0 & 7,0 & 18,0 & 7,0 & 10,0 \\
\hline
\end{tabular}

* Probabilidade de o efeito dos híbridos ser nulo.

\subsubsection{Digestibilidade "in situ"}

\subsubsection{Matéria seca}

Houve efeito significativo dos híbridos sobre a digestibilidade da MS em todos os tempos de incubação e em ambos os anos (tabelas 17 e 18), demonstrando a existência de grande variação genética para esse parâmetro, como já fora observado anteriormente ( Roth et al., 1970; Vattikonda \& Hunter, 1983; Buxton \& Castler, 1993; Lundvall et al., 1994). A existência de 
variabilidade genética é a base para qualquer programa de seleção de híbridos.

Tabela 17 . Digestibilidade "in situ" da MS da fração volumosa dos híbridos de milho em 1996.

\begin{tabular}{|c|c|c|c|c|c|c|c|c|c|c|c|c|}
\hline Híbrido & 0 & $\mathrm{~h}$ & 3 & $\bar{h}$ & & $\mathrm{~h}$ & & $2 h$ & $24 h$ & & $8 \mathrm{~h}$ & $72 h$ \\
\hline ZEN 8392 & 42,4 & a & 45 & $\bar{a}$ & 47,7 & $a$ & 57,6 & a & 63,8 a & 73,7 & $a$ & 74,4 a \\
\hline XL220 & 41,6 & $a b$ & 43,6 & a & 48,7 & a & 54,1 & $a b$ & 62,7 a & 70,8 & abcd & $70,4 a b c$ \\
\hline DINA766 & 40,5 & $b c$ & 41,9 & b & 45,1 & $a b$ & 51,9 & bcd & 62,8 a & 67,4 & abcdef & $70,9 \mathrm{abc}$ \\
\hline AG5011 & 40,1 & bcd & 41 & $b c$ & 42,8 & bcde & 52,4 & $a b c$ & $60,9 a b$ & 69,8 & abcde & $68,7 \mathrm{abc}$ \\
\hline AGROMEN & 39,6 & cde & 41,3 & $b c$ & 42,1 & bcdef & 52,2 & $b c$ & $59,6 \mathrm{ab}$ & 70,7 & abcd & $69,8 \mathrm{abc}$ \\
\hline ZEN 8501 & 39,1 & cde & 41,3 & $b c$ & 43,6 & $b c$ & 50,9 & bcde & $60,4 \mathrm{ab}$ & 68,4 & abcdef & $69,3 \mathrm{abc}$ \\
\hline ZEN 8452 & 38,9 & cde & 40,1 & $\mathrm{~cd}$ & 43 & bcd & 50 & bcdef & $57,9 \mathrm{ab}$ & 68,5 & abcdef & $67 \mathrm{abc}$ \\
\hline P3041 & 38,6 & def & 40,3 & $\mathrm{~cd}$ & 43,5 & $b c$ & 51,7 & bcd & $58,7 \mathrm{ab}$ & 67 & abcdef & $66,9 \mathrm{abc}$ \\
\hline XL370 & 38,4 & ef & 40,3 & $\mathrm{~cd}$ & 42,9 & bcde & 49,9 & bcdef & $60,2 \mathrm{ab}$ & 70,8 & abcd & $72,6 \mathrm{ab}$ \\
\hline AG122 & 37,1 & $\mathrm{fg}$ & 39 & de & 41 & cdefgh & 48,5 & cdefg & $57,5 \mathrm{ab}$ & 69,4 & abcdef & $68,3 \mathrm{abc}$ \\
\hline C701 & 36,5 & gh & 38,1 & efg & 41,6 & bcdefg & 48,6 & cdefg & $58,1 \quad a b$ & 63,5 & ef & $68,9 a b c$ \\
\hline C505 & 36,4 & ghi & 37,6 & efgh & 39,8 & defghi & 47,4 & cdefg & 55,6 ab & 64,3 & def & $67,7 \mathrm{abc}$ \\
\hline C909 & 36,3 & ghi & 38,9 & de & 43 & bcd & 52,2 & $b c$ & $59,9 a b$ & 72,1 & $a b$ & $71,2 a b c$ \\
\hline DINA769 & 36,2 & ghi & 38,5 & ef & 40,9 & cdefgh & 49,3 & bcdefg & $61,2 \mathrm{ab}$ & 69,4 & abcdef & $69 a b c$ \\
\hline FO01 & 36,2 & ghi & 37,7 & efgh & 41,3 & cdefg & 48,1 & cdefg & 55,1 ab & 64,3 & def & $66,1 \mathrm{abc}$ \\
\hline P3072 & 36,1 & ghi & 36,9 & fghi & 40,6 & cdefgh & 49,6 & bcdefg & $58,6 \mathrm{ab}$ & 67,8 & $a b c d$ & $70,6 \mathrm{abc}$ \\
\hline C808 & 35,8 & ghij & 38,9 & $\mathrm{de}$ & 41,9 & bcdef & 50,8 & bcde & $60,5 \mathrm{ab}$ & 71,7 & $a b c$ & $69,5 \mathrm{abc}$ \\
\hline P3027 & 35,3 & $\mathrm{hij}$ & 37,3 & fghi & 39,4 & efghij & 47,3 & cdefg & $55,9 \mathrm{ab}$ & 69 & abcdef & $66,7 \mathrm{abc}$ \\
\hline C969 & 34,8 & hij & 36,5 & hi & 39,2 & fghij & 46,3 & efg & $55,7 \mathrm{ab}$ & 68,1 & abcdef & $66,1 \mathrm{abc}$ \\
\hline DINA657 & 34,7 & $\mathrm{ijk}$ & 36,9 & ghi & 39,6 & defghij & 48,6 & cdefg & $54,6 \mathrm{ab}$ & 65,5 & bcdef & $65,4 \mathrm{abc}$ \\
\hline $\mathrm{C} 425$ & 34,3 & $\mathrm{jk}$ & 36,4 & hi & 38,9 & fghij & 47,4 & cdefg & $54,3 \mathrm{ab}$ & 67,9 & abcdef & $64,2 \mathrm{abc}$ \\
\hline $\mathrm{C} 806$ & 34,3 & $\mathrm{jk}$ & 37,3 & fghi & 41,1 & cdefgh & 49,4 & bcdefg & $60,5 \mathrm{ab}$ & 68,7 & abcdef & $69,2 \mathrm{abc}$ \\
\hline XL660 & 34,3 & $\mathrm{jk}$ & 35,9 & $\mathrm{ij}$ & 38,7 & fghij & 45,7 & efg & $57,1 \mathrm{ab}$ & 65 & bcdef & $69,6 \mathrm{abc}$ \\
\hline BR3123 & 33 & lk & 35,9 & $\mathrm{ij}$ & 39 & fghij & 49,3 & bcdefg & $57,4 \mathrm{ab}$ & 67,6 & abcdef & $67,4 \mathrm{abc}$ \\
\hline DINA887 & 32 & $\operatorname{lm}$ & 34,4 & $\mathrm{kj}$ & 38,2 & ghij & 46,8 & defg & $56,2 \mathrm{ab}$ & 62,3 & & $60,8 \mathrm{c}$ \\
\hline $\mathrm{C} 805$ & 30,9 & $\mathrm{~nm}$ & 33,4 & $\mathrm{kl}$ & 36,2 & $\overline{\mathbf{j}}$ & 44,4 & $\mathrm{~g}$ & $56,4 \mathrm{ab}$ & 65,5 & bcdef & $66,2 \mathrm{abc}$ \\
\hline C333 & 30,4 & $\mathrm{~nm}$ & 33,6 & $\mathrm{kl}$ & 37,6 & hij & 44,4 & $\mathrm{~g}$ & 52,9 b & 64 & def & $64,9 a b c$ \\
\hline $\mathrm{C} 435$ & 29,2 & $\mathrm{n}$ & 32,4 & 1 & 36,5 & $\mathrm{ij}$ & 44,8 & $\mathrm{fg}$ & $56,4 \mathrm{ab}$ & 64,8 & cdef & $62,8 \mathrm{bc}$ \\
\hline $\mathrm{CV}$ & & 49 & & 28 & & 2,73 & &, 40 & 5,25 & & 3,32 & 5,28 \\
\hline
\end{tabular}

A digestibilidade "in situ" da MS após 48 horas de incubação variou de 62,3 a 73,7\% em 1996 (tabela 17), e de 49,5 a 62,5\% em 1997 (tabela 18). 
Tabela 18 . Digestibilidade "in situ" da MS da fração volumosa dos híbridos de milho em 1997.

\begin{tabular}{cccccccccc}
\hline Hibrido & Oh & $3 \mathrm{~h}$ & $6 \mathrm{~h}$ & \multicolumn{1}{c}{$12 \mathrm{~h}$} & $24 \mathrm{~h}$ & $48 \mathrm{~h}$ & $72 \mathrm{~h}$ \\
\hline EXCELER & $37,6 \mathrm{a}$ & $38,8 \mathrm{a}$ & $41 \mathrm{ab}$ & $45 \mathrm{ab}$ & $51,9 \mathrm{ab}$ & $59,2 \mathrm{abcd}$ & $64,5 \mathrm{abc}$ \\
C909 & $37,2 \mathrm{ab}$ & $38,3 \mathrm{a}$ & $41,6 \mathrm{a}$ & $46,1 \mathrm{a}$ & $51,5 \mathrm{ab}$ & $61,5 \mathrm{ab}$ & $65,2 \mathrm{ab}$ \\
ZEN 8392 & $36,8 \mathrm{ab}$ & $38,2 \mathrm{a}$ & $40,1 \mathrm{ab}$ & $44,3 \mathrm{abc}$ & $51,8 \mathrm{ab}$ & $62,2 \mathrm{a}$ & $66,6 \mathrm{a}$ \\
ZEN 8501 & $36,3 \mathrm{abc}$ & $37,1 \mathrm{ab}$ & $39 \mathrm{abc}$ & $44,4 \mathrm{abc}$ & $52,9 \mathrm{a}$ & $59,5 \mathrm{abc}$ & $64,3 \mathrm{abcd}$ \\
C333 & $35,2 \mathrm{bcd}$ & $37,1 \mathrm{ab}$ & $38,6 \mathrm{bc}$ & $43,2 \mathrm{abcd}$ & $50,2 \mathrm{ab}$ & $55,7 \mathrm{abcdefg}$ & $61,7 \mathrm{bcdefg}$ \\
XL360 & $34,7 \mathrm{cde}$ & $35,4 \mathrm{bc}$ & $37,1 \mathrm{~cd}$ & $41,5 \mathrm{cdef}$ & $48 \mathrm{abcde}$ & $57,7 \mathrm{abcde}$ & $62,5 \mathrm{abcde}$ \\
C435 & $33,7 \mathrm{def}$ & $34,4 \mathrm{~cd}$ & $35 \mathrm{defg}$ & $41,3 \mathrm{cdef}$ & $46,4 \mathrm{bcdef}$ & $55 \mathrm{bcdefg}$ & $59,8 \mathrm{cdefghi}$ \\
ZEN 8452 & $33 \mathrm{efg}$ & $33,6 \mathrm{de}$ & $35,3 \mathrm{def}$ & $42,5 \mathrm{bcde}$ & $48,7 \mathrm{abc}$ & $56,8 \mathrm{abcdef}$ & $61,7 \mathrm{bcdefg}$ \\
AG1043 & $32,9 \mathrm{efg}$ & $34,1 \mathrm{cde}$ & $36,9 \mathrm{~cd}$ & $41,9 \mathrm{bcdef}$ & $48,5 \mathrm{abcd}$ & $58,7 \mathrm{abcde}$ & $61,4 \mathrm{bcdefgh}$ \\
DINA769 & $32,6 \mathrm{fgh}$ & $33,6 \mathrm{de}$ & $35,6 \mathrm{de}$ & $40,5 \mathrm{defg}$ & $46,4 \mathrm{bcdef}$ & $55,3 \mathrm{bcdefg}$ & 59,4 efghi \\
P3041 & $31,8 \mathrm{fghi}$ & $32,4 \mathrm{ef}$ & $33,6 \mathrm{efgh}$ & $37,7 \mathrm{ghi}$ & $42,9 \mathrm{def}$ & $52,1 \mathrm{efg}$ & $57,4 \mathrm{fghi}$ \\
COL4 & $31,4 \mathrm{ghij}$ & $32,8 \mathrm{def}$ & $33,8 \mathrm{efgh}$ & $38,5 \mathrm{fghi}$ & $44 \mathrm{cdef}$ & $53,8 \mathrm{cdefg}$ & $56,9 \mathrm{hi}$ \\
P3027 & $31 \mathrm{ghij}$ & $31,5 \mathrm{fg}$ & $34,7 \mathrm{defg}$ & $39,5 \mathrm{efgh}$ & $43,5 \mathrm{cdef}$ & $53,1 \mathrm{cdefg}$ & $59,7 \mathrm{defghi}$ \\
AG5011 & $30,7 \mathrm{hij}$ & $30,5 \mathrm{gh}$ & $32,3 \mathrm{ghi}$ & $36,3 \mathrm{hij}$ & $41,3 \mathrm{f}$ & $49,8 \mathrm{~g}$ & $55,5 \mathrm{i}$ \\
FO01 & $30,2 \mathrm{ijk}$ & $31,2 \mathrm{fgh}$ & $33,3 \mathrm{efgh}$ & $37,4 \mathrm{ghi}$ & $42,5 \mathrm{ef}$ & $49,5 \mathrm{~g}$ & $55,4 \mathrm{i}$ \\
DINA766 & $30,1 \mathrm{jjk}$ & $31,1 \mathrm{fgh}$ & $33,5 \mathrm{efgh}$ & $41,5 \mathrm{cdef}$ & $47,4 \mathrm{abcde}$ & $57,1 \mathrm{abcdef}$ & $62 \mathrm{abcdef}$ \\
AG1051 & $29,7 \mathrm{jkl}$ & $31,3 \mathrm{fgh}$ & $32,8 \mathrm{fghi}$ & $39,5 \mathrm{efgh}$ & $43,8 \mathrm{cdef}$ & $53,3 \mathrm{cdefg}$ & $59,1 \mathrm{efghi}$ \\
DINA556 & $28,4 \mathrm{klm}$ & $29,6 \mathrm{hi}$ & $31,8 \mathrm{hij}$ & $35,9 \mathrm{ij}$ & $41,6 \mathrm{f}$ & $50,6 \mathrm{fg}$ & $57 \mathrm{ghi}$ \\
DINA657 & $27,8 \mathrm{~lm}$ & $28,2 \mathrm{ij}$ & $30,5 \mathrm{ij}$ & $35,6 \mathrm{ij}$ & $43 \mathrm{cdef}$ & $52,7 \mathrm{defg}$ & $58,7 \mathrm{efghi}$ \\
AG9014 & $27,6 \mathrm{~m}$ & $28,3 \mathrm{ij}$ & $29,2 \mathrm{j}$ & $33,7 \mathrm{j}$ & $40,8 \mathrm{f}$ & $50,8 \mathrm{fg}$ & $55,8 \mathrm{i}$ \\
MASTER & $26,7 \mathrm{~m}$ & $27,7 \mathrm{j}$ & $29,3 \mathrm{j}$ & $36 \mathrm{hij}$ & $41,4 \mathrm{f}$ & $50,7 \mathrm{fg}$ & $57,1 \mathrm{ghi}$ \\
\hline C.V. & 1,60 & 1,74 & 2,55 & 2,84 & 4,02 & 3,89 & 2,55 \\
\hline
\end{tabular}

\subsubsection{Fibra em detergente neutro (FDN)}

Semelhante a degradação da MS, houve efeito significativo dos híbridos sobre a digestibilidade do FDN em todos os tempos de incubação e em ambos os anos (tabelas 19 e 20). 
Tabela 19 . Digestibilidade "in situ" do FDN da fração volumosa dos hibridos de milho em 1996.

\begin{tabular}{|c|c|c|c|c|c|c|c|c|}
\hline Híbrido & & Oh & $3 h$ & $6 h$ & $12 \mathrm{~h}$ & $24 h$ & $48 h$ & $72 h$ \\
\hline C909 & 19,2 & a & $22,7 \mathrm{ab}$ & $27,7 \mathrm{a}$ & $40,5 \mathrm{ab}$ & 52,6 a & $68,1 \mathrm{a}$ & $66,5 \mathrm{a}$ \\
\hline ZEN 8392 & 18,7 & a & 23,1 a & $26,0 \mathrm{ab}$ & $43,7 \mathrm{a}$ & $51,4 \mathrm{ab}$ & $65,3 \mathrm{ab}$ & $64,9 \mathrm{a}$ \\
\hline BR3123 & 16,3 & $a b$ & $18,1 \mathrm{abcd}$ & $22,8 \mathrm{abc}$ & $39,4 \mathrm{abc}$ & $49,4 a b$ & $63,8 \mathrm{sbcd}$ & $61,6 \mathrm{a}$ \\
\hline $\mathrm{C} 805$ & 16,3 & $a b$ & 17,9 abcde & 19,9 abcde & 33,0 abcdef & $49,2 \mathrm{ab}$ & 60,5 abcdef & $60,6 a$ \\
\hline$X L 220$ & 14,9 & $a b c$ & $19,2 \mathrm{abc}$ & $25,6 \mathrm{ab}$ & $37,4 \mathrm{abcd}$ & $49,6 \mathrm{ab}$ & 60,7 abcdef & 59,4 a \\
\hline AG5011 & 13,8 & abcd & 17,0 abcde & 20,5 abcde & $38,3 \mathrm{abc}$ & $48,7 \mathrm{ab}$ & 61.9 abcde & 57,3 a \\
\hline C806 & 13,3 & abcde & 17,4 abcde & $23,6 \mathrm{abc}$ & 36,8 abcde & $50,4 \mathrm{ab}$ & $63,7 \mathrm{abcd}$ & $64,2 \mathrm{a}$ \\
\hline DINA887 & 12,9 & abcdef & 16,6 bcde & $21,9 \mathrm{abcd}$ & 33,7 abcdef & $46,0 \mathrm{ab}$ & 53,3 cdef & $53,5 \mathrm{a}$ \\
\hline XL370 & 12,8 & abcdef & 13,1 cdefgh & 17,7 abcdef & 30,5 bcdefg & $47,3 \mathrm{ab}$ & 61,3 abcde & $61,5 \mathrm{a}$ \\
\hline P3041 & 12,6 & abcdefg & 15,4 cdef & 20,4 abcde & 33,0 abcdef & $44,4 \mathrm{ab}$ & 56,6 abcdef & 55,7 a \\
\hline P3027 & 12,1 & abcdefg & 14,7 cdefg & 16,2 bcdef & 29,5 cdefg & $42,6 \mathrm{ab}$ & $63,4 \mathrm{abcd}$ & 56,1 a \\
\hline P3072 & 12,0 & abcdefg & 11,9 defgh & 17,8 abcdef & 34,1 abcdef & $44,8 \mathrm{ab}$ & 58,5 abcdef & $62,1 \mathrm{a}$ \\
\hline ZEN 8452 & 11,1 & abcdefg & $8,2 \mathrm{hi}$ & 15,3 cdef & 27,0 defg & $40,5 \mathrm{ab}$ & 57,2 abcdef & 52,3 a \\
\hline C333 & 10,9 & abcdefg & 16,3 bcde & $21,2 \mathrm{abcd}$ & 31,5 bcdefg & $43,4 \mathrm{ab}$ & 59,7 abcdef & $60,3 a$ \\
\hline $\mathrm{C} 808$ & 10,8 & abcdefg & 15,3 cdefg & 20,9 abcd & 35,0 abcdef & $49,4 a b$ & $65,0 \mathrm{abc}$ & $60,9 a$ \\
\hline XL660 & 8,9 & bcdefg & 12,5 defgh & 14,6 cdef & 26,7 defg & $43,7 \mathrm{ab}$ & 56,2 bcdef & 58,5 a \\
\hline $\mathrm{C} 435$ & 8,1 & bcdefg & 11,5 efghij & $21,5 \mathrm{abcd}$ & 30,7 bcdefg & $45,3 \mathrm{ab}$ & 58,3 abcdef & 53,9 a \\
\hline $\mathrm{C} 425$ & 6,7 & bcdefg & $9,5 \mathrm{fghi}$ & 14,6 cdef & 30,3 bcdefg & $37,4 \mathrm{~b}$ & 59,4 abcdef & 50,9 a \\
\hline AGROMEN & 6,5 & cdefg & 13,7 cdefgh & 13,8 cdef & 34,3 abcdef & $43,2 \mathrm{ab}$ & 59,2 abcdef & 56,5 a \\
\hline DINA657 & 6,5 & cdefg & 12,0 defgh & 14,7 cdef & 29,1 cdefg & $39,1 \mathrm{ab}$ & 53,7 bcdef & 53,4 a \\
\hline AG122 & 6,2 & cdefg & 12,0 defgh & 13,8 cdef & 26,8 defg & $42,0 \mathrm{ab}$ & 58,9 abcdef & 55,5 a \\
\hline ZEN 8501 & 6,2 & cdefg & $7,3 \mathrm{hi}$ & $12,2 \mathrm{def}$ & 29,1 cdefg & $40,9 \mathrm{ab}$ & 55,4 bcdef & 54,5 a \\
\hline C701 & 5,9 & cdefg & $12,8 \mathrm{cdefgh}$ & $14,6 \mathrm{cdef}$ & $26,2 \mathrm{efg}$ & $42,6 \mathrm{ab}$ & $49,2 \mathrm{f}$ & $54,3 \mathrm{a}$ \\
\hline DINA766 & 5,9 & cdefg & $5,2 \mathrm{i}$ & 10,5 ef & $21,6 \mathrm{~g}$ & $42,0 \mathrm{ab}$ & $49,3 \mathrm{f}$ & 52,5 a \\
\hline FOO1 & 5,5 & defg & $8,8 \mathrm{ghi}$ & $13,6 \mathrm{cdef}$ & 27,0 defg & $37,0 \mathrm{~b}$ & 52,2 def & $51,7 \mathrm{a}$ \\
\hline DINA769 & 4,5 & efg & 9,1 fghi & $9,5 \mathrm{f}$ & $26,0 \mathrm{fg}$ & $47,1 \mathrm{ab}$ & 57,2 abcdef & $54,6 \mathrm{a}$ \\
\hline C969 & 4,0 & $\mathrm{fg}$ & 9,3 fghi & $8,9 \mathrm{f}$ & $26,7 \mathrm{efg}$ & $39,1 \mathrm{ab}$ & 57,3 abcdef & $51,3 \mathrm{a}$ \\
\hline C505 & 3,8 & $\mathrm{~g}$ & $7,6 \mathrm{hi}$ & $8,6 \mathrm{f}$ & $26,7 \mathrm{efg}$ & $39,2 \mathrm{ab}$ & 50,6 ef & 54,4 a \\
\hline C.V. & & 27.55 & 15,04 & 18,34 & 10,59 & 10,04 & 6,30 & 9,31 \\
\hline
\end{tabular}


Tabela 20 . Digestibilidade "in situ" do FDN da fração volumosa dos híbridos de milho em 1997.

\begin{tabular}{|c|c|c|c|c|c|c|c|}
\hline Híbrido & On & $3 h$ & $6 h$ & $12 \mathrm{~h}$ & $24 h$ & $48 h$ & $72 \mathrm{~h}$ \\
\hline $\mathrm{C} 435$ & 23,4 a & $22,8 \mathrm{a}$ & $24,7 \mathrm{ab}$ & $32,2 \mathrm{a}$ & $38,8 \mathrm{ab}$ & $48,4 a$ & 55,2 \\
\hline AG1051 & $20,5 \mathrm{ab}$ & 16,6 bcde & 20,4 abcdef & $29,4 \mathrm{abc}$ & $36,4 a b c$ & $45,9 \mathrm{ab}$ & $53,5 \mathrm{ab}$ \\
\hline FO01 & $19,1 \mathrm{abc}$ & $17,9 \mathrm{abcd}$ & $22,6 \mathrm{abcd}$ & $26,9 \mathrm{abcd}$ & $35,1 \mathrm{abc}$ & $42,3 \mathrm{abc}$ & $49,7 \mathrm{bcd}$ \\
\hline $\mathrm{C} 333$ & $17,8 \mathrm{abcd}$ & $20,1 \mathrm{abc}$ & $24,1 \mathrm{abc}$ & $30,8 \mathrm{ab}$ & $39,4 a b$ & $45,6 \mathrm{abc}$ & $54,8 \mathrm{ab}$ \\
\hline P3027 & $17,4 \mathrm{abcd}$ & $20,4 \mathrm{ab}$ & 25,5 a & 32,2 a & $38,5 \mathrm{ab}$ & $48,0 \mathrm{ab}$ & $56,4 a b$ \\
\hline MASTER & $16,6 \mathrm{abcd}$ & 18,3 abcd & 17,4 bcdefg & $28,6 \mathrm{abc}$ & $36,6 a b c$ & $44,5 \mathrm{abc}$ & $53,2 \mathrm{abc}$ \\
\hline ZEN & $16,1 \mathrm{abcd}$ & $17,6 \mathrm{abcd}$ & 20,0 abcdef & 31,2 a & $38,6 a b$ & 50,3 a & $55,1 \mathrm{ab}$ \\
\hline P30 & $15,7 \mathrm{abcd}$ & $19,3 \mathrm{abcd}$ & 22,2 abcde & $26,6 \mathrm{abcd}$ & $35,2 a b c$ & $44,3 a b c$ & 51, \\
\hline$X L 360$ & 15,6 abcd & $19,8 \mathrm{abc}$ & 20,7 abcdef & 24,1 cde & $35,2 a b c$ & $47,0 \mathrm{ab}$ & $55,4 \mathrm{ab}$ \\
\hline $\mathrm{C} 909$ & $14,6 \mathrm{abcd}$ & 13,4 defg & 18,8 abcdefg & 25,6 abcde & $34,5 \mathrm{abc}$ & $48,4 \mathrm{a}$ & $54,8 \mathrm{ab}$ \\
\hline DINA556 & $13,9 \mathrm{abcd}$ & 16,7 bcde & 17,7 bcdefg & 23,8 cde & $35,5 \mathrm{abc}$ & $44,1 \mathrm{abc}$ & $50,6 \mathrm{abc}$ \\
\hline DINA769 & 13,3 abcd & 15,2 bcdef & 17,0 cdefg & 25,9 abcde & $34,4 \mathrm{abc}$ & $44,7 a b c$ & $50,7 \mathrm{abc}$ \\
\hline ZEN 8501 & $13,2 \mathrm{abcd}$ & 17,4 abcde & 17,3 bcdefg & $27,2 \mathrm{abcd}$ & $40,3 \mathrm{a}$ & $50,7 \mathrm{a}$ & $55,7 \mathrm{ab}$ \\
\hline AG1043 & $13,1 \mathrm{abcd}$ & $18,1 \mathrm{abcd}$ & 21,8 abcdef & $29,5 a b c$ & $37,9 a b$ & 49,8 a & $53,7 \mathrm{ab}$ \\
\hline ZEN 8392 & 12,9 abcd & 16,4 bcde & 20,2 abcdef & 25,7 abcde & $38,3 \mathrm{ab}$ & $50,2 \mathrm{a}$ & 57,5 a \\
\hline AG5011 & $12,6 \mathrm{abcd}$ & $13,6 \mathrm{defg}$ & $14,9 \mathrm{efg}$ & 19,5 ef & $28,0 \mathrm{~cd}$ & $37,2 \mathrm{c}$ & $46,2 \mathrm{~cd}$ \\
\hline AG9014 & $11,2 \mathrm{bcd}$ & 14,4 cdefg & 16,1 defg & 24,4 bcde & $32,3 \mathrm{abcd}$ & $43,7 \mathrm{abc}$ & $51,6 \mathrm{abc}$ \\
\hline DINA766 & $9,4 \mathrm{bcd}$ & $13,6 \mathrm{defg}$ & 16,3 defg & $28,7 \mathrm{abc}$ & $34,4 a b c$ & $47,6 \mathrm{ab}$ & $53,5 \mathrm{ab}$ \\
\hline EXCELER & $8.5 \mathrm{~cd}$ & $11,5 \mathrm{efg}$ & $15,0 \mathrm{efg}$ & $21,3 \mathrm{def}$ & $33,4 \mathrm{abcd}$ & $43,2 \mathrm{abc}$ & $51,3 a b c$ \\
\hline COL4 & $7,1 \mathrm{~d}$ & $8,9 \mathrm{~g}$ & $14,7 \mathrm{fg}$ & $15,6 \mathrm{f}$ & $24,7 \mathrm{~d}$ & $39,7 b c$ & $43,5 d$ \\
\hline DINA657 & $6,4 \mathrm{~d}$ & $9,4 \mathrm{fg}$ & $11,9 \mathrm{~g}$ & $21,8 \mathrm{def}$ & $30,2 \mathrm{bcd}$ & $43,0 \mathrm{abc}$ & $51,2 \mathrm{abc}$ \\
\hline C.V. & 20.58 & 11,82 & 12,57 & 8,13 & 8,73 & $\overline{6,06}$ & 4,24 \\
\hline
\end{tabular}

\subsubsection{Cinética da degradação}

\subsubsection{Matéria seca}

Vemos nas tabelas 21 e 22 que a degradação efetiva da MS variou de 46,7 a $57,9 \%$ em 1996 e de 37 a $48 \%$ em 1997. Susmel et al. (1990) encontraram uma digestibilidade efetiva "in situ" do FDN de silagens de milho de $51,0 \%$. Ferret et al. (1997) encontrou uma variação de 37,7 a $60,5 \%$ para a digestibilidade efetiva "in situ" do FDN de 11 silagens de milho. Deinum \& Bakker (1981) relatam uma média de digestibilidade da fração volumosa de hibridos de milho "in vitro", corrigida para "in vivo", como sendo $66,7 \%$. 
Tabela 21. Cinética da degradação ruminal da MS da fração volumosa dos híbridos de milho em 1996.

\begin{tabular}{|c|c|c|c|c|c|c|}
\hline hibrido & $A$ & $\bar{B}$ & $c$ & lag & & $e^{1}$ \\
\hline ZEN8392 & 42,40 & 33,30 & 5,10 & 1,70 & 57,90 & a \\
\hline$X L 220$ & 41,60 & 30,30 & 5,50 & 1,63 & 56,20 & $a b$ \\
\hline DINA766 & 41,20 & 29,60 & 5,90 & 3,78 & 54,50 & abcde \\
\hline AG5011 & 40,60 & 29,40 & 6,70 & 4,75 & 53,80 & abcd \\
\hline AGROMEN & 40,40 & 31,00 & 5,80 & 4,78 & 53,50 & c \\
\hline C909 & 36,30 & 36,50 & 5,50 & 2,03 & 53,40 & $a b c$ \\
\hline XL370 & 39,30 & 35,50 & 4,50 & 3,83 & 53,20 & c \\
\hline ZEN8501 & 39,40 & 30,40 & 5,70 & 3,33 & 53,10 & c \\
\hline C808 & 35,80 & 36,40 & 5,30 & 1,89 & 52,90 & c \\
\hline P3041 & 38,60 & 29,60 & 5,60 & 2,21 & 52,60 & c \\
\hline DINA769 & 37,30 & 33,00 & 6,50 & 4,45 & 52,20 & bc \\
\hline ZEN8452 & 39,50 & 29,70 & 5,30 & 3,74 & 52,10 & c \\
\hline C806 & 34,40 & 35,10 & 6,20 & 2,24 & 51,70 & $\mathrm{~cd}$ \\
\hline P3072 & 36,10 & 35,90 & 4,70 & 2,61 & 51,40 & $\mathrm{~cd}$ \\
\hline AG122 & 38,10 & 32,70 & 5,00 & 4,32 & 51,30 & abcde \\
\hline C701 & 36,50 & 32,80 & 4,50 & 1,90 & 50,60 & d \\
\hline BR3123 & 33,10 & 36,00 & 5,50 & 1,91 & 50,20 & $b c$ \\
\hline P3027 & 36,30 & 33,20 & 5,10 & 4,29 & 49,90 & de \\
\hline FO01 & 36,20 & 31,80 & 4,30 & 1,75 & 49,60 & de \\
\hline C505 & 37,00 & 32,10 & 4,40 & 3,65 & 49,50 & de \\
\hline DINA657 & 34,70 & 32,70 & 4,80 & 1,85 & 49,30 & de \\
\hline XL660 & 35,10 & 35,80 & 4,40 & 3,64 & 49,10 & abcde \\
\hline C969 & 34,70 & 33,70 & 5,30 & 3,75 & 49,10 & bc \\
\hline C425 & 35,40 & 31,80 & 5,30 & 3,80 & 49,00 & abcde \\
\hline DINA887 & 32,00 & 30,20 & 7,10 & 2,25 & 47,90 & e \\
\hline C805 & 30,90 & 37,40 & 5,00 & 2,26 & 47,60 & e \\
\hline C435 & 29,20 & 35,70 & 6,20 & 1,93 & 47,20 & e \\
\hline C333 & 30,50 & 37,00 & 4,30 & 1,05 & 46,70 & abcde \\
\hline
\end{tabular}


Tabela 22. Cinética da degradação ruminal da MS da fração volumosa dos híbridos de milho em 1997.

\begin{tabular}{|c|c|c|c|c|c|c|}
\hline & $A$ & $\mathrm{~B}$ & C & Lag & & eg.ef \\
\hline híbrido & - & $0-$ & $\% \cdot h^{-1}$ & $h$ & & $-\%$ \\
\hline C909 & 37,20 & 33,20 & 2,70 & 1,20 & 48,00 & a \\
\hline ZEN8392 & 36,90 & 37,10 & 2,40 & 1,94 & 47,70 & a \\
\hline EXCELER & 37,60 & 32,20 & 2,50 & 1,48 & 47,60 & a \\
\hline ZEN8501 & 36,80 & 29,30 & 3,70 & 3,78 & 47,10 & $a b$ \\
\hline C333 & 35,20 & 30,50 & 2,70 & 0,79 & 45,40 & bc \\
\hline AG1043 & 32,90 & 32,60 & 3,10 & 1,83 & 44,40 & $\mathrm{~cd}$ \\
\hline XL360 & 35,10 & 34,50 & 2,30 & 3,51 & 44,40 & abcdefgh \\
\hline ZEN8452 & 33,40 & 31,00 & 3,40 & 3,26 & 44,00 & $\mathrm{~cd}$ \\
\hline C435 & 34,10 & 30,10 & 2,80 & 3,98 & 42,90 & $a b c$ \\
\hline DINA766 & 30,10 & 35,30 & 3,30 & 2,11 & 42,60 & de \\
\hline DINA769 & 32,60 & 31,80 & 2,70 & 1,91 & 42,60 & de \\
\hline COL4 & 32,20 & 29,50 & 2,80 & 3,99 & 40,90 & ef \\
\hline P3027 & 31,00 & 40,20 & 1,70 & 0,94 & 40,90 & abcdefgh \\
\hline AG1051 & 29,70 & 36,90 & 2,20 & 0,82 & 40,50 & $a b c$ \\
\hline P3041 & 32,10 & 35,10 & 1,90 & 3,53 & 40,10 & $\mathrm{fg}$ \\
\hline F001 & 30,20 & 32,80 & 2,00 & 0,94 & 39,20 & $h$ \\
\hline DINA657 & 27,80 & 38,40 & 2,30 & 2,62 & 38,50 & gh \\
\hline AG5011 & 30,60 & 35,60 & 1,70 & 3,00 & 38,50 & gh \\
\hline DINA556 & 28,40 & 39,10 & 1,80 & 1,05 & 38,30 & gh \\
\hline MASTER & 26,70 & 37,70 & 2,30 & 1,76 & 37,50 & $\mathrm{~h}$ \\
\hline AG9014 & 28,00 & 34,70 & 2,40 & 4,58 & 37,00 & h \\
\hline
\end{tabular}

\subsubsection{Fibra em detergente neutro (FDN)}

A digestibilidade do FDN da fração volumosa dos híbridos, também apresentou uma grande variação genética (tabelas 19 e 20). Em 1996, foi verificado uma diferença entre os híbridos de até 7,6 horas no tempo de retenção ruminal do FDN (tabela 23), em 1997, a amplitude de variação do tempo de retenção ruminal foi de 5,1 horas (tabela 24).

Varga \& Hoover (1983) relatam um tempo de retenção do FDN de silagens de milho como 14,5 horas. Já Madsen et al. (1993) encontraram um tempo de 
retenção do FDN de silagens de milho, supondo uma taxa de passagem de $5 \% \cdot h^{-1}$, de 17,3 horas.

Tabela 23. Cinética da degradação ruminal do FDN da fração volumosa de híbridos de milho em 1996.

\begin{tabular}{|c|c|c|c|c|c|}
\hline Híbrido & $\begin{array}{c}\mathrm{B} \\
\\
\end{array}$ & $\begin{array}{c}U \\
\% \cdot h^{-1}\end{array}$ & C & Lag & Fill $^{1}$ \\
\hline C909 & 51,10 & 30,00 & 5,10 & 1,44 & $12,49 a b$ \\
\hline ZEN8392 & 47,70 & 33,40 & 6,60 & 1,86 & $12,63 a b$ \\
\hline C806 & 53,60 & 32,90 & 5,50 & 1,47 & 13,13 abcde \\
\hline C333 & 51,70 & 34,80 & 4,10 & 1,17 & 13,81 ad \\
\hline P3041 & 46,90 & 40,10 & 4,50 & 1,23 & 14,18 abcd \\
\hline DINA657 & 49,60 & 43,90 & 5,40 & 1,44 & 15,00 abcde \\
\hline C808 & 50,30 & 35,60 & 7,30 & 4,14 & $15,36 \mathrm{~cd}$ \\
\hline$X L 220$ & 44,20 & 38,90 & 6,90 & 3,87 & 15,37 abcde \\
\hline BR3123 & 44,20 & 37,30 & 8,00 & 4,68 & 15,54 abcde \\
\hline DINA887 & 39,20 & 45,30 & 8,70 & 3,91 & 15,83 abcde \\
\hline P3072 & 51,80 & 35,60 & 5,20 & 3,94 & 16,12 abcde \\
\hline P3027 & 45,80 & 40,50 & 6,40 & 4,05 & 16,16 bcde \\
\hline AG5011 & 44,30 & 40,50 & 9,10 & 4,93 & 16,18 abcde \\
\hline AG122 & 50,10 & 40,70 & 5,50 & 3,59 & 16,48 bcde \\
\hline C435 & 45,40 & 43,20 & 8,30 & 4,58 & 16,64 cde \\
\hline XL370 & 50,70 & 36,80 & 5,90 & 4,95 & 16,96 cde \\
\hline F001 & 46,90 & 46,50 & 5,90 & 3,42 & 17,03 cde \\
\hline ZEN8452 & 47,90 & 43,30 & 5,80 & 4,21 & 17,32 abcde \\
\hline C701 & 46,50 & 45,50 & 5,80 & 4,04 & 17,43 abcde \\
\hline ZEN8501 & 49,20 & 43,90 & 7,40 & 4,72 & 17,47 cde \\
\hline AGROMEN & 48,90 & 41,50 & 8,10 & 5,50 & $17,54 \mathrm{de}$ \\
\hline C425 & 47,90 & 44,10 & 6,90 & 4,84 & 17,68 e \\
\hline DINA766 & 45,60 & 49,10 & 6,20 & 3,85 & 17,73 abcde \\
\hline C505 & 49,50 & 44,50 & 5,60 & 4,50 & 18,08 cde \\
\hline C969 & 49,30 & 44,00 & 7,70 & 5,59 & $18,26 \mathrm{de}$ \\
\hline C805 & 40,90 & 40,40 & 10,00 & 8,15 & 18,97 abcde \\
\hline XL660 & 46,30 & 41,80 & 7,70 & 7,38 & 19,39 \\
\hline DINA769 & 48,50 & 44,30 & 14,60 & 8,76 & 20,09 abcde \\
\hline
\end{tabular}

Tempo de retenção ruminal supondo-se taxa de passagem de $5 \% \cdot \mathrm{h}^{-1}$. 
Tabela 24. Cinética da degradação ruminal do FDN da fração volumosa de hibridos de milho em 1997.

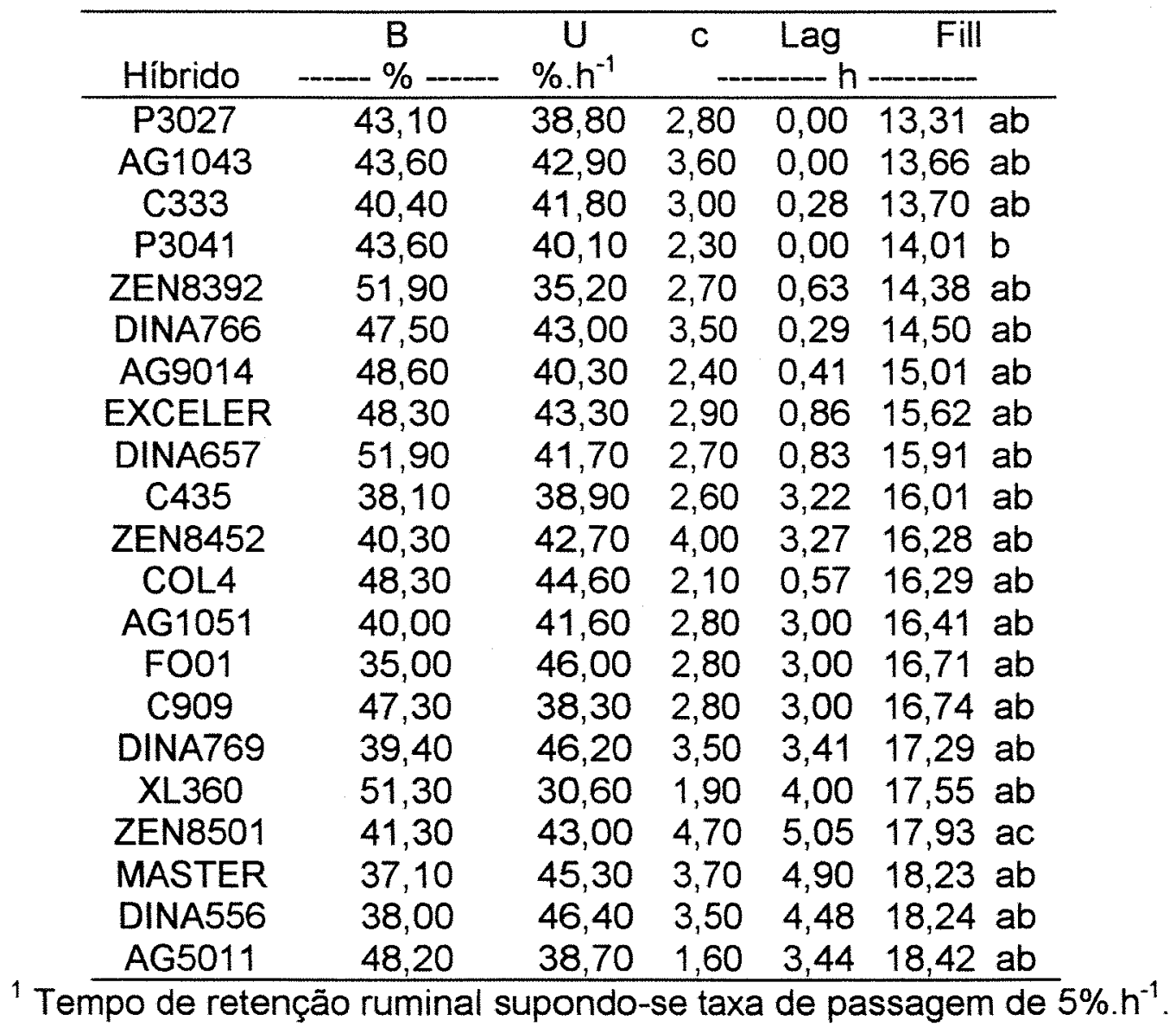

Diferenças tão expressivas na digestibilidade da MS e do FDN da fração volumosa dos híbridos de milho, podem certamente levar a diferenças de consumo de MS e energia digestivel por animais cujo consumo esteja limitado pelo efeito de enchimento da dieta (vacas de alta produção em início da lactação).

\subsection{Efeito do ciclo fenológico}

Dentre os hibridos analisados neste experimento, encontramos todos os tipos de ciclos fenológicos. Uma vez que não foi feita distinção entre os hibridos 
quando a época de plantio e de colheita, o tipo de ciclo fenológico do híbrido pode ter afetado sua performance. Na tabela 25 encontramos o efeito do ciclo fenológico sobre os parâmetros estudados.

Tabela 25. Efeito do ciclo fenológico dos híbridos sobre as variáveis estudadas.

\begin{tabular}{|c|c|c|c|c|c|c|c|}
\hline Ciclo fenológico* & № & \multicolumn{5}{|c|}{1996} & Fill \\
\hline Normal & 3 & $13217,9 \mathrm{a}$ & $5447,7 a$ & $28,3 a$ & $40,5 \mathrm{a}$ & $48,5 a$ & $16,7 a$ \\
\hline Semi precoce & 3 & $13294,4 \mathrm{a}$ & 4771,2 a & $27,7 a$ & $35,8 \mathrm{a}$ & $52,1 \mathrm{a}$ & $16,9 a$ \\
\hline Precoce & 11 & $12218,8 a$ & 4379,7 a & 26,9 a & $35,9 a$ & $51,2 \mathrm{a}$ & $16,1 \mathrm{a}$ \\
\hline Super precoce & \multicolumn{7}{|c|}{1997} \\
\hline Normal & 4 & $21279,8 \mathrm{a}$ & $10552,7 \mathrm{a}$ & $34,2 \mathrm{a}$ & $49,7 b$ & $42,4 \mathrm{a}$ & $15,1 \mathrm{a}$ \\
\hline Semi precoce & 3 & $20270,3 a b$ & $10060,6 a b$ & 34,3 a & $49,8 a b$ & $41,8 \mathrm{a}$ & $16,5 a$ \\
\hline Precoce & 10 & $19360,3 b c$ & $10261,1 \mathrm{a}$ & 34,0 a & $53,1 \mathrm{a}$ & $42,3 a$ & $16,3 \mathrm{a}$ \\
\hline Super precoce & 4 & $17920,2 \mathrm{C}$ & $9253,4 \mathrm{~b}$ & $34,0 \mathrm{a}$ & $51,6 a b$ & $42,5 \mathrm{a}$ & $15,9 a$ \\
\hline \multicolumn{8}{|c|}{ PTOT = Produção de MS total (kg/ha) } \\
\hline \multicolumn{8}{|c|}{ PESP = Produção de espigas $(\mathrm{kg} / \mathrm{ha})$} \\
\hline \multicolumn{8}{|c|}{$\mathrm{MSpl}=$ teor de matéria seca da planta inteira. } \\
\hline \multicolumn{8}{|c|}{ Deg. Ef. = degradação efetiva da MS supondo-se uma taxa de passagem de $5 \% \cdot h^{-1}$} \\
\hline \multicolumn{8}{|c|}{ Fill = tempo de retenção ruminal do FDN $(h)$} \\
\hline
\end{tabular}

Vemos que não houve efeito do ciclo fenológico sobre as variáveis estudadas em 1996, apesar da tendência de maior produção total de MS dos híbridos de ciclo normal e semi-precoce. No ano experimental de 1997 o efeito do ciclo fenológico sobre a produção de MS ficou evidente, os híbridos de ciclo precoce e super precoce apresentaram menor produção de MS do que os híbridos de ciclo normal. A produção de espigas dos híbridos de ciclo super 
precoce também foi inferior a produção dos híbridos de ciclo normal.

Este comportamento dos híbridos era esperado, uma vez que os hibridos de ciclo normal estariam mais adaptados a época de plantio utilizada na região (5/10 e 08/11 em 1996 e 1997 respectivamente). Devido as temperaturas diárias elevadas durante os meses de novembro e dezembro, os híbridos de ciclo mais precoce rapidamente atingiram a somatória calórica necessária ao florescimento e encurtaram o ciclo prejudicando a produção.

No entanto, não houve efeito do ciclo fenológico sobre a digestibilidade da MS e do FDN da fração volumosa dos híbridos estudados, ou mesmo sobre o teor de matéria seca da planta inteira no momento da colheita.

Este resultado demonstra que, apesar da menor produção dos híbridos mais precoces, o ciclo fenológico não afetou o grau de maturidade das plantas no momento da colheita.

\subsection{Relação entre as variáveis analisadas.}

\subsubsection{Caracteristicas agronômicas vs. composição química da fração volumosa.}

Vemos na tabela 26 e 27, que a porcentagem de espigas na MS se correlacionou negativamente com o teor de MS da fração volumosa em ambos os anos, e se correlacionou positivamente com o teor de MS das espigas em 1997.

Estes resultados demonstram que, em geral, as plantas com maior porcentagem de espigas apresentaram um menor teor de MS na fração volumosa, para um mesmo teor de MS da planta inteira. Ou seja, uma maior diferença de umidade entre a espiga e a fração volumosa (dry-down). A correlação positiva entre a porcentagem de espigas na MS e o dry-down em ambos os anos confirma essa observação (tabelas 26 e 27 ).

A produção total de MS não se mostrou correlacionada com a 
porcentagem de espigas na MS em 1996 (tabela 26). Em 1997, os híbridos que apresentaram maior porcentagem de espigas na MS, apresentaram menor produção total de MS por área ( $r=-0,31$, tabela 27), concordando com 0 observado por Roth et al. (1970) e por Nussio et al. (1992).

Provavelmente devido a desuniformidade no teor de MS das parcelas em 1996, a produção total de MS foi positivamente correlacionada com o teor de MS da planta inteira ( $r=0,62$, tabela 26), o que não se repetiu em 1997 (tabela 27). 
Tabela 26. Correlação entre as características de produção e a composição bromatológica da fração volumosa em 1996.

\begin{tabular}{|c|c|c|c|c|c|c|}
\hline & PESP & PFIB & PTOT & $\%$ ESPIGA & MSPL & DRY-DOWN \\
\hline PESP & $\begin{array}{c}1 \\
0,000\end{array}$ & $\begin{array}{c}-0,039 \\
0,739\end{array}$ & $\begin{array}{l}0,585 \\
0,000\end{array}$ & $\begin{array}{l}0,788 \\
0,000\end{array}$ & $\begin{array}{l}0,437 \\
0,000\end{array}$ & $\begin{array}{l}0,627 \\
0,000\end{array}$ \\
\hline PFIB & $\begin{array}{c}-0,039 \\
0,739\end{array}$ & $\begin{array}{c}1 \\
0,000\end{array}$ & $\begin{array}{l}0,788 \\
0,000\end{array}$ & $\begin{array}{c}-0,618 \\
0,000\end{array}$ & $\begin{array}{l}0,430 \\
0,000\end{array}$ & $\begin{array}{l}0,217 \\
0,061\end{array}$ \\
\hline PTOT & $\begin{array}{l}0,585 \\
0,000\end{array}$ & $\begin{array}{l}0,788 \\
0,000\end{array}$ & $\begin{array}{c}1 \\
0,000\end{array}$ & $\begin{array}{c}-0,016 \\
0,891\end{array}$ & $\begin{array}{l}0,618 \\
0,000\end{array}$ & $\begin{array}{l}0,563 \\
0,000\end{array}$ \\
\hline \%ESPIGA & $\begin{array}{l}0,788 \\
0,000\end{array}$ & $\begin{array}{c}-0,618 \\
0,000\end{array}$ & $\begin{array}{c}-0,016 \\
0,891\end{array}$ & $\begin{array}{c}1 \\
0,000\end{array}$ & $\begin{array}{l}0,107 \\
0,362\end{array}$ & $\begin{array}{l}0,387 \\
0,001\end{array}$ \\
\hline MSPL & $\begin{array}{l}0,437 \\
0,000\end{array}$ & $\begin{array}{l}0,430 \\
0,000\end{array}$ & $\begin{array}{l}0,618 \\
0,000\end{array}$ & $\begin{array}{l}0,107 \\
0,362\end{array}$ & $\begin{array}{c}1 \\
0,000\end{array}$ & $\begin{array}{l}0,567 \\
0,000\end{array}$ \\
\hline MS & $\begin{array}{c}-0,053 \\
0,654\end{array}$ & $\begin{array}{l}0,640 \\
0,000\end{array}$ & $\begin{array}{l}0,487 \\
0,000\end{array}$ & $\begin{array}{c}-0,411 \\
0,000\end{array}$ & $\begin{array}{l}0,774 \\
0,000\end{array}$ & $\begin{array}{l}0,111 \\
0,342\end{array}$ \\
\hline MM & $\begin{array}{l}0,033 \\
0,778\end{array}$ & $\begin{array}{c}-0,255 \\
0,019\end{array}$ & $\begin{array}{c}-0,185 \\
0,112\end{array}$ & $\begin{array}{l}0,182 \\
0,118\end{array}$ & $\begin{array}{r}-0,327 \\
0,004\end{array}$ & $\begin{array}{l}0,039 \\
0,735\end{array}$ \\
\hline PB & $\begin{array}{c}-0,101 \\
0,390\end{array}$ & $\begin{array}{l}0,181 \\
0,100\end{array}$ & $\begin{array}{l}0,102 \\
0,385\end{array}$ & $\begin{array}{c}-0,217 \\
0,061\end{array}$ & $\begin{array}{c}-0,016 \\
0,893\end{array}$ & $\begin{array}{l}0,067 \\
0,569\end{array}$ \\
\hline FDN & $\begin{array}{l}0,188 \\
0,106\end{array}$ & $\begin{array}{c}-0,483 \\
0,000\end{array}$ & $\begin{array}{c}-0,255 \\
0,027\end{array}$ & $\begin{array}{l}0,440 \\
0,000\end{array}$ & $\begin{array}{c}-0,089 \\
0,449\end{array}$ & $\begin{array}{c}-0,019 \\
0,871\end{array}$ \\
\hline FDA & $\begin{array}{l}0,214 \\
0,066\end{array}$ & $\begin{array}{r}-0,275 \\
0,011\end{array}$ & $\begin{array}{c}-0,079 \\
0,503\end{array}$ & $\begin{array}{l}0,341 \\
0,003\end{array}$ & $\begin{array}{c}-0,093 \\
0,430\end{array}$ & $\begin{array}{l}0,119 \\
0,308\end{array}$ \\
\hline LIG & $\begin{array}{c}-0,040 \\
0,731\end{array}$ & $\begin{array}{c}-0,297 \\
0,006\end{array}$ & $\begin{array}{c}-0,265 \\
0,022\end{array}$ & $\begin{array}{l}0,124 \\
0,289\end{array}$ & $\begin{array}{c}-0,105 \\
0,369\end{array}$ & $\begin{array}{c}-0,186 \\
0,109\end{array}$ \\
\hline CEL & $\begin{array}{l}0,236 \\
0,042\end{array}$ & $\begin{array}{c}-0,110 \\
0,319\end{array}$ & $\begin{array}{l}0,076 \\
0,515\end{array}$ & $\begin{array}{l}0,275 \\
0,017\end{array}$ & $\begin{array}{r}-0,037 \\
0,755\end{array}$ & $\begin{array}{l}0,239 \\
0,038\end{array}$ \\
\hline HEM & $\begin{array}{l}0,071 \\
0,548\end{array}$ & $\begin{array}{c}-0,392 \\
0,000\end{array}$ & $\begin{array}{c}-0,263 \\
0,023\end{array}$ & $\begin{array}{l}0,291 \\
0,011\end{array}$ & $\begin{array}{c}-0,040 \\
0,735\end{array}$ & $\begin{array}{c}-0,119 \\
0,308\end{array}$ \\
\hline CELFDN & $\begin{array}{l}0,115 \\
0,326\end{array}$ & $\begin{array}{l}0,247 \\
0,024\end{array}$ & $\begin{array}{l}0,276 \\
0,017\end{array}$ & $\begin{array}{r}-0,037 \\
0,755\end{array}$ & $\begin{array}{l}0,031 \\
0,793\end{array}$ & $\begin{array}{l}0,276 \\
0,016\end{array}$ \\
\hline LIGFDN & $\begin{array}{c}-0,102 \\
0,382\end{array}$ & $\begin{array}{c}-0,208 \\
0,058\end{array}$ & $\begin{array}{c}-0,237 \\
0,040\end{array}$ & $\begin{array}{l}0,023 \\
0,844\end{array}$ & $\begin{array}{c}-0,110 \\
0,346\end{array}$ & $\begin{array}{c}-0,223 \\
0,055\end{array}$ \\
\hline FDAFDN & $\begin{array}{l}0,053 \\
0,649\end{array}$ & $\begin{array}{l}0,193 \\
0,079\end{array}$ & $\begin{array}{l}0,183 \\
0,115\end{array}$ & $\begin{array}{c}-0,069 \\
0,558\end{array}$ & $\begin{array}{c}-0,023 \\
0,844\end{array}$ & $\begin{array}{l}0,163 \\
0,162\end{array}$ \\
\hline MSESP & $\begin{array}{l}0,537 \\
0,000\end{array}$ & $\begin{array}{l}0,431 \\
0,000 \\
\end{array}$ & $\begin{array}{l}0,681 \\
0,000 \\
\end{array}$ & $\begin{array}{l}0,190 \\
0,102 \\
\end{array}$ & $\begin{array}{l}0,791 \\
0,000\end{array}$ & $\begin{array}{c}0,929 \\
0,0001\end{array}$ \\
\hline
\end{tabular}


Tabela 27. Correlação entre as características de produção e a composição bromatológica da fração volumosa em 1997.

\begin{tabular}{|c|c|c|c|c|c|c|}
\hline & PESP & PFIB & PTOT & $\%$ ESPIGA & MSPL & DRY-DOWN \\
\hline PESP & $\begin{array}{c}1 \\
0,000\end{array}$ & $\begin{array}{l}0,330 \\
0,008\end{array}$ & $\begin{array}{l}0,757 \\
0,000\end{array}$ & $\begin{array}{l}0,384 \\
0,002\end{array}$ & $\begin{array}{l}0,241 \\
0,057\end{array}$ & $\begin{array}{l}0,358 \\
0,004\end{array}$ \\
\hline PFIB & $\begin{array}{l}0,330 \\
0,008\end{array}$ & $\begin{array}{c}1 \\
0,000\end{array}$ & $\begin{array}{l}0,867 \\
0,000\end{array}$ & $\begin{array}{c}-0,740 \\
0,000\end{array}$ & $\begin{array}{l}0,136 \\
0,289\end{array}$ & $\begin{array}{r}-0,256 \\
0,045\end{array}$ \\
\hline PTOT & $\begin{array}{l}0,757 \\
0,000\end{array}$ & $\begin{array}{l}0,867 \\
0,000\end{array}$ & $\begin{array}{c}1 \\
0,000\end{array}$ & $\begin{array}{c}-0,309 \\
0,014\end{array}$ & $\begin{array}{l}0,221 \\
0,082\end{array}$ & $\begin{array}{l}0,011 \\
0,932\end{array}$ \\
\hline \%ESPIGA & $\begin{array}{l}0,384 \\
0,002\end{array}$ & $\begin{array}{c}-0,740 \\
0,000\end{array}$ & $\begin{array}{r}-0,309 \\
0,014\end{array}$ & $\begin{array}{c}1 \\
0,000\end{array}$ & $\begin{array}{l}0,060 \\
0,642\end{array}$ & $\begin{array}{l}0,520 \\
0,000\end{array}$ \\
\hline MSPL & $\begin{array}{l}0,241 \\
0,057\end{array}$ & $\begin{array}{l}0,136 \\
0,289\end{array}$ & $\begin{array}{l}0,221 \\
0,082\end{array}$ & $\begin{array}{l}0,060 \\
0,642\end{array}$ & $\begin{array}{c}1 \\
0,000\end{array}$ & $\begin{array}{l}0,077 \\
0,549\end{array}$ \\
\hline MS & $\begin{array}{l}0,018 \\
0,891\end{array}$ & $\begin{array}{l}0,322 \\
0,011\end{array}$ & $\begin{array}{l}0,231 \\
0,070\end{array}$ & $\begin{array}{c}-0,288 \\
0,023\end{array}$ & $\begin{array}{l}0,887 \\
0,000\end{array}$ & $\begin{array}{r}-0,315 \\
0,013\end{array}$ \\
\hline MM & $\begin{array}{c}-0,023 \\
0,863\end{array}$ & $\begin{array}{c}-0,225 \\
0,086\end{array}$ & $\begin{array}{r}-0,167 \\
0,205\end{array}$ & $\begin{array}{l}0,216 \\
0,101\end{array}$ & $\begin{array}{l}0,047 \\
0,723\end{array}$ & $\begin{array}{l}0,143 \\
0,281\end{array}$ \\
\hline PB & $\begin{array}{r}-0,163 \\
0,210\end{array}$ & $\begin{array}{c}-0,135 \\
0,300\end{array}$ & $\begin{array}{r}-0,177 \\
0,171\end{array}$ & $\begin{array}{l}0,017 \\
0,894\end{array}$ & $\begin{array}{r}-0,343 \\
0,007\end{array}$ & $\begin{array}{c}-0,129 \\
0,318\end{array}$ \\
\hline FDN & $\begin{array}{l}0,105 \\
0,416\end{array}$ & $\begin{array}{r}-0,051 \\
0,694\end{array}$ & $\begin{array}{l}0,020 \\
0,878\end{array}$ & $\begin{array}{l}0,150 \\
0,246\end{array}$ & $\begin{array}{l}0,330 \\
0,009\end{array}$ & $\begin{array}{l}0,195 \\
0,128\end{array}$ \\
\hline FDA & $\begin{array}{l}0,082 \\
0,526\end{array}$ & $\begin{array}{c}-0,213 \\
0,097\end{array}$ & $\begin{array}{r}-0,104 \\
0,422\end{array}$ & $\begin{array}{l}0,278 \\
0,029\end{array}$ & $\begin{array}{l}0,107 \\
0,408\end{array}$ & $\begin{array}{l}0,287 \\
0,024\end{array}$ \\
\hline LIG & $\begin{array}{c}-0,161 \\
0,211\end{array}$ & $\begin{array}{c}-0,168 \\
0,193\end{array}$ & $\begin{array}{r}-0,200 \\
0,119\end{array}$ & $\begin{array}{l}0,066 \\
0,612\end{array}$ & $\begin{array}{r}-0,057 \\
0,660\end{array}$ & $\begin{array}{l}0,214 \\
0,095\end{array}$ \\
\hline CEL & $\begin{array}{l}0,135 \\
0,295\end{array}$ & $\begin{array}{c}-0,120 \\
0,354\end{array}$ & $\begin{array}{r}-0,012 \\
0,927\end{array}$ & $\begin{array}{l}0,220 \\
0,086\end{array}$ & $\begin{array}{l}0,249 \\
0,051\end{array}$ & $\begin{array}{l}0,182 \\
0,156\end{array}$ \\
\hline HEM & $\begin{array}{l}0,054 \\
0,676\end{array}$ & $\begin{array}{l}0,162 \\
0,209\end{array}$ & $\begin{array}{l}0,140 \\
0,278\end{array}$ & $\begin{array}{c}-0,099 \\
0,445\end{array}$ & $\begin{array}{l}0,334 \\
0,008\end{array}$ & $\begin{array}{r}-0,047 \\
0,718\end{array}$ \\
\hline CELFDN & $\begin{array}{l}0,071 \\
0,582\end{array}$ & $\begin{array}{r}-0,106 \\
0,412\end{array}$ & $\begin{array}{r}-0,036 \\
0,782\end{array}$ & $\begin{array}{l}0,137 \\
0,287\end{array}$ & $\begin{array}{l}0,009 \\
0,947\end{array}$ & $\begin{array}{l}0,045 \\
0,728\end{array}$ \\
\hline LIGFDN & $\begin{array}{r}-0,215 \\
0,094\end{array}$ & $\begin{array}{l}0,029 \\
0,823\end{array}$ & $\begin{array}{c}-0,092 \\
0,476\end{array}$ & $\begin{array}{c}-0,196 \\
0,127\end{array}$ & $\begin{array}{r}-0,166 \\
0,197\end{array}$ & $\begin{array}{l}0,031 \\
0,809\end{array}$ \\
\hline FDAFDN & $\begin{array}{c}-0,003 \\
0,980\end{array}$ & $\begin{array}{c}-0,236 \\
0,065\end{array}$ & $\begin{array}{r}-0,164 \\
0,202\end{array}$ & $\begin{array}{l}0,217 \\
0,091\end{array}$ & $\begin{array}{c}-0,213 \\
0,096\end{array}$ & $\begin{array}{l}0,181 \\
0,159\end{array}$ \\
\hline MSESP & $\begin{array}{l}0,368 \\
0,003 \\
\end{array}$ & $\begin{array}{c}-0,049 \\
0,705 \\
\end{array}$ & $\begin{array}{l}0,161 \\
0,208 \\
\end{array}$ & $\begin{array}{l}0,330 \\
0,008 \\
\end{array}$ & $\begin{array}{l}0,650 \\
0,000 \\
\end{array}$ & $\begin{array}{l}0,790 \\
0,000 \\
\end{array}$ \\
\hline
\end{tabular}


Em 1996, os híbridos com maior porcentagem de espigas na MS também apresentaram maiores teores de FDN e FDA na fração volumosa ( $r=0,44$ e 0,34 respectivamente, tabela 26 ). Essa correlação, apesar de baixa, sugere um efeito de translocação de carboidratos solúveis do colmo para os grãos, conforme sugerido por Russel et al. (1992), e observado por Deinum \& Bakker (1981); Coors (1996) e Nussio et al. (1992).

Em 1997 não foi observada correlação entre a porcentagem de espigas na MS e o teor de FDN da fração volumosa, porém a correlação com o teor de FDA se manteve significativa $(r=0,28)$ (tabela 27). Lundvall et al. (1994) também encontrou uma baixa correlação positiva entre a produção de grãos e o teor de FDN da fração volumosa $(r=0,32)$, o mesmo ocorrendo no trabalho de Nussio et al. (1992).

Já Ferret et al. (1997) encontrou correlações mais elevadas entre o teor de FDA da fração volumosa e a porcentagem de grãos das silagens $(r=0,69)$, o mesmo ocorrendo no trabalho de Coors (1996), onde foi observado um elevado coeficiente de correlação $(r=0,81)$ entre a porcentagem de grãos na MS e o teor de FDN da fração volumosa para híbridos tardios.

A falta de correlação entre a porcentagem de grãos e o teor de FDN da fração volumosa em 1997, pode refletir a menor variação na porcentagem de espigas na MS entre os materiais, se comparado com 1996.

Quando os dados dos dois anos experimentais são analisados em conjunto (tabela 28 ), verificamos uma alta correlação entre a porcentagem de espigas na MS e o teor de FDN e FDA da fração volumosa ( $r=0,62$ e 0,69 respectivamente). Demonstrando que no ano em que os híbridos apresentaram maiores porcentagens de espigas na MS (1997), a fração volumosa apresentou um maior teor de FDN do que em 1996. 
Tabela 28. Correlação entre as características de produção e a composição bromatológica da fração volumosa $(1996+1997)$.

\begin{tabular}{|c|c|c|c|c|c|c|}
\hline & PESP & PFIB & PTOT & $\%$ ESPIGA & MSPL & DRY-DOWN \\
\hline PESP & $\begin{array}{c}1 \\
0,000\end{array}$ & $\begin{array}{l}0,525 \\
0,000\end{array}$ & $\begin{array}{l}0,931 \\
0,000\end{array}$ & $\begin{array}{l}0,849 \\
0,000\end{array}$ & $\begin{array}{l}0,794 \\
0,000\end{array}$ & $\begin{array}{l}0,880 \\
0,000\end{array}$ \\
\hline PFIB & $\begin{array}{l}0,525 \\
0,000\end{array}$ & $\begin{array}{c}1 \\
0,000\end{array}$ & $\begin{array}{l}0,799 \\
0,000\end{array}$ & $\begin{array}{l}0,029 \\
0,734\end{array}$ & $\begin{array}{l}0,574 \\
0,000\end{array}$ & $\begin{array}{l}0,464 \\
0,000\end{array}$ \\
\hline PTOT & $\begin{array}{l}0,931 \\
0,000\end{array}$ & $\begin{array}{l}0,799 \\
0,000\end{array}$ & $\begin{array}{c}1 \\
0,000\end{array}$ & $\begin{array}{l}0,613 \\
0,000\end{array}$ & $\begin{array}{l}0,807 \\
0,000\end{array}$ & $\begin{array}{l}0,821 \\
0,000\end{array}$ \\
\hline$\%$ ESPIGA & $\begin{array}{l}0,849 \\
0,000\end{array}$ & $\begin{array}{l}0,029 \\
0,734\end{array}$ & $\begin{array}{l}0,613 \\
0,000\end{array}$ & $\begin{array}{c}1 \\
0,000\end{array}$ & $\begin{array}{l}0,598 \\
0,000\end{array}$ & $\begin{array}{l}0,761 \\
0,000\end{array}$ \\
\hline MSPL & $\begin{array}{l}0,794 \\
0,000\end{array}$ & $\begin{array}{l}0,574 \\
0,000\end{array}$ & $\begin{array}{l}0,807 \\
0,000\end{array}$ & $\begin{array}{l}0,598 \\
0,000\end{array}$ & $\begin{array}{c}1 \\
0,000\end{array}$ & $\begin{array}{l}0,765 \\
0,000\end{array}$ \\
\hline MS & $\begin{array}{l}0,225 \\
0,008\end{array}$ & $\begin{array}{l}0,551 \\
0,000\end{array}$ & $\begin{array}{l}0,387 \\
0,000\end{array}$ & $\begin{array}{r}-0,037 \\
0,672\end{array}$ & $\begin{array}{l}0,710 \\
0,000\end{array}$ & $\begin{array}{l}0,168 \\
0,049\end{array}$ \\
\hline MM & $\begin{array}{l}0,178 \\
0,039\end{array}$ & $\begin{array}{c}-0,092 \\
0,275\end{array}$ & $\begin{array}{l}0,088 \\
0,311\end{array}$ & $\begin{array}{l}0,249 \\
0,004\end{array}$ & $\begin{array}{l}0,081 \\
0,352\end{array}$ & $\begin{array}{l}0,206 \\
0,017\end{array}$ \\
\hline PB & $\begin{array}{c}-0,556 \\
0,000\end{array}$ & $\begin{array}{c}-0,267 \\
0,001\end{array}$ & $\begin{array}{c}-0,504 \\
0,000\end{array}$ & $\begin{array}{c}-0,486 \\
0,000\end{array}$ & $\begin{array}{c}-0,524 \\
0,000\end{array}$ & $\begin{array}{c}-0,471 \\
0,000\end{array}$ \\
\hline FDN & $\begin{array}{l}0,590 \\
0,000\end{array}$ & $\begin{array}{l}0,096 \\
0,250\end{array}$ & $\begin{array}{l}0,467 \\
0,000\end{array}$ & $\begin{array}{l}0,616 \\
0,000\end{array}$ & $\begin{array}{l}0,508 \\
0,000\end{array}$ & $\begin{array}{l}0,518 \\
0,000\end{array}$ \\
\hline FDA & $\begin{array}{l}0,751 \\
0,000\end{array}$ & $\begin{array}{l}0,282 \\
0,001\end{array}$ & $\begin{array}{l}0,654 \\
0,000\end{array}$ & $\begin{array}{l}0,689 \\
0,000\end{array}$ & $\begin{array}{l}0,600 \\
0,000\end{array}$ & $\begin{array}{l}0,711 \\
0,000\end{array}$ \\
\hline LIG & $\begin{array}{l}0,376 \\
0,000\end{array}$ & $\begin{array}{l}0,057 \\
0,494\end{array}$ & $\begin{array}{l}0,285 \\
0,001\end{array}$ & $\begin{array}{l}0,388 \\
0,000\end{array}$ & $\begin{array}{l}0,288 \\
0,001\end{array}$ & $\begin{array}{l}0,339 \\
0,000\end{array}$ \\
\hline CEL & $\begin{array}{l}0,635 \\
0,000\end{array}$ & $\begin{array}{l}0,247 \\
0,003\end{array}$ & $\begin{array}{l}0,564 \\
0,000\end{array}$ & $\begin{array}{l}0,585 \\
0,000\end{array}$ & $\begin{array}{l}0,533 \\
0,000\end{array}$ & $\begin{array}{l}0,613 \\
0,000\end{array}$ \\
\hline HEM & $\begin{array}{c}-0,147 \\
0,086\end{array}$ & $\begin{array}{c}-0,245 \\
0,003\end{array}$ & $\begin{array}{c}-0,204 \\
0,017\end{array}$ & $\begin{array}{c}-0,016 \\
0,853\end{array}$ & $\begin{array}{c}-0,059 \\
0,490\end{array}$ & $\begin{array}{c}-0,204 \\
0,016\end{array}$ \\
\hline CELFDN & $\begin{array}{l}0,309 \\
0,000\end{array}$ & $\begin{array}{l}0,240 \\
0,004\end{array}$ & $\begin{array}{l}0,330 \\
0,000\end{array}$ & $\begin{array}{l}0,217 \\
0,011\end{array}$ & $\begin{array}{l}0,239 \\
0,005\end{array}$ & $\begin{array}{l}0,351 \\
0,000\end{array}$ \\
\hline LIGFDN & $\begin{array}{l}0,190 \\
0,026\end{array}$ & $\begin{array}{l}0,056 \\
0,502\end{array}$ & $\begin{array}{l}0,151 \\
0,078\end{array}$ & $\begin{array}{l}0,175 \\
0,041\end{array}$ & $\begin{array}{l}0,120 \\
0,162\end{array}$ & $\begin{array}{l}0,149 \\
0,082\end{array}$ \\
\hline FDAFDN & $\begin{array}{l}0,581 \\
0,000\end{array}$ & $\begin{array}{l}0,338 \\
0,000\end{array}$ & $\begin{array}{l}0,555 \\
0,000\end{array}$ & $\begin{array}{l}0,460 \\
0,000\end{array}$ & $\begin{array}{l}0,418 \\
0,000\end{array}$ & $\begin{array}{l}0,589 \\
0,000\end{array}$ \\
\hline MSESP & $\begin{array}{l}0,870 \\
0,000\end{array}$ & $\begin{array}{l}0,572 \\
0,000\end{array}$ & $\begin{array}{l}0,859 \\
0,000\end{array}$ & $\begin{array}{l}0,689 \\
0,000\end{array}$ & $\begin{array}{l}0,895 \\
0,000\end{array}$ & $\begin{array}{l}0,964 \\
0,000\end{array}$ \\
\hline
\end{tabular}




\subsubsection{Características agronômicas vs. digestibilidade "in situ" da MS da fração volumosa.}

Apesar de correlacionada com o teor de FDN e FDA da fração volumosa, a porcentagem de espigas na MS não se mostrou correlacionada com a digestibilidade "in situ" em ambos os anos experimentais (tabela 29 e 30). Em 1996, houve uma correlação negativa entre a porcentagem de espigas na MS e a fração solúvel do material (degradabilidade as 0 horas), porém não refletiu em correlação negativa com a degradabilidade efetiva da MS (tabela 29). Não houve correlação entre a produção total de MS e a digestibilidade da MS da fração volumosa, concordando com Coors (1996), e demonstrando a possibilidade de se selecionar um material de elevada produção de matéria seca e de grãos, e com elevada digestibilidade da fração volumosa.

Em 1996, o hibrido XL 220 foi o $3^{\circ}$ híbrido com maior produção total de MS (tabela 13) e $\circ 2^{\circ}$ híbrido com maior degradabilidade efetiva da MS (tabela 21). O hibrido DINA 766 foi $\circ 4^{\circ}$ colocado na produção de espigas e $\circ 3^{\circ}$ colocado na degradabilidade efetiva da MS. Em 1997, o híbrido C333 apresentou a maior produção total de MS (tabela 14) e foi o $5^{\circ}$ híbrido com maior digestibilidade da fração volumosa (tabela 22). O híbrido ZENECA 8392 foi o segundo hibrido com maior produção de espigas (tabela 14) e o segundo com maior digestibilidade da fração volumosa (tabela 22). Esses resultados exemplificam a afirmação anterior. 
Tabela 29. Correlação entre as características agronômicas e a digestibilidade "in situ" da MS da fração volumosa em 1996.

\begin{tabular}{|c|c|c|c|c|c|}
\hline Oh & $\begin{array}{c}\text { PESP } \\
-0,036 \\
0,856\end{array}$ & $\begin{array}{l}\text { PFIB } \\
0,449 \\
0,017\end{array}$ & $\begin{array}{l}\text { PTOT } \\
0,366 \\
0,056\end{array}$ & $\begin{array}{c}\% \text { ESPIGA } \\
-0,384 \\
0,044\end{array}$ & $\begin{array}{c}\text { MSPL } \\
0,247 \\
0,205\end{array}$ \\
\hline $3 \mathrm{~h}$ & $\begin{array}{c}-0,063 \\
0,752\end{array}$ & $\begin{array}{l}0,396 \\
0,037\end{array}$ & & & $\begin{array}{l}0,234 \\
0,230\end{array}$ \\
\hline $6 \mathrm{~h}$ & $\begin{array}{c}-0,082 \\
0,680\end{array}$ & $\begin{array}{l}0,352 \\
0,067\end{array}$ & & & $\begin{array}{l}0,278 \\
0,153\end{array}$ \\
\hline $12 \mathrm{~h}$ & $\begin{array}{c}-0,169 \\
0,389\end{array}$ & $\begin{array}{l}0,168 \\
0,392\end{array}$ & & & $\begin{array}{l}0,029 \\
0,885\end{array}$ \\
\hline $24 h$ & $\begin{array}{c}-0,202 \\
0,302\end{array}$ & $\begin{array}{l}0,033 \\
0,867\end{array}$ & & & $\begin{array}{l}0,019 \\
0,922\end{array}$ \\
\hline $48 \mathrm{~h}$ & $\begin{array}{r}-0,097 \\
0,624\end{array}$ & $\begin{array}{c}-0,006 \\
0,976\end{array}$ & & & $\begin{array}{r}-0,145 \\
0,462\end{array}$ \\
\hline $72 \mathrm{~h}$ & $\begin{array}{c}-0,058 \\
0,770\end{array}$ & $\begin{array}{l}0,219 \\
0,263\end{array}$ & & & $\begin{array}{r}-0,012 \\
0,952\end{array}$ \\
\hline A & $\begin{array}{l}0,012 \\
0,952\end{array}$ & $\begin{array}{l}0,469 \\
0,012\end{array}$ & $\begin{array}{l}0,405 \\
0,032\end{array}$ & & $\begin{array}{l}0,246 \\
0,206\end{array}$ \\
\hline$B$ & $\begin{array}{c}-0,042 \\
0,832\end{array}$ & $\begin{array}{c}-0,425 \\
0,024\end{array}$ & $\begin{array}{c}-0,383 \\
0,044\end{array}$ & & $\begin{array}{c}-0,408 \\
0,031\end{array}$ \\
\hline$C$ & $\begin{array}{r}-0,091 \\
0,644\end{array}$ & $\begin{array}{c}-0,342 \\
0,075\end{array}$ & $\begin{array}{c}-0,298 \\
0,123\end{array}$ & & $\begin{array}{c}-0,034 \\
0,864\end{array}$ \\
\hline Lag & $\begin{array}{l}0,248 \\
0,203\end{array}$ & $\begin{array}{l}0,233 \\
0,232\end{array}$ & $\begin{array}{l}0,330 \\
0,087\end{array}$ & $\begin{array}{l}0,015 \\
0,939\end{array}$ & $\begin{array}{l}0,064 \\
0,747\end{array}$ \\
\hline eg. & $\begin{array}{c}-0,130 \\
0,508 \\
\end{array}$ & $\begin{array}{l}0,211 \\
0,281 \\
\end{array}$ & $\begin{array}{l}0,125 \\
0,524 \\
\end{array}$ & $\begin{array}{c}-0,303 \\
0,116 \\
\end{array}$ & $\begin{array}{l}0,087 \\
0,660 \\
\end{array}$ \\
\hline
\end{tabular}

$A=$ fração solúvel

$B=$ fração insolúvel potencialmente degradável

$C=$ taxa de degradação da fração $B$

Lag = tempo de colonização

Deg.ef. = degradação efetiva supondo-se $5 \% \cdot \mathrm{h}^{-1}$ como taxa de passagem ruminal 
Tabela 30. Correlação entre as características agronômicas e a digestibilidade "in situ" da MS da fração volumosa em 1997.

\begin{tabular}{|c|c|c|c|c|c|}
\hline & PESP & PFIB & PTOT & $\%$ ESPIGA & MSPL \\
\hline Oh & $\begin{array}{r}-0,012 \\
0,959\end{array}$ & $\begin{array}{l}0,335 \\
0,138\end{array}$ & $\begin{array}{l}0,228 \\
0,320\end{array}$ & $\begin{array}{l}-0,381 \\
0,088\end{array}$ & $\begin{array}{l}0,073 \\
0,754\end{array}$ \\
\hline $3 h$ & $\begin{array}{l}0,027 \\
0,908\end{array}$ & $\begin{array}{l}0,378 \\
0,091\end{array}$ & $\begin{array}{l}0,278 \\
0,222\end{array}$ & $\begin{array}{r}-0,401 \\
0,072\end{array}$ & $\begin{array}{l}0,123 \\
0,596\end{array}$ \\
\hline $6 h$ & $\begin{array}{l}0,062 \\
0,791\end{array}$ & $\begin{array}{l}0,400 \\
0,073\end{array}$ & $\begin{array}{l}0,310 \\
0,171\end{array}$ & $\begin{array}{l}-0,400 \\
0,073\end{array}$ & $\begin{array}{l}0,087 \\
0,708\end{array}$ \\
\hline $12 \mathrm{~h}$ & $\begin{array}{l}0,131 \\
0,572\end{array}$ & $\begin{array}{l}0,457 \\
0,038\end{array}$ & $\begin{array}{l}0,384 \\
0,085\end{array}$ & $\begin{array}{l}-0,421 \\
0,058\end{array}$ & $\begin{array}{l}0,050 \\
0,829\end{array}$ \\
\hline $24 \mathrm{~h}$ & $\begin{array}{l}0,110 \\
0,635\end{array}$ & $\begin{array}{l}0,354 \\
0,116\end{array}$ & $\begin{array}{l}0,302 \\
0,183\end{array}$ & $\begin{array}{c}-0,328 \\
0,146\end{array}$ & $\begin{array}{l}0,125 \\
0,590\end{array}$ \\
\hline $48 \mathrm{~h}$ & $\begin{array}{l}0,146 \\
0,526\end{array}$ & $\begin{array}{l}0,205 \\
0,373\end{array}$ & $\begin{array}{l}0,216 \\
0,346\end{array}$ & $\begin{array}{l}-0,157 \\
0,495\end{array}$ & $\begin{array}{l}0,077 \\
0,741\end{array}$ \\
\hline $72 \mathrm{~h}$ & $\begin{array}{l}0,183 \\
0,428\end{array}$ & $\begin{array}{l}0,265 \\
0,246\end{array}$ & $\begin{array}{l}0,276 \\
0,225\end{array}$ & $\begin{array}{l}-0,187 \\
0,417\end{array}$ & $\begin{array}{l}0,083 \\
0,720\end{array}$ \\
\hline$A$ & $\begin{array}{r}-0,017 \\
0,941\end{array}$ & $\begin{array}{l}0,331 \\
0,143\end{array}$ & $\begin{array}{l}0,223 \\
0,332\end{array}$ & $\begin{array}{r}-0,382 \\
0,088\end{array}$ & $\begin{array}{l}0,091 \\
0,696\end{array}$ \\
\hline B & $\begin{array}{l}0,194 \\
0,399\end{array}$ & $\begin{array}{c}-0,289 \\
0,203\end{array}$ & $\begin{array}{c}-0,106 \\
0,648\end{array}$ & $\begin{array}{l}0,461 \\
0,035\end{array}$ & $\begin{array}{l}-0,208 \\
0,365\end{array}$ \\
\hline c & $\begin{array}{l}0,037 \\
0,873\end{array}$ & $\begin{array}{l}0,189 \\
0,413\end{array}$ & $\begin{array}{l}0,150 \\
0,515\end{array}$ & $\begin{array}{c}-0,219 \\
0,341\end{array}$ & $\begin{array}{l}0,104 \\
0,653\end{array}$ \\
\hline Lag & $\begin{array}{c}-0,310 \\
0,171\end{array}$ & $\begin{array}{l}-0,443 \\
0,044\end{array}$ & $\begin{array}{c}-0,464 \\
0,034\end{array}$ & $\begin{array}{l}0,236 \\
0,303\end{array}$ & $\begin{array}{c}-0,016 \\
0,946\end{array}$ \\
\hline Deg.ef & $\begin{array}{l}0,104 \\
0,655 \\
\end{array}$ & $\begin{array}{l}0,370 \\
0,099 \\
\end{array}$ & $\begin{array}{l}0,310 \\
0,171 \\
\end{array}$ & $\begin{array}{c}-0,348 \\
0,122 \\
\end{array}$ & $\begin{array}{l}0,096 \\
0,678 \\
\end{array}$ \\
\hline \multicolumn{6}{|c|}{$\bar{A}=$ fração solúvel } \\
\hline $\begin{array}{l}B=\text { fraçã } \\
C=\text { taxa } \\
\text { Lag }=\text { ter }\end{array}$ & $\begin{array}{l}\text { o insolúve } \\
\text { de degrac } \\
\text { npo de co }\end{array}$ & $\begin{array}{l}\text { l potenc } \\
\text { dação da } \\
\text { lonizaçãã }\end{array}$ & $\begin{array}{l}\text { ialmente } \\
\text { fração B }\end{array}$ & degradável & \\
\hline
\end{tabular}

Deg.ef. = degradação efetiva supondo-se $5 \% \cdot \mathrm{h}^{-1}$ como taxa de passagem ruminal 


\subsubsection{Caracteristicas agronômicas vs. digestibilidade "in situ" do FDN da fração volumosa.}

A porcentagem de espigas na MS não se mostrou correlacionada com a digestibilidade do FDN em 1996 ou em 1997 (tabelas 31 e 32), demonstrando que os híbridos com maior enchimento de grãos não necessariamente se apresentam mais lignificados e com menor digestibilidade da parede celular, semelhante ao apontado por Deinum \& Bakker (1981).

Tabela 31. Correlação entre a digestibilidade "in situ" do FDN da fração volumosa e as características agronômicas de híbridos de milho em 1996.

\begin{tabular}{|c|c|c|c|c|c|c|c|c|c|c|c|c|}
\hline & $0 \mathrm{~h}$ & $3 \mathrm{~h}$ & $6 \mathrm{~h}$ & $12 \mathrm{~h}$ & $24 \mathrm{~h}$ & $48 \mathrm{~h}$ & $72 \mathrm{~h}$ & $B$ & c & LAG & $\mathrm{U}$ & FILL \\
\hline PESP & $\begin{array}{l}0,033 \\
0,867\end{array}$ & $\begin{array}{l}0,029 \\
0,884\end{array}$ & $\begin{array}{r}-0,070 \\
0,725\end{array}$ & $\begin{array}{r}-0,204 \\
0,297\end{array}$ & $\begin{array}{c}-0,075 \\
0,705\end{array}$ & $\begin{array}{r}-0,018 \\
0,928\end{array}$ & $\begin{array}{r}-0,049 \\
0,804\end{array}$ & $\begin{array}{l}0,003 \\
0,989\end{array}$ & $\begin{array}{c}-0,184 \\
0,349\end{array}$ & $\begin{array}{c}-0,063 \\
0,750\end{array}$ & $\begin{array}{c}-0,024 \\
0,905\end{array}$ & $\begin{array}{l}0,008 \\
0,967\end{array}$ \\
\hline PFIB & $\begin{array}{c}-0,402 \\
0,034\end{array}$ & $\begin{array}{r}-0,290 \\
0,134\end{array}$ & $\begin{array}{c}-0,388 \\
0,041\end{array}$ & $\begin{array}{r}-0,403 \\
0,034\end{array}$ & $\begin{array}{c}-0,401 \\
0,035\end{array}$ & $\begin{array}{r}-0,355 \\
0,064\end{array}$ & $\begin{array}{r}-0,366 \\
0,055\end{array}$ & $\begin{array}{l}0,075 \\
0,705\end{array}$ & $\begin{array}{c}-0,204 \\
0,297\end{array}$ & $\begin{array}{c}-0,016 \\
0,936\end{array}$ & $\begin{array}{l}0,361 \\
0,059\end{array}$ & $\begin{array}{l}0,214 \\
0,275\end{array}$ \\
\hline PTOT & $\begin{array}{c}-0,286 \\
0,140\end{array}$ & $\begin{array}{c}-0,202 \\
0,304\end{array}$ & $\begin{array}{c}-0,336 \\
0,080\end{array}$ & $\begin{array}{r}-0,408 \\
0,031\end{array}$ & $\begin{array}{c}-0,349 \\
0,069\end{array}$ & $\begin{array}{c}-0,272 \\
0,161\end{array}$ & $\begin{array}{c}-0,312 \\
0,106\end{array}$ & $\begin{array}{l}0,078 \\
0,695\end{array}$ & $\begin{array}{r}-0,272 \\
0,162\end{array}$ & $\begin{array}{r}-0,077 \\
0,699\end{array}$ & $\begin{array}{l}0,257 \\
0,186\end{array}$ & $\begin{array}{l}0,143 \\
0,467\end{array}$ \\
\hline \%ESPIGA & $\begin{array}{l}0,291 \\
0,133\end{array}$ & $\begin{array}{l}0,220 \\
0,260\end{array}$ & $\begin{array}{l}0,205 \\
0,296\end{array}$ & $\begin{array}{l}0,087 \\
0,659\end{array}$ & $\begin{array}{l}0,218 \\
0,266\end{array}$ & $\begin{array}{l}0,152 \\
0,441\end{array}$ & $\begin{array}{l}0,154 \\
0,434\end{array}$ & $\begin{array}{r}-0,187 \\
0,341\end{array}$ & $\begin{array}{l}0,068 \\
0,730\end{array}$ & $\begin{array}{l}0,036 \\
0,855\end{array}$ & $\begin{array}{r}-0,179 \\
0,362\end{array}$ & $\begin{array}{r}-0,069 \\
0,727\end{array}$ \\
\hline MSPL & $\begin{array}{r}-0,292 \\
0,132 \\
\end{array}$ & $\begin{array}{r}-0,187 \\
0,340 \\
\end{array}$ & $\begin{array}{r}-0,199 \\
0,310 \\
\end{array}$ & $\begin{array}{r}-0,337 \\
0,080 \\
\end{array}$ & $\begin{array}{r}-0,233 \\
0,232 \\
\end{array}$ & $\begin{array}{r}-0,366 \\
0,055 \\
\end{array}$ & $\begin{array}{r}-0,317 \\
0,100\end{array}$ & $\begin{array}{c}-0,046 \\
0,818\end{array}$ & $\begin{array}{r}-0,206 \\
0,294 \\
\end{array}$ & $\begin{array}{r}-0,167 \\
0,397 \\
\end{array}$ & $\begin{array}{l}0,264 \\
0,175 \\
\end{array}$ & $\begin{array}{l}0,020 \\
0,919 \\
\end{array}$ \\
\hline \multicolumn{13}{|c|}{$\mathrm{B}=$ fração insolúvel do FDN potencialmente degradável } \\
\hline \multicolumn{13}{|c|}{$c=$ taxa de degradação do $B$} \\
\hline \multicolumn{13}{|c|}{ LAG $=$ tempo de colonização } \\
\hline \multicolumn{13}{|c|}{$U$ = fração não degradável do FDN } \\
\hline empc & 10 & & & & & & & & & & & \\
\hline
\end{tabular}

A produção total de MS se mostrou positivamente correlacionada com a degradabilidade do FDN em 1997 nos períodos de incubação ruminal de 6, 12 e 24 horas, o que no entanto não refletiu em uma correlação negativa com 0 
tempo de retenção ruminal do FDN (tabela 32).

Contrariando esse resultado, em 1996, a produção total de MS se mostrou negativamente correlacionada com a degradabilidade do FDN após 12 horas de incubação "in situ" (tabela 31). Um fator que pode ter causado essa discrepância de resultados, foi a desuniformidade no teor de MS dos híbridos em 1996, levando a uma maior produção total de MS e menor digestibilidade do FDN, para os híbridos com estágio de maturidade mais avançado.

Tabela 32. Correlação entre a digestibilidade "in situ" do FDN e as características agronômicas de híbridos de milho em 1997.

\begin{tabular}{|c|c|c|c|c|c|c|c|c|c|c|c|c|}
\hline & Oh & $3 \mathrm{~h}$ & $6 h$ & $12 \mathrm{~h}$ & $24 h$ & $48 h$ & $72 h$ & $\mathrm{~B}$ & $\mathrm{C}$ & LAG & $\underline{U}$ & Fill \\
\hline PESP & $\begin{array}{l}0,035 \\
0,881\end{array}$ & $\begin{array}{l}0,115 \\
0,621\end{array}$ & $\begin{array}{l}0,277 \\
0,225\end{array}$ & $\begin{array}{l}0,259 \\
0,256\end{array}$ & $\begin{array}{l}0,219 \\
0,339\end{array}$ & $\begin{array}{l}0,270 \\
0,237\end{array}$ & $\begin{array}{l}0,221 \\
0,336\end{array}$ & $\begin{array}{l}0,008 \\
0,972\end{array}$ & $\begin{array}{l}0,098 \\
0,673\end{array}$ & $\begin{array}{r}-0,295 \\
0,195\end{array}$ & $\begin{array}{c}-0,032 \\
0,889\end{array}$ & $\begin{array}{r}-0,380 \\
0,089\end{array}$ \\
\hline PFIB & $\begin{array}{l}0,474 \\
0,030\end{array}$ & $\begin{array}{l}0,423 \\
0,056\end{array}$ & $\begin{array}{l}0,617 \\
0,003\end{array}$ & $\begin{array}{l}0,483 \\
0,027\end{array}$ & $\begin{array}{l}0,497 \\
0,022\end{array}$ & $\begin{array}{l}0,355 \\
0,114\end{array}$ & $\begin{array}{l}0,327 \\
0,147\end{array}$ & $\begin{array}{c}-0,456 \\
0,038\end{array}$ & $\begin{array}{l}0,270 \\
0,237\end{array}$ & $\begin{array}{l}0,030 \\
0,898\end{array}$ & $\begin{array}{l}0,096 \\
0,678\end{array}$ & $\begin{array}{r}-0,203 \\
0,378\end{array}$ \\
\hline PTOT & $\begin{array}{l}0,349 \\
0,121\end{array}$ & $\begin{array}{l}0,353 \\
0,117\end{array}$ & $\begin{array}{l}0,569 \\
0,007\end{array}$ & $\begin{array}{l}0,467 \\
0,033\end{array}$ & $\begin{array}{l}0,457 \\
0,037\end{array}$ & $\begin{array}{l}0,383 \\
0,087\end{array}$ & $\begin{array}{l}0,339 \\
0,133\end{array}$ & $\begin{array}{r}-0,315 \\
0,165\end{array}$ & $\begin{array}{l}0,238 \\
0,300\end{array}$ & $\begin{array}{r}-0,126 \\
0,586\end{array}$ & $\begin{array}{l}0,051 \\
0,825\end{array}$ & $\begin{array}{r}-0,331 \\
0,142\end{array}$ \\
\hline$\%$ ESPIGA & $\begin{array}{r}-0,441 \\
0,045\end{array}$ & $\begin{array}{c}-0,331 \\
0,143\end{array}$ & $\begin{array}{c}-0,428 \\
0,053\end{array}$ & $\begin{array}{c}-0,326 \\
0,150\end{array}$ & $\begin{array}{r}-0,367 \\
0,102\end{array}$ & $\begin{array}{r}-0,213 \\
0,354\end{array}$ & $\begin{array}{c}-0,199 \\
0,386\end{array}$ & $\begin{array}{l}0,467 \\
0,033\end{array}$ & $\begin{array}{r}-0,243 \\
0,289\end{array}$ & $\begin{array}{r}-0,223 \\
0,331\end{array}$ & $\begin{array}{r}-0,139 \\
0,549\end{array}$ & $\begin{array}{r}-0,041 \\
0,859\end{array}$ \\
\hline MSPL & $\begin{array}{r}-0,077 \\
0,741 \\
\end{array}$ & $\begin{array}{r}-0,115 \\
0,618 \\
\end{array}$ & $\begin{array}{c}-0,002 \\
0,994 \\
\end{array}$ & $\begin{array}{l}-0,081 \\
0,726 \\
\end{array}$ & $\begin{array}{r}-0,016 \\
0,944 \\
\end{array}$ & $\begin{array}{r}-0,007 \\
0,978 \\
\end{array}$ & $\begin{array}{l}0,046 \\
0,844 \\
\end{array}$ & $\begin{array}{r}-0,053 \\
0,820 \\
\end{array}$ & $\begin{array}{l}0,025 \\
0,914 \\
\end{array}$ & $\begin{array}{l}0,034 \\
0,885 \\
\end{array}$ & $\begin{array}{l}0,148 \\
0,523 \\
\end{array}$ & $\begin{array}{l}0,074 \\
0,748 \\
\end{array}$ \\
\hline \multicolumn{13}{|c|}{$\mathrm{B}=$ fração insolúvel do FDN potencialmente degradável } \\
\hline \multicolumn{13}{|c|}{$c=$ taxa de degradação do $B$} \\
\hline \multicolumn{13}{|c|}{ LAG = tempo de colonização } \\
\hline \multicolumn{13}{|c|}{$U=$ fração não degradável do FDN } \\
\hline tem & in & مีว & 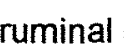 & 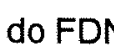 & & & & & & & & \\
\hline
\end{tabular}

Os resultados mostram que a maior produção de massa ou de grãos não possui grande influência sobre a digestibilidade do FDN, permitindo a seleção de híbridos com elevada produção e elevada digestibilidade do FDN da fração volumosa.

A digestibilidade do FDN não se mostrou fortemente correlacionada com a 
digestibilidade da MS, principalmente nos horários iniciais de incubação $(0,3$ e 6 horas), sendo que a degradabilidade efetiva da MS (Deg.ef) não se mostrou correlacionada com o tempo de retenção ruminal do FDN (Fill) em ambos os anos (dados não mostrados).

A falta de correlação entre a digestibilidade do FDN e da MS nos períodos iniciais se deve, provavelmente, a pequena degradação da fibra que ocorre até 6 horas de incubação (Van Soest, 1994).

No entanto, as taxas de degradação da MS e do FDN (c) se mostraram correlacionadas em ambos os anos $(r=0,40$ e $r=0,54$ em 1996 e 1997 respectivamente), provavelmente porque se aplica somente a fração insolúvel potencialmente degradável da MS (B), deixando de lado o efeito do conteúdo celular.

\subsubsection{Análises químicas vs. digestibilidade "in situ" da MS da fração volumosa.}

A digestibilidade "in situ" da MS da fração volumosa, em ambos os anos, se mostrou fortemente correlacionada com o teor de FDA e FDN em todos os tempos de incubação, porém não se mostrou correlacionada com o teor de lignina do material (tabelas 33 e 34).

Em 1996, o parâmetro que melhor se correlacionou com a degradabilidade efetiva da MS (Deg.ef) foi o teor de FDA $(r=-0,83$ ), enquanto que em 1997, o teor de FDN da fração volumosa se mostrou melhor correlacionado com a degradabilidade efetiva do que o teor de FDA $(r=-0,75)$ ( tabelas 33 e 34).

O uso do procedimento "stepwise regression" do SAS permitiu o estabelecimento de uma equação para estimativa da degradabilidade efetiva da MS (Deg.ef) baseado nas análises químicas. Em 1996 a equação de regressão foi:

Deg.ef $=141,32-0,2233 * \mathrm{MS}-0,8635 *$ FDN $-0,56689 * \mathrm{FDA} / \mathrm{FDN}\left(\mathrm{R}^{2}=0,79\right)$

Em 1997 a equação desenvolvida foi: 


$$
\text { Deg.ef }=\mathbf{1 1 3 , 3}-\mathbf{1 , 5 8} * \mathrm{~PB}-\mathbf{0 , 8 9}{ }^{*} \mathrm{FDN} \quad\left(\mathrm{R}^{2}=0,64\right)
$$

Quando os dados dos dois anos foram analisados em conjunto, a análise química que mais se correlacionou com a Deg.ef foi o teor de FDA $(r=-0,92)$ (tabela 35). A equação de regressão desenvolvida para os dois anos foi:

Deg.ef $=100,6077-01,4085^{*}$ FDA $\left(R^{2}=0,86\right)$

Tabela 33. Correlação entre a degradação "in situ" da MS e as análises bromatológicas da fração volumosa em 1996.

\begin{tabular}{|c|c|c|c|c|c|c|c|c|c|c|c|c|}
\hline & Oh & $3 h$ & $6 \mathrm{~h}$ & $12 \mathrm{~h}$ & $24 h$ & $48 \mathrm{~h}$ & $72 h$ & A & $B$ & $\mathrm{c}$ & Lag & Deg.ef \\
\hline MS & $\begin{array}{l}0,289 \\
0,136\end{array}$ & $\begin{array}{l}0,275 \\
0,156\end{array}$ & $\begin{array}{l}0,281 \\
0,147\end{array}$ & $\begin{array}{l}0,065 \\
0,744\end{array}$ & $\begin{array}{c}-0,018 \\
0,929\end{array}$ & $\begin{array}{c}-0,169 \\
0,390\end{array}$ & $\begin{array}{l}0,015 \\
0,938\end{array}$ & $\begin{array}{l}0,283 \\
0,145\end{array}$ & $\begin{array}{c}-0,425 \\
0,024\end{array}$ & $\begin{array}{r}-0,188 \\
0,339\end{array}$ & $\begin{array}{l}0,008 \\
0,966\end{array}$ & $\begin{array}{l}0,093 \\
0,638\end{array}$ \\
\hline PB & $\begin{array}{c}-0,013 \\
0,946\end{array}$ & $\begin{array}{c}-0,007 \\
0,971\end{array}$ & $\begin{array}{l}0,006 \\
0,977\end{array}$ & $\begin{array}{c}-0,146 \\
0,458\end{array}$ & $\begin{array}{l}0,014 \\
0,943\end{array}$ & $\begin{array}{c}-0,040 \\
0,841\end{array}$ & $\begin{array}{c}-0,023 \\
0,908\end{array}$ & $\begin{array}{l}0,009 \\
0,962\end{array}$ & $\begin{array}{c}-0,041 \\
0,835\end{array}$ & $\begin{array}{l}-0,018 \\
0,927\end{array}$ & $\begin{array}{l}0,110 \\
0,576\end{array}$ & $\begin{array}{c}-0,043 \\
0,826\end{array}$ \\
\hline FDN & $\begin{array}{c}-0,882 \\
0,000\end{array}$ & $\begin{array}{r}-0,821 \\
0,000\end{array}$ & $\begin{array}{c}-0,748 \\
0,000\end{array}$ & $\begin{array}{c}-0,678 \\
0,000\end{array}$ & $\begin{array}{c}-0,599 \\
0,001\end{array}$ & $\begin{array}{c}-0,424 \\
0,025\end{array}$ & $\begin{array}{c}-0,660 \\
0,000\end{array}$ & $\begin{array}{r}-0,903 \\
0,000\end{array}$ & $\begin{array}{l}0,582 \\
0,001\end{array}$ & $\begin{array}{l}0,041 \\
0,836\end{array}$ & $\begin{array}{r}-0,454 \\
0,015\end{array}$ & $\begin{array}{cc}4 & -0,737 \\
5 & 0,000\end{array}$ \\
\hline FDA & $\begin{array}{c}-0,760 \\
0,000\end{array}$ & $\begin{array}{c}-0,809 \\
0,000\end{array}$ & $\begin{array}{c}-0,776 \\
0,000\end{array}$ & $\begin{array}{c}-0,770 \\
0,000\end{array}$ & $\begin{array}{c}-0,796 \\
0,000\end{array}$ & $\begin{array}{c}-0,653 \\
0,000\end{array}$ & $\begin{array}{c}-0,706 \\
0,000\end{array}$ & $\begin{array}{c}-0,756 \\
0,000\end{array}$ & $\begin{array}{l}0,301 \\
0,120\end{array}$ & $\begin{array}{c}-0,149 \\
0,450\end{array}$ & $\begin{array}{c}-0,193 \\
0,325\end{array}$ & $\begin{array}{cc}3 & -0,833 \\
0,000\end{array}$ \\
\hline LIG & $\begin{array}{c}-0,399 \\
0,036\end{array}$ & $\begin{array}{c}-0,341 \\
0,076\end{array}$ & $\begin{array}{c}-0,311 \\
0,108\end{array}$ & $\begin{array}{c}-0,230 \\
0,239\end{array}$ & $\begin{array}{c}-0,214 \\
0,274\end{array}$ & $\begin{array}{c}-0,273 \\
0,160\end{array}$ & $\begin{array}{r}-0,307 \\
0,112\end{array}$ & $\begin{array}{r}-0,431 \\
0,022\end{array}$ & $\begin{array}{l}0,255 \\
0,191\end{array}$ & $\begin{array}{l}0,002 \\
0,993\end{array}$ & $\begin{array}{c}-0,442 \\
0,018\end{array}$ & $\begin{array}{cc}2 & -0,299 \\
3 & 0,122\end{array}$ \\
\hline CEL & $\begin{array}{c}-0,536 \\
0,003\end{array}$ & $\begin{array}{c}-0,609 \\
0,001\end{array}$ & $\begin{array}{c}-0,579 \\
0,001\end{array}$ & $\begin{array}{c}-0,604 \\
0,001\end{array}$ & $\begin{array}{c}-0,626 \\
0,000\end{array}$ & $\begin{array}{c}-0,464 \\
0,013\end{array}$ & $\begin{array}{c}-0,497 \\
0,007\end{array}$ & $\begin{array}{c}-0,520 \\
0,005\end{array}$ & $\begin{array}{l}0,202 \\
0,303\end{array}$ & $\begin{array}{c}-0,127 \\
0,519\end{array}$ & $\begin{array}{l}0,004 \\
0,984\end{array}$ & $\begin{array}{r}-0,631 \\
+\quad 0,000\end{array}$ \\
\hline HEM & $\begin{array}{c}-0,563 \\
0,002\end{array}$ & $\begin{array}{c}-0,445 \\
0,018\end{array}$ & $\begin{array}{c}-0,374 \\
0,050\end{array}$ & $\begin{array}{c}-0,287 \\
0,138\end{array}$ & $\begin{array}{c}-0,162 \\
0,410\end{array}$ & $\begin{array}{c}-0,044 \\
0,823\end{array}$ & $\begin{array}{r}-0,314 \\
0,104\end{array}$ & $\begin{array}{c}-0,594 \\
0,001\end{array}$ & $\begin{array}{l}0,528 \\
0,004\end{array}$ & $\begin{array}{l}0,171 \\
0,385\end{array}$ & $\begin{array}{c}-0,445 \\
0,018\end{array}$ & $\begin{array}{cc}5 & -0,314 \\
3 & 0,103\end{array}$ \\
\hline CELFDN & $\begin{array}{r}0,116 \\
0,558\end{array}$ & $\begin{array}{r}-0,004 \\
0,982\end{array}$ & $\begin{array}{r}-0,029 \\
0,882\end{array}$ & $\begin{array}{c}-0,110 \\
0,577\end{array}$ & $\begin{array}{c}-0,178 \\
0,364\end{array}$ & $\begin{array}{r}-0,160 \\
0,417\end{array}$ & $\begin{array}{c}-0,011 \\
0,957\end{array}$ & $\begin{array}{l}0,149 \\
0,451\end{array}$ & $\begin{array}{r}-0,234 \\
0,231\end{array}$ & $\begin{array}{c}-0,152 \\
0,439\end{array}$ & $\begin{array}{l}0,351 \\
0,067\end{array}$ & $\begin{array}{cc}1 & -0,089 \\
7 & 0,653\end{array}$ \\
\hline LIGFDN & $\begin{array}{r}-0,187 \\
0,340\end{array}$ & $\begin{array}{r}-0,135 \\
0,494\end{array}$ & $\begin{array}{r}-0,120 \\
0,544\end{array}$ & $\begin{array}{c}-0,039 \\
0,845\end{array}$ & $\begin{array}{c}-0,063 \\
0,751\end{array}$ & $\begin{array}{c}-0,158 \\
0,422\end{array}$ & $\begin{array}{c}-0,147 \\
0,455\end{array}$ & $\begin{array}{r}-0,220 \\
0,260\end{array}$ & $\begin{array}{l}0,126 \\
0,523\end{array}$ & $\begin{array}{r}-0,004 \\
0,982\end{array}$ & $\begin{array}{r}-0,382 \\
0,045\end{array}$ & $\begin{array}{cc}2 & -0,108 \\
5 & 0,583\end{array}$ \\
\hline FDAFDN & $\begin{array}{r}0,093 \\
0,637 \\
\end{array}$ & $\begin{array}{c}-0,038 \\
0,848 \\
\end{array}$ & $\begin{array}{r}-0,083 \\
0,674 \\
\end{array}$ & $\begin{array}{c}-0,156 \\
0,429 \\
\end{array}$ & $\begin{array}{r}-0,275 \\
0,156\end{array}$ & $\begin{array}{c}-0,311 \\
0,107\end{array}$ & $\begin{array}{r}-0,101 \\
0,608 \\
\end{array}$ & $\begin{array}{l}0,123 \\
0,533 \\
\end{array}$ & $\begin{array}{c}-0,312 \\
0,106 \\
\end{array}$ & $\begin{array}{c}-0,220 \\
0,261\end{array}$ & $\begin{array}{l}0,296 \\
0,126 \\
\end{array}$ & $\begin{array}{c}-0,165 \\
0,402 \\
\end{array}$ \\
\hline $\begin{array}{l}B=f r \\
C=t a\end{array}$ & & & & & & & & & & & & \\
\hline
\end{tabular}


Tabela 34. Correlação entre a degradação "in situ" da MS e as análises bromatológicas e da fração volumosa em 1997.

\begin{tabular}{|c|c|c|c|c|c|c|c|c|c|c|c|c|}
\hline & $\overline{O h}$ & $3 h$ & $6 \mathrm{~h}$ & $12 \mathrm{~h}$ & $24 h$ & $48 h$ & $72 h$ & $\bar{A}$ & $B$ & c & Lag & $\overline{\text { Deg.e }_{f}}$ \\
\hline MS & $\begin{array}{l}0,032 \\
0,891\end{array}$ & $\begin{array}{l}0,080 \\
0,732\end{array}$ & $\begin{array}{l}0,059 \\
0,799\end{array}$ & $\begin{array}{l}0,017 \\
0,943\end{array}$ & $\begin{array}{l}0,016 \\
0,945\end{array}$ & $\begin{array}{c}-0,058 \\
0,802\end{array}$ & $\begin{array}{r}-0,056 \\
0,810\end{array}$ & $\begin{array}{l}0,046 \\
0,845\end{array}$ & $\begin{array}{c}-0,246 \\
0,283\end{array}$ & $\begin{array}{l}0,011 \\
0,963\end{array}$ & $\begin{array}{c}-0,111 \\
0,633\end{array}$ & $\begin{array}{l}0,019 \\
0,934\end{array}$ \\
\hline PB & $\begin{array}{c}-0,481 \\
0,027\end{array}$ & $\begin{array}{c}-0,486 \\
0,026\end{array}$ & $\begin{array}{c}-0,499 \\
0,021\end{array}$ & $\begin{array}{c}-0,445 \\
0,043\end{array}$ & $\begin{array}{c}-0,456 \\
0,038\end{array}$ & $\begin{array}{c}-0,488 \\
0,025\end{array}$ & $\begin{array}{c}-0,517 \\
0,016\end{array}$ & $\begin{array}{c}-0,491 \\
0,024\end{array}$ & $\begin{array}{l}0,082 \\
0,724\end{array}$ & $\begin{array}{c}-0,068 \\
0,770\end{array}$ & $\begin{array}{l}0,053 \\
0,818\end{array}$ & $\begin{array}{c}-0,490 \\
0,024\end{array}$ \\
\hline FDN & $\begin{array}{c}-0,833 \\
0,000\end{array}$ & $\begin{array}{c}-0,809 \\
0,000\end{array}$ & $\begin{array}{c}-0,813 \\
0,000\end{array}$ & $\begin{array}{c}-0,730 \\
0,000\end{array}$ & $\begin{array}{c}-0,674 \\
0,001\end{array}$ & $\begin{array}{c}-0,635 \\
0,002\end{array}$ & $\begin{array}{l}-0,678 \\
0,001\end{array}$ & $\begin{array}{c}-0,813 \\
0,000\end{array}$ & $\begin{array}{l}0,191 \\
0,408\end{array}$ & $\begin{array}{c}-0,051 \\
0,825\end{array}$ & $\begin{array}{l}0,158 \\
0,494\end{array}$ & $\begin{array}{c}-0,749 \\
0,000\end{array}$ \\
\hline FDA & $\begin{array}{c}-0,713 \\
0,000\end{array}$ & $\begin{array}{c}-0,695 \\
0,001\end{array}$ & $\begin{array}{c}-0,678 \\
0,001\end{array}$ & $\begin{array}{c}-0,575 \\
0,006\end{array}$ & $\begin{array}{c}-0,547 \\
0,010\end{array}$ & $\begin{array}{c}-0,588 \\
0,005\end{array}$ & $\begin{array}{c}-0,577 \\
0,006\end{array}$ & $\begin{array}{c}-0,699 \\
0,000\end{array}$ & $\begin{array}{l}0,141 \\
0,543\end{array}$ & $\begin{array}{l}0,024 \\
0,918\end{array}$ & $\begin{array}{l}0,008 \\
0,973\end{array}$ & $\begin{array}{c}-0,628 \\
0,002\end{array}$ \\
\hline LIG & $\begin{array}{c}-0,146 \\
0,529\end{array}$ & $\begin{array}{c}-0,136 \\
0,558\end{array}$ & $\begin{array}{c}-0,211 \\
0,358\end{array}$ & $\begin{array}{c}-0,198 \\
0,391\end{array}$ & $\begin{array}{r}-0,194 \\
0,399\end{array}$ & $\begin{array}{r}-0,358 \\
0,111\end{array}$ & $\begin{array}{r}-0,385 \\
0,085\end{array}$ & $\begin{array}{c}-0,123 \\
0,597\end{array}$ & $\begin{array}{c}-0,405 \\
0,069\end{array}$ & $\begin{array}{l}0,108 \\
0,642\end{array}$ & $\begin{array}{l}0,186 \\
0,419\end{array}$ & $\begin{array}{c}-0,223 \\
0,332\end{array}$ \\
\hline CEL & $\begin{array}{c}-0,757 \\
0,000\end{array}$ & $\begin{array}{c}-0,729 \\
0,000\end{array}$ & $\begin{array}{c}-0,686 \\
0,001\end{array}$ & $\begin{array}{c}-0,578 \\
0,006\end{array}$ & $\begin{array}{r}-0,564 \\
0,008\end{array}$ & $\begin{array}{r}-0,527 \\
0,014\end{array}$ & $\begin{array}{r}-0,494 \\
0,023\end{array}$ & $\begin{array}{c}-0,750 \\
0,000\end{array}$ & $\begin{array}{l}0,364 \\
0,104\end{array}$ & $\begin{array}{r}-0,101 \\
0,663\end{array}$ & $\begin{array}{c}-0,112 \\
0,629\end{array}$ & $\begin{array}{r}-0,630 \\
0,002\end{array}$ \\
\hline HEM & $\begin{array}{r}-0,490 \\
0,024\end{array}$ & $\begin{array}{c}-0,462 \\
0,035\end{array}$ & $\begin{array}{c}-0,494 \\
0,023\end{array}$ & $\begin{array}{r}-0,476 \\
0,029\end{array}$ & $\begin{array}{r}-0,411 \\
0,064\end{array}$ & $\begin{array}{r}-0,287 \\
0,207\end{array}$ & $\begin{array}{c}-0,375 \\
0,094\end{array}$ & $\begin{array}{c}-0,473 \\
0,030\end{array}$ & $\begin{array}{l}0,132 \\
0,570\end{array}$ & $\begin{array}{c}-0,078 \\
0,736\end{array}$ & $\begin{array}{l}0,248 \\
0,278\end{array}$ & $\begin{array}{c}-0,438 \\
0,047\end{array}$ \\
\hline CELFDN & $\begin{array}{r}V-0,300 \\
0,186\end{array}$ & $\begin{array}{r}-0,289 \\
0,204\end{array}$ & $\begin{array}{c}-0,212 \\
0,357\end{array}$ & $\begin{array}{c}-0,141 \\
0,543\end{array}$ & $\begin{array}{r}-0,197 \\
0,393\end{array}$ & $\begin{array}{r}-0,183 \\
0,427\end{array}$ & $\begin{array}{c}3-0,085- \\
0,713\end{array}$ & $\begin{array}{c}-0,315 \\
0,165\end{array}$ & $\begin{array}{l}0,380 \\
0,090\end{array}$ & $\begin{array}{c}-0,152 \\
0,511\end{array}$ & $\begin{array}{c}-0,374 \\
0,095\end{array}$ & $\begin{array}{c}-0,209 \\
0,362\end{array}$ \\
\hline LIGFDN & $\begin{array}{l}0,113 \\
0,626\end{array}$ & $\begin{array}{l}30,111 \\
0,632\end{array}$ & $\begin{array}{l}0,033 \\
0,887\end{array}$ & $\begin{array}{l}0,013 \\
0,956\end{array}$ & $\begin{array}{rr}3 & -0,001 \\
6 & 0,998\end{array}$ & $\begin{array}{rr}1 & -0,186 \\
8 & 0,420\end{array}$ & $\begin{array}{rr}6 & -0,201 \\
0 & 0,382\end{array}$ & $\begin{array}{l}0,129 \\
0,576\end{array}$ & $\begin{array}{rr}9 & -0,480 \\
0 & 0,028\end{array}$ & $\begin{array}{l}0,110 \\
3,636\end{array}$ & $\begin{array}{l}0,155 \\
0,502\end{array}$ & $\begin{array}{r}-0,005 \\
0,983\end{array}$ \\
\hline FDAFDN & $\begin{array}{r}N-0,071 \\
0,759 \\
\end{array}$ & $\begin{array}{r}-0,083 \\
\quad 0,719 \\
\end{array}$ & $\begin{array}{r}-0,046 \\
0,842 \\
\end{array}$ & $\begin{array}{l}0,011 \\
0,961 \\
\end{array}$ & $\begin{array}{r}-0,026 \\
10,913 \\
\end{array}$ & $\begin{array}{rr}6 & -0,159 \\
3 & 0,491 \\
\end{array}$ & $\begin{array}{rr}9 & -0,077 \\
1 & 0,740 \\
\end{array}$ & $\begin{array}{r}-0,077 \\
0,741 \\
\end{array}$ & $\begin{array}{r}-0,016 \\
0,946 \\
\end{array}$ & $\begin{array}{l}0,083 \\
0,721 \\
\end{array}$ & $\begin{array}{r}-0,202 \\
0,380 \\
\end{array}$ & $\begin{array}{r}-0,058 \\
0,802 \\
\end{array}$ \\
\hline $\begin{array}{l}C= \\
\text { Lag }\end{array}$ & 2 & 4 & 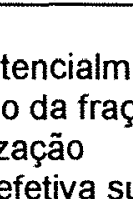 & & & & & & & & & \\
\hline
\end{tabular}

A falta de correlação do teor de lignina da fração volumosa com a digestibilidade do material demonstra que esse parâmetro não é adequado para se verificar diferenças entre materiais no mesmo estágio de maturidade, como foi anteriormente reportado por Jung (1996). Outro aspecto que contribuiu para a falta de correlação com o teor de lignina foi seu elevado coeficiente de 
variação observado neste experimento (tabelas 15 e 16 ).

Tabela 35. Correlação entre a degradação "in situ" da MS e as análises bromatológicas da fração volumosa (1996 e 1997).

\begin{tabular}{|c|c|c|c|c|c|c|c|c|c|c|c|c|}
\hline & $\mathrm{Oh}$ & $3 \mathrm{~h}$ & $6 h$ & $12 \mathrm{~h}$ & $24 h$ & $48 h$ & $72 h$ & $\mathrm{~A}$ & $\mathrm{~B}$ & $\mathrm{C}$ & Lag & Deg.ef \\
\hline MS & $\begin{array}{c}-0,052 \\
0,725\end{array}$ & $\begin{array}{c}-0,107 \\
0,465\end{array}$ & $\begin{array}{c}-0,149 \\
0,307\end{array}$ & $\begin{array}{c}-0,298 \\
0,038\end{array}$ & $\begin{array}{c}-0,346 \\
0,015\end{array}$ & $\begin{array}{c}-0,399 \\
0,005\end{array}$ & $\begin{array}{c}-0,317 \\
0,027\end{array}$ & $\begin{array}{c}-0,054 \\
0,712\end{array}$ & $\begin{array}{c}-0,239 \\
0,098\end{array}$ & $\begin{array}{c}-0,407 \\
0,004\end{array}$ & $\begin{array}{c}-0,125 \\
0,390\end{array}$ & $\begin{array}{c}-0,293 \\
0,041\end{array}$ \\
\hline PB & $\begin{array}{l}0,229 \\
0,114\end{array}$ & $\begin{array}{l}0,306 \\
0,033\end{array}$ & $\begin{array}{l}0,358 \\
0,012\end{array}$ & $\begin{array}{l}0,458 \\
0,001\end{array}$ & $\begin{array}{l}0,535 \\
0,000\end{array}$ & $\begin{array}{l}0,536 \\
0,000\end{array}$ & $\begin{array}{l}0,439 \\
0,002\end{array}$ & $\begin{array}{l}0,241 \\
0,095\end{array}$ & $\begin{array}{c}-0,105 \\
0,472\end{array}$ & $\begin{array}{l}0,631 \\
0,000\end{array}$ & $\begin{array}{l}0,225 \\
0,119\end{array}$ & $\begin{array}{l}0,470 \\
0,001\end{array}$ \\
\hline FDN & $\begin{array}{c}-0,896 \\
0,000\end{array}$ & $\begin{array}{c}-0,888 \\
0,000\end{array}$ & $\begin{array}{c}-0,874 \\
0,000\end{array}$ & $\begin{array}{c}-0,844 \\
0,000\end{array}$ & $\begin{array}{c}-0,807 \\
0,000\end{array}$ & $\begin{array}{c}-0,769 \\
0,000\end{array}$ & $\begin{array}{c}-0,831 \\
0,000\end{array}$ & $\begin{array}{c}-0,902 \\
0,000\end{array}$ & $\begin{array}{l}0,409 \\
0,004\end{array}$ & $\begin{array}{c}-0,604 \\
0,000\end{array}$ & $\begin{array}{c}-0,306 \\
0,033\end{array}$ & $\begin{array}{c}-0,858 \\
0,000\end{array}$ \\
\hline FDA & $\begin{array}{c}-0,778 \\
0,000\end{array}$ & $\begin{array}{c}-0,844 \\
0,000\end{array}$ & $\begin{array}{c}-0,866 \\
0,000\end{array}$ & $\begin{array}{l}-0,900 \\
0,000\end{array}$ & $\begin{array}{c}-0,911 \\
0,000\end{array}$ & $\begin{array}{c}-0,904 \\
0,000\end{array}$ & $\begin{array}{c}-0,879 \\
0,000\end{array}$ & $\begin{array}{c}-0,779 \\
0,000\end{array}$ & $\begin{array}{l}0,262 \\
0,069\end{array}$ & $\begin{array}{c}-0,786 \\
0,000\end{array}$ & $\begin{array}{c}-0,254 \\
0,078\end{array}$ & $\begin{array}{c}-0,917 \\
0,000\end{array}$ \\
\hline LIG & $\begin{array}{c}-0,516 \\
0,000\end{array}$ & $\begin{array}{c}-0,524 \\
0,000\end{array}$ & $\begin{array}{c}-0,551 \\
0,000\end{array}$ & $\begin{array}{c}-0,566 \\
0,000\end{array}$ & $\begin{array}{c}-0,575 \\
0,000\end{array}$ & $\begin{array}{c}-0,616 \\
0,000\end{array}$ & $\begin{array}{c}-0,614 \\
0,000\end{array}$ & $\begin{array}{c}-0,530 \\
0,000\end{array}$ & $\begin{array}{l}0,100 \\
0,494\end{array}$ & $\begin{array}{l}-0,505 \\
0,000\end{array}$ & $\begin{array}{c}-0,309 \\
0,031\end{array}$ & $\begin{array}{c}-0,589 \\
0,000\end{array}$ \\
\hline CEL & $\begin{array}{c}-0,750 \\
0,000\end{array}$ & $\begin{array}{c}-0,806 \\
0,000\end{array}$ & $\begin{array}{c}-0,804 \\
0,000\end{array}$ & $\begin{array}{c}-0,808 \\
0,000\end{array}$ & $\begin{array}{c}-0,805 \\
0,000\end{array}$ & $\begin{array}{c}-0,772 \\
0,000\end{array}$ & $\begin{array}{c}-0,762 \\
0,000\end{array}$ & $\begin{array}{c}-0,745 \\
0,000\end{array}$ & $\begin{array}{l}0,319 \\
0,026\end{array}$ & $\begin{array}{c}-0,656 \\
0,000\end{array}$ & $\begin{array}{c}-0,198 \\
0,173\end{array}$ & $\begin{array}{c}-0,822 \\
0,000\end{array}$ \\
\hline HEM & $\begin{array}{c}-0,322 \\
0,024\end{array}$ & $\begin{array}{r}-0,190 \\
0,192\end{array}$ & $\begin{array}{c}-0,126 \\
0,390\end{array}$ & $\begin{array}{c}-0,009 \\
0,953\end{array}$ & $\begin{array}{l}0,080 \\
0,583\end{array}$ & $\begin{array}{l}0,140 \\
0,338\end{array}$ & $\begin{array}{c}-0,017 \\
0,908\end{array}$ & $\begin{array}{c}-0,331 \\
0,020\end{array}$ & $\begin{array}{l}0,306 \\
0,033\end{array}$ & $\begin{array}{l}0,245 \\
0,090\end{array}$ & $\begin{array}{c}-0,135 \\
0,356\end{array}$ & $\begin{array}{c}-0,004 \\
0,978\end{array}$ \\
\hline CELFDN & $\begin{array}{c}\checkmark-0,158 \\
0,279\end{array}$ & $\begin{array}{c}-0,255 \\
0,078\end{array}$ & $\begin{array}{c}-0,268 \\
0,063\end{array}$ & $\begin{array}{c}-0,313 \\
0,029\end{array}$ & $\begin{array}{c}-0,345 \\
0,015\end{array}$ & $\begin{array}{r}-0,340 \\
0,017\end{array}$ & $\begin{array}{c}-0,262 \\
0,070\end{array}$ & $\begin{array}{c}-0,143 \\
0,326\end{array}$ & $\begin{array}{l}0,019 \\
0,897\end{array}$ & $\begin{array}{c}-0,340 \\
0,017\end{array}$ & $\begin{array}{l}0,051 \\
0,726\end{array}$ & $\begin{array}{c}-0,317 \\
0,027\end{array}$ \\
\hline LIGFDN & $\begin{array}{c}-0,302 \\
0,035\end{array}$ & $\begin{array}{c}-0,314 \\
0,028\end{array}$ & $\begin{array}{c}-0,350 \\
0,014\end{array}$ & $\begin{array}{c}-0,376 \\
0,008\end{array}$ & $\begin{array}{l}-0,407 \\
0,004\end{array}$ & $\begin{array}{c}-0,462 \\
0,001\end{array}$ & $\begin{array}{c}-0,441 \\
0,002\end{array}$ & $\begin{array}{c}-0,320 \\
0,025\end{array}$ & $\begin{array}{c}-0,007 \\
0,960\end{array}$ & $\begin{array}{c}-0,395 \\
0,005\end{array}$ & $\begin{array}{l}-0,274 \\
0,057\end{array}$ & $\begin{array}{r}-0,402 \\
0,004\end{array}$ \\
\hline FDAFDN & $\begin{array}{r}-0,364 \\
0,010 \\
\end{array}$ & $\begin{array}{r}-0,491 \\
0,000 \\
\end{array}$ & $\begin{array}{r}-0,543 \\
0,000 \\
\end{array}$ & $\begin{array}{r}-0,637 \\
0,000 \\
\end{array}$ & $\begin{array}{r}-0,697 \\
0,000 \\
\end{array}$ & $\begin{array}{r}-0,727 \\
0,000 \\
\end{array}$ & $\begin{array}{r}-0,618 \\
0,000 \\
\end{array}$ & $\begin{array}{r}-0,360 \\
0,011 \\
\end{array}$ & $\begin{array}{l}0,003 \\
0,983 \\
\end{array}$ & $\begin{array}{r}-0,705 \\
0,000 \\
\end{array}$ & $\begin{array}{r}-0,102 \\
0,487 \\
\end{array}$ & $\begin{array}{r}-0,652 \\
0,000 \\
\end{array}$ \\
\hline 18 & soli & & ão & $10 \mathrm{~B}$ & $\mathrm{rac}$ & & & & & & & \\
\hline
\end{tabular}

Nenhuma análise química foi capaz de explicar as diferenças na taxa de degradação da porção insolúvel (c) entre os híbridos de milho (tabelas 33 e 34). Segundo (Jung \& Allen, 1995), a falta de correlação entre as análises químicas e a taxa de degradação da fração insolúvel (c) ocorre porque a mesma não é 
um composto homogêneo, mas sim constituída por diferentes tecidos com diferentes taxas de degradação.

O coeficiente de correlação elevado entre a Deg.ef e o teor de FDA quando os dados foram analisados em conjunto, demonstra que esse parâmetro explicou adequadamente a diferença entre os anos experimentais quanto a digestibilidade da fração volumosa, como pode ser visualizado na figura 5 .

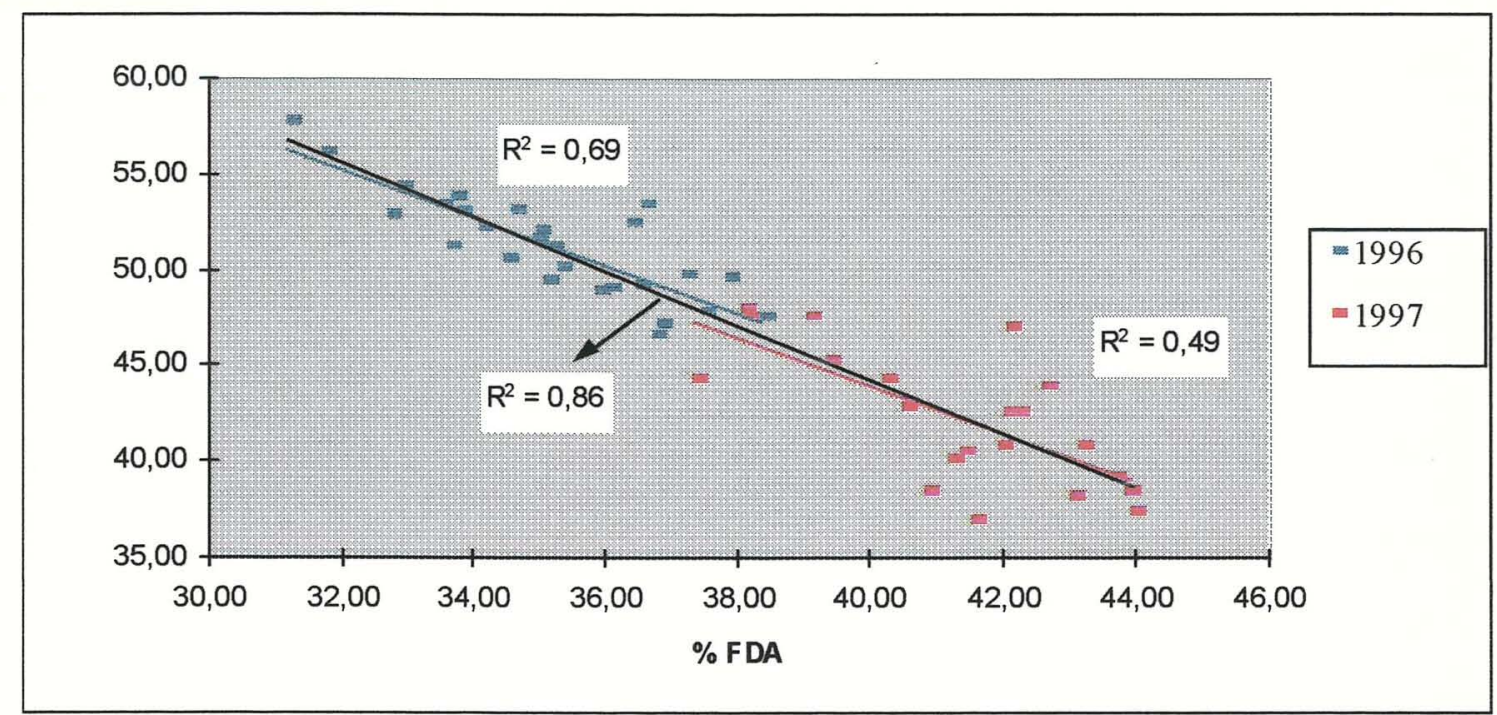

Figura 5. Relação entre o teor de FDA e a digestibilidade "in situ" da fração volumosa de híbridos de milho

\subsubsection{Análises químicas vs. digestibilidade "in situ" do FDN da fração volumosa.}

Em 1996, ocorreu uma correlação negativa entre o teor de MS da fração volumosa e a digestibilidade do FDN nos tempos mais avançados de incubação (12, 24, 48 e 72 horas) levando a uma correlação positiva do teor de MS com a fração indegradável do FDN $(r=0,39)$ ( tabela 36). Essa correlação entre o teor de MS da fração volumosa e a digestibilidade do FDN não ocorreu em 1997 
(tabela 37).

Tabela 36. Correlação entre a digestibilidade "in situ" do FDN e composição bromatológica da fração volumosa em 1996.

\begin{tabular}{|c|c|c|c|c|c|c|c|c|c|c|c|c|}
\hline & 0 & 3 & 6 & 12 & 24 & 48 & 72 & $B$ & $\bar{c}$ & LAG & $U$ & FILL \\
\hline MS & $\begin{array}{c}-0,425 \\
0,024\end{array}$ & $\begin{array}{c}-0,257 \\
0,186\end{array}$ & $\begin{array}{c}-0,312 \\
0,106\end{array}$ & $\begin{array}{c}-0,375 \\
0,049\end{array}$ & $\begin{array}{c}-0,378 \\
0,047\end{array}$ & $\begin{array}{c}-0,451 \\
0,016\end{array}$ & $\begin{array}{c}-0,392 \\
0,039\end{array}$ & $\begin{array}{l}0,015 \\
0,940\end{array}$ & $\begin{array}{r}-0,178 \\
0,364\end{array}$ & $\begin{array}{c}-0,150 \\
0,446\end{array}$ & $\begin{array}{l}0,392 \\
0,039\end{array}$ & $\begin{array}{l}0,089 \\
0,652\end{array}$ \\
\hline PB & $\begin{array}{c}-0,368 \\
0,054\end{array}$ & $\begin{array}{c}-0,429 \\
0,023\end{array}$ & $\begin{array}{c}-0,282 \\
0,145\end{array}$ & $\begin{array}{c}-0,347 \\
0,071\end{array}$ & $\begin{array}{c}-0,152 \\
0,441\end{array}$ & $\begin{array}{c}-0,105 \\
0,594\end{array}$ & $\begin{array}{c}-0,163 \\
0,407\end{array}$ & $\begin{array}{l}0,215 \\
0,272\end{array}$ & $\begin{array}{l}0,136 \\
0,490\end{array}$ & $\begin{array}{l}0,206 \\
0,292\end{array}$ & $\begin{array}{l}0,166 \\
0,399\end{array}$ & $\begin{array}{l}0,288 \\
0,137\end{array}$ \\
\hline FDN & $\begin{array}{l}0,111 \\
0,575\end{array}$ & $\begin{array}{l}0,195 \\
0,321\end{array}$ & $\begin{array}{l}0,255 \\
0,191\end{array}$ & $\begin{array}{l}0,098 \\
0,621\end{array}$ & $\begin{array}{l}0,084 \\
0,672\end{array}$ & $\begin{array}{l}0,176 \\
0,371\end{array}$ & $\begin{array}{l}0,073 \\
0,713\end{array}$ & $\begin{array}{c}-0,146 \\
0,457\end{array}$ & $\begin{array}{l}0,137 \\
0,487\end{array}$ & $\begin{array}{l}0,044 \\
0,823\end{array}$ & $\begin{array}{c}-0,143 \\
0,467\end{array}$ & $\begin{array}{r}-0,070 \\
0,725\end{array}$ \\
\hline FDA & $\begin{array}{c}-0,045 \\
0,821\end{array}$ & $\begin{array}{r}-0,047 \\
0,812\end{array}$ & $\begin{array}{c}-0,036 \\
0,854\end{array}$ & $\begin{array}{c}-0,216 \\
0,269\end{array}$ & $\begin{array}{c}-0,286 \\
0,140\end{array}$ & $\begin{array}{c}-0,138 \\
0,484\end{array}$ & $\begin{array}{c}-0,202 \\
0,302\end{array}$ & $\begin{array}{r}-0,214 \\
0,274\end{array}$ & $\begin{array}{r}-0,055 \\
0,782\end{array}$ & $\begin{array}{l}0,029 \\
0,882\end{array}$ & $\begin{array}{l}0,146 \\
0,457\end{array}$ & $\begin{array}{l}0,104 \\
0,597\end{array}$ \\
\hline LIG & $\begin{array}{l}0,267 \\
0,169\end{array}$ & $\begin{array}{l}0,295 \\
0,127\end{array}$ & $\begin{array}{l}0,327 \\
0,090\end{array}$ & $\begin{array}{l}0,242 \\
0,214\end{array}$ & $\begin{array}{l}0,157 \\
0,424\end{array}$ & $\begin{array}{l}0,083 \\
0,673\end{array}$ & $\begin{array}{l}0,152 \\
0,441\end{array}$ & $\begin{array}{c}-0,225 \\
0,251\end{array}$ & $\begin{array}{l}0,089 \\
0,653\end{array}$ & $\begin{array}{c}-0,090 \\
0,650\end{array}$ & $\begin{array}{c}-0,113 \\
0,566\end{array}$ & $\begin{array}{c}-0,189 \\
0,336\end{array}$ \\
\hline CEL & $\begin{array}{r}-0,100 \\
0,612\end{array}$ & $\begin{array}{c}-0,099 \\
0,617\end{array}$ & $\begin{array}{r}-0,114 \\
0,564\end{array}$ & $\begin{array}{r}-0,266 \\
0,172\end{array}$ & $\begin{array}{c}-0,277 \\
0,153\end{array}$ & $\begin{array}{c}-0,112 \\
0,570\end{array}$ & $\begin{array}{c}-0,195 \\
0,319\end{array}$ & $\begin{array}{c}-0,107 \\
0,587\end{array}$ & $\begin{array}{c}-0,132 \\
0,503\end{array}$ & $\begin{array}{l}0,030 \\
0,880\end{array}$ & $\begin{array}{l}0,121 \\
0,540\end{array}$ & $\begin{array}{l}0,123 \\
0,533\end{array}$ \\
\hline HEM & $\begin{array}{l}0,181 \\
0,358\end{array}$ & $\begin{array}{l}0,292 \\
0,131\end{array}$ & $\begin{array}{l}0,363 \\
0,058\end{array}$ & $\begin{array}{l}0,298 \\
0,124\end{array}$ & $\begin{array}{l}0,334 \\
0,082\end{array}$ & $\begin{array}{l}0,339 \\
0,078\end{array}$ & $\begin{array}{l}0,254 \\
0,192\end{array}$ & $\begin{array}{c}-0,024 \\
0,902\end{array}$ & $\begin{array}{l}0,223 \\
0,255\end{array}$ & $\begin{array}{l}0,035 \\
0,859\end{array}$ & $\begin{array}{r}-0,303 \\
0,117\end{array}$ & $\begin{array}{r}-0,173 \\
0,378\end{array}$ \\
\hline CELFDN & $\begin{array}{r}-0,197 \\
0,315\end{array}$ & $\begin{array}{c}-0,264 \\
0,175\end{array}$ & $\begin{array}{r}-0,315 \\
0,102\end{array}$ & $\begin{array}{r}-0,357 \\
0,062\end{array}$ & $\begin{array}{c}-0,346 \\
0,071\end{array}$ & $\begin{array}{c}-0,256 \\
0,188\end{array}$ & $\begin{array}{c}-0,262 \\
0,178\end{array}$ & $\begin{array}{r}-0,004 \\
0,984\end{array}$ & $\begin{array}{c}-0,230 \\
0,240\end{array}$ & $\begin{array}{l}0,007 \\
0,973\end{array}$ & $\begin{array}{l}0,243 \\
0,212\end{array}$ & $\begin{array}{l}0,190 \\
0,332\end{array}$ \\
\hline LIGFDN & $\begin{array}{l}0,286 \\
0,140\end{array}$ & $\begin{array}{l}0,303 \\
0,117\end{array}$ & $\begin{array}{l}0,316 \\
0,101\end{array}$ & $\begin{array}{l}0,281 \\
0,148\end{array}$ & $\begin{array}{l}0,168 \\
0,394\end{array}$ & $\begin{array}{l}0,073 \\
0,712\end{array}$ & $\begin{array}{l}0,169 \\
0,391\end{array}$ & $\begin{array}{c}-0,193 \\
0,325\end{array}$ & $\begin{array}{l}0,054 \\
0,785\end{array}$ & $\begin{array}{c}-0,136 \\
0,489\end{array}$ & $\begin{array}{c}-0,115 \\
0,559\end{array}$ & $\begin{array}{c}-0,225 \\
0,249\end{array}$ \\
\hline FDAFDA - & $\begin{array}{r}0,191 \\
0,329\end{array}$ & $\begin{array}{r}-0,295 \\
0,127\end{array}$ & $\begin{array}{r}-0,345 \\
0,072\end{array}$ & $\begin{array}{c}-0,385 \\
0,043\end{array}$ & $\begin{array}{c}-0,450 \\
0,016\end{array}$ & $\begin{array}{c}-0,378 \\
0,047\end{array}$ & $\begin{array}{c}-0,341 \\
0,076\end{array}$ & $\begin{array}{r}-0,094 \\
0,634\end{array}$ & $\begin{array}{r}-0,227 \\
0,246\end{array}$ & $\begin{array}{c}-0,018 \\
0,929\end{array}$ & $\begin{array}{l}0,353 \\
0,066\end{array}$ & $\begin{array}{l}0,210 \\
0,284\end{array}$ \\
\hline 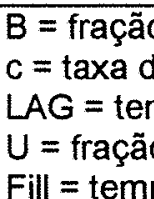 & 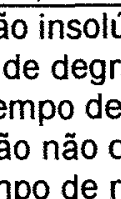 & & & & & & & & & & & \\
\hline
\end{tabular}

O teor de FDA se mostrou fortemente correlacionado com a fração não degradável do FDN em $1997(r=0,74)$, o mesmo ocorrendo com o teor de lignina no FDN ( $r=0,65)$ (tabela 37), enquanto em 1996, nenhuma análise química se mostrou correlacionada com a fração não degradável do FDN. Allen 
(1996) encontrou uma correlação positiva entre o teor de lignina no FDN e a fração não degradável do FDN, e não observou nenhuma correlação entre a taxa de degradação do FDN e alguma análise química.

Tabela 37. Correlação entre a digestibilidade "in situ" do FDN e composição bromatológica da fração volumosa em 1997.

\begin{tabular}{|c|c|c|c|c|c|c|c|c|c|c|c|c|}
\hline & On & $3 h$ & $6 h$ & $12 h$ & $24 h$ & $48 \mathrm{~h}$ & $72 h$ & $\mathrm{~B}$ & $c$ & LAG & $U$ & Fill \\
\hline MS & $\begin{array}{l}0,227 \\
0,323\end{array}$ & $\begin{array}{l}0,112 \\
0,628\end{array}$ & $\begin{array}{l}0,209 \\
0,364\end{array}$ & $\begin{array}{l}0,103 \\
0,656\end{array}$ & $\begin{array}{l}0,116 \\
0,618\end{array}$ & $\begin{array}{l}0,003 \\
0,991\end{array}$ & $\begin{array}{l}0,042 \\
0,857\end{array}$ & $\begin{array}{c}-0,349 \\
0,122\end{array}$ & $\begin{array}{l}0,092 \\
0,691\end{array}$ & $\begin{array}{l}0,127 \\
0,582\end{array}$ & $\begin{array}{l}0,235 \\
0,305\end{array}$ & $\begin{array}{l}0,069 \\
0,766\end{array}$ \\
\hline$P B$ & $\begin{array}{l}0,138 \\
0,552\end{array}$ & $\begin{array}{l}0,094 \\
0,687\end{array}$ & $\begin{array}{c}-0,036 \\
0,878\end{array}$ & $\begin{array}{l}0,158 \\
0,493\end{array}$ & $\begin{array}{c}-0,038 \\
0,872\end{array}$ & $\begin{array}{r}-0,207 \\
0,369\end{array}$ & $\begin{array}{r}-0,240 \\
0,295\end{array}$ & $\begin{array}{c}-0,323 \\
0,153\end{array}$ & $\begin{array}{l}0,081 \\
0,728\end{array}$ & $\begin{array}{r}-0,019 \\
0,934\end{array}$ & $\begin{array}{l}0,335 \\
0,138\end{array}$ & $\begin{array}{r}-0,020 \\
0,931\end{array}$ \\
\hline FDN & $\begin{array}{r}-0,199 \\
0,387\end{array}$ & $\begin{array}{r}-0,213 \\
0,355\end{array}$ & $\begin{array}{c}-0,296 \\
0,193\end{array}$ & $\begin{array}{r}-0,087 \\
0,709\end{array}$ & $\begin{array}{c}-0,291 \\
0,201\end{array}$ & $\begin{array}{r}-0,297 \\
0,191\end{array}$ & $\begin{array}{c}-0,419 \\
0,059\end{array}$ & $\begin{array}{c}-0,220 \\
0,337\end{array}$ & $\begin{array}{l}0,112 \\
0,629\end{array}$ & $\begin{array}{r}-0,015 \\
0,950\end{array}$ & $\begin{array}{l}0,517 \\
0,017\end{array}$ & $\begin{array}{l}0,104 \\
0,652\end{array}$ \\
\hline FDA & $\begin{array}{r}-0,137 \\
0,555\end{array}$ & $\begin{array}{r}-0,197 \\
0,391\end{array}$ & $\begin{array}{c}-0,284 \\
0,213\end{array}$ & $\begin{array}{r}-0,021 \\
0,929\end{array}$ & $\begin{array}{r}-0,201 \\
0,382\end{array}$ & $\begin{array}{r}-0,300 \\
0,186\end{array}$ & $\begin{array}{c}-0,438 \\
0,047\end{array}$ & $\begin{array}{c}-0,453 \\
0,039\end{array}$ & $\begin{array}{l}0,328 \\
0,147\end{array}$ & $\begin{array}{l}0,149 \\
0,519\end{array}$ & $\begin{array}{l}0,742 \\
0,000\end{array}$ & $\begin{array}{l}0,231 \\
0,314\end{array}$ \\
\hline LIG & $\begin{array}{l}0,203 \\
0,378\end{array}$ & $\begin{array}{l}0,164 \\
0,479\end{array}$ & $\begin{array}{c}-0,015 \\
0,948\end{array}$ & $\begin{array}{r}-0,113 \\
0,625\end{array}$ & $\begin{array}{c}-0,025 \\
0,915\end{array}$ & $\begin{array}{c}-0,306 \\
0,178\end{array}$ & $\begin{array}{r}-0,387 \\
0,084\end{array}$ & $\begin{array}{c}-0,555 \\
0,009\end{array}$ & $\begin{array}{l}0,149 \\
0,519\end{array}$ & $\begin{array}{l}0,431 \\
0,051\end{array}$ & $\begin{array}{l}0,477 \\
0,029\end{array}$ & $\begin{array}{l}0,443 \\
0,045\end{array}$ \\
\hline CEL & $\begin{array}{r}-0,177 \\
0,443\end{array}$ & $\begin{array}{r}-0,275 \\
0,227\end{array}$ & $\begin{array}{c}-0,247 \\
0,281\end{array}$ & $\begin{array}{l}0,031 \\
0,894\end{array}$ & $\begin{array}{c}-0,243 \\
0,289\end{array}$ & $\begin{array}{c}-0,268 \\
0,241\end{array}$ & $\begin{array}{c}-0,355 \\
0,114\end{array}$ & $\begin{array}{c}-0,300 \\
0,187\end{array}$ & $\begin{array}{l}0,195 \\
0,398\end{array}$ & $\begin{array}{c}-0,072 \\
0,758\end{array}$ & $\begin{array}{l}0,630 \\
0,002\end{array}$ & $\begin{array}{l}0,023 \\
0,920\end{array}$ \\
\hline HEM & $\begin{array}{c}-0,172 \\
0,457\end{array}$ & $\begin{array}{r}-0,117 \\
0,614\end{array}$ & $\begin{array}{c}-0,150 \\
0,516\end{array}$ & $\begin{array}{c}-0,126 \\
0,588\end{array}$ & $\begin{array}{c}-0,249 \\
0,276\end{array}$ & $\begin{array}{c}-0,132 \\
0,569\end{array}$ & $\begin{array}{r}-0,167 \\
0,469\end{array}$ & $\begin{array}{l}0,201 \\
0,383\end{array}$ & $\begin{array}{c}-0,229 \\
0,318\end{array}$ & $\begin{array}{c}-0,218 \\
0,342\end{array}$ & $\begin{array}{r}-0,057 \\
0,807\end{array}$ & $\begin{array}{r}-0,117 \\
0,615\end{array}$ \\
\hline CELFDI & $\begin{array}{r}-0,054 \\
0,815\end{array}$ & $\begin{array}{r}-0,211 \\
0,358\end{array}$ & $\begin{array}{c}-0,059 \\
0,801\end{array}$ & $\begin{array}{l}0,174 \\
0,450\end{array}$ & $\begin{array}{r}-0,047 \\
0,838\end{array}$ & $\begin{array}{c}-0,087 \\
0,708\end{array}$ & $\begin{array}{c}-0,092 \\
0,693\end{array}$ & $\begin{array}{c}-0,264 \\
0,247\end{array}$ & $\begin{array}{l}0,221 \\
0,336\end{array}$ & $\begin{array}{c}-0,104 \\
0,653\end{array}$ & $\begin{array}{l}0,472 \\
0,031\end{array}$ & $\begin{array}{c}-0,092 \\
0,693\end{array}$ \\
\hline LIGFDN & $\begin{array}{l}0,140 \\
0,545\end{array}$ & $\begin{array}{l}0,028 \\
0,905\end{array}$ & $\begin{array}{c}-0,016 \\
0,945\end{array}$ & $\begin{array}{l}0,012 \\
0,960\end{array}$ & $\begin{array}{l}0,053 \\
0,819\end{array}$ & $\begin{array}{c}-0,220 \\
0,337\end{array}$ & $\begin{array}{r}-0,297 \\
0,192\end{array}$ & $\begin{array}{c}-0,574 \\
0,007\end{array}$ & $\begin{array}{l}0,295 \\
0,194\end{array}$ & $\begin{array}{l}0,178 \\
0,439\end{array}$ & $\begin{array}{l}0,649 \\
0,002\end{array}$ & $\begin{array}{l}0,172 \\
0,457\end{array}$ \\
\hline FDAFDN & $\begin{array}{r}0,054 \\
0,816 \\
\end{array}$ & $\begin{array}{r}-0,030 \\
0,897 \\
\end{array}$ & $\begin{array}{c}-0,062 \\
0,789\end{array}$ & $\begin{array}{l}0,103 \\
0,658\end{array}$ & $\begin{array}{l}0,080 \\
0,729 \\
\end{array}$ & $\begin{array}{r}-0,091 \\
0,695 \\
\end{array}$ & $\begin{array}{c}-0,151 \\
0,513\end{array}$ & $\begin{array}{c}-0,477 \\
0,029\end{array}$ & $\begin{array}{l}0,418 \\
0,059\end{array}$ & $\begin{array}{l}0,274 \\
0,229\end{array}$ & $\begin{array}{l}0,552 \\
0,010\end{array}$ & $\begin{array}{l}0,242 \\
0,291\end{array}$ \\
\hline $\begin{array}{l}c=\text { taxa } \\
\text { LAG }=t \\
U=\text { fraç }\end{array}$ & $\begin{array}{l}\text { de insolú } \\
\text { de degr } \\
\text { empo de } \\
\text { áo não o }\end{array}$ & $\begin{array}{l}\text { úvel do } \\
\text { adação } \\
\text { coloniz } \\
\text { degradá }\end{array}$ & $\begin{array}{l}\text { FDN po } \\
\text { o do B } \\
\text { zzação } \\
\text { ável do F }\end{array}$ & tenci & & egradá & & & & & & \\
\hline
\end{tabular}

Semelhante ao observado para a degradabilidade da MS, não houve nenhuma correlação entre a composição química da fração volumosa e a sua 
taxa de degradação do FDN (tabelas 36 e 37).

A única análise quimica que se mostrou correlacionada com o tempo de retenção ruminal do FDN (Fill) foi o teor de lignina ( $r=0,44$, tabela 37) em 1997.

\subsubsection{Composição química e digestibilidade da fração volumosa vs. composição química das silagens em 1996.}

Como pode ser observado na tabela 38 , baseando-se nas análises químicas, as silagens confeccionadas em 1996 podem ser consideradas de boa qualidade. O teor de FDA variou de 22,2 a $33,1 \%$, enquanto o nitrogênio ligado ao FDA variou de 3,3 a $7,55 \%$ do $\mathrm{N}$ total.

$\mathrm{O}$ nitrogênio na forma amoniacal $\left(\mathrm{N}-\mathrm{NH}_{3}\right)$ variou de 12,8 a $29,42 \%$ do $\mathrm{N}$ total. Os valores de N-FDA mostraram-se baixos (Bergen, 1988), indicando que ocorreu pequena penetração de ar na massa após a ensilagem, sendo a anaerobiose rapidamente atingida. No entanto, os teores de $\mathrm{N}-\mathrm{NH}_{3}$ se mostram elevados (Moe \& Carr, 1985) demonstrando a ocorrência de fermentação Clostridiana na massa ensilada. $\mathrm{O}$ excesso de $\mathrm{N}-\mathrm{NH}_{3}$ ocorreu, provavelmente, devido ao elevado grau de umidade das silagens (18,4 a $29,7 \%$ de MS, tabela 38). A correlação negativa entre o teor de MS das silagens e o teor de $\mathrm{N}-\mathrm{NH}_{3}$ $(r=-0,48)$, confirma essa afirmação (tabela 39).

Ao contrário do que seria esperado, não houve correlação entre a porcentagem de espigas do híbrido e o teor de FDA das silagens (tabela 41), provavelmente devido ao maior teor de FDA da fração volumosa de híbridos com maior porcentagem de espigas na MS (tabela 26), concordando com Undersander (1993).

Os híbridos com maior produção da fração volumosa e de MS total se mostraram negativamente correlacionados com o teor de FDA das silagens ( $r=-$ 0,60 e $-0,61$ respectivamente, tabela 41 ), resultado do menor teor de FDA da fração volumosa (tabela 26). 
Tabela 38. Composição bromatológica das silagens de milho de 1996.

\begin{tabular}{|c|c|c|c|c|c|c|c|c|c|c|c|}
\hline \multirow[t]{2}{*}{ Híbrido } & \multirow[t]{2}{*}{$\mathrm{pH}$} & \multirow[t]{2}{*}{ MS } & \multirow[t]{2}{*}{ MM } & $\mathrm{PB}$ & FDN & FDA & LIG & HEM & \multirow[t]{2}{*}{ CEL } & \multirow{2}{*}{\multicolumn{2}{|c|}{$\begin{array}{c}\mathrm{N}-\mathrm{FDA} \quad \mathrm{N}-\mathrm{NH}_{3} \\
-\ldots \% \mathrm{~PB}--\end{array}$}} \\
\hline & & & & & -.. & MS & & & & & \\
\hline C701 & 3,65 & 29,51 & 3,84 & 8,15 & 54,80 & 28,63 & 6,86 & 26,18 & 20,94 & 6,48 & 12,80 \\
\hline P3041 & 3,65 & 22,25 & 5,38 & 7,78 & 57,05 & 30,71 & 5,91 & 26,34 & 24,21 & 6,80 & 20,33 \\
\hline ZEN8452 & 3,58 & 22,08 & 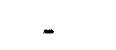 & 9,64 & 46,13 & 29,68 & 4,04 & 16,45 & 24,60 & 3,30 & 22,71 \\
\hline DINA887 & 3,6 & 25,10 & 4,33 & 7,83 & 64,99 & 33,04 & 6,45 & 31,95 & 26,01 & 6,33 & 20,14 \\
\hline DINA766 & 3,65 & 29,75 & 3,96 & 8,91 & 42,38 & 22,16 & 3,04 & 20,23 & 18,33 & 4,25 & 16,59 \\
\hline C435 & 3,68 & 20,72 & 6,17 & 9,05 & 52,78 & 31,83 & 5,27 & 20,95 & 25,81 & 6,06 & 23,46 \\
\hline ZEN8392 & 3,58 & 18,42 & 5,99 & 9,13 & 49,80 & 32,32 & 5,29 & 17,48 & 26,01 & 5,06 & 20,92 \\
\hline DINA657 & 3,64 & 27,61 & 4,26 & 9,06 & 50,10 & 27,15 & 4,38 & 22,95 & 21,81 & 6,49 & 19,35 \\
\hline C805 & 3,55 & 22,23 & 4,80 & 9,08 & 50,65 & 29,93 & 4,63 & 20,73 & 24,91 & 5,12 & 19,60 \\
\hline DINA769 & 3,61 & 24,49 & 4,82 & 8,98 & 49,79 & 28,85 & 3,33 & 20,94 & 24,87 & 5,40 & 21,98 \\
\hline ZEN8501 & 3,61 & 29,27 & 4,49 & 9,40 & 44,63 & 24,68 & 3,70 & 19,94 & 20,58 & 5,16 & 17,58 \\
\hline XL660 & 3,77 & 25,52 & 4,93 & 8,79 & 54,21 & 30,22 & 4,87 & 23,99 & 25,93 & 6,03 & 29,42 \\
\hline BR3123 & 3,48 & 23,18 & 5,14 & 8,95 & 55,45 & 30,38 & 6,06 & 25,07 & 24,07 & 3,45 & 21,20 \\
\hline AG5011 & 3,72 & 27,34 & 5,19 & 8,89 & 52,03 & 27,51 & 3,44 & 24,52 & 22,71 & 3,58 & 14,47 \\
\hline AGROMEN & 3,59 & 23,01 & 5,10 & 8,85 & 46,69 & 25,02 & 7,15 & 21,67 & 17,32 & 6,13 & 21,60 \\
\hline P3027 & 3,58 & 24,84 & 5,01 & 9,37 & 51,22 & 26,61 & 2,61 & 24,60 & 23,55 & 5,08 & 17,00 \\
\hline C969 & 3,65 & 27,95 & 4,95 & 9,25 & 43,44 & 28,87 & 4,80 & 14,57 & 19,82 & 4,73 & 20,41 \\
\hline C425 & 3,56 & 25,48 & 4,81 & 7,35 & 57,33 & 28,31 & 6,15 & 29,02 & 17,29 & 95 & 16,44 \\
\hline XL370 & 3,72 & 24,51 & - & 8,29 & 65,49 & 28,76 & 4,63 & 36,73 & 23,85 & 6,22 & 19,48 \\
\hline C333 & 3,62 & 25,03 & 4,44 & 8,11 & 65,76 & 32,13 & 5,35 & 33,63 & 24,75 & 6,82 & 19,48 \\
\hline$X L 220$ & 3,7 & 27,80 & 5,18 & 9,41 & 48,63 & 23,83 & 2,80 & 24,80 & 20,32 & 5,36 & 18,49 \\
\hline P3072 & 3,68 & 20,74 & 5,12 & 6,94 & 60,21 & 31,68 & 3,61 & 28,52 & 27,54 & 7,54 & 15,28 \\
\hline C909 & 3,63 & 19,41 & 6,29 & 9,40 & 52,64 & 28,93 & 2,90 & 23,71 & 29,12 & 4,99 & 24,09 \\
\hline FO01 & 3,53 & 26,62 & 37,93 & 9,53 & 56,46 & 30,52 & 4,93 & 25,94 & 24,65 & 6,52 & 13,87 \\
\hline C505 & 3,7 & 25,88 & 4,98 & 8,74 & 48,92 & 27,61 & 6,32 & 21,30 & 20,18 & 5,92 & 17,49 \\
\hline C806 & 3,61 & 21,31 & 4,73 & 8,28 & 54,69 & 32,76 & 4,29 & 21,94 & 28,67 & 7,55 & 22,42 \\
\hline
\end{tabular}


Tabela 39. Correlação entre a composição química das silagens de milho dos híbridos de 1996.

\begin{tabular}{|c|c|c|c|c|c|c|c|c|c|c|c|c|}
\hline & $\mathrm{PH}$ & MSS & MMs & PBS & FDNs & FDAs & LIGs & HEMs & CELS & CINs & N-FDA & $\mathrm{N}-\mathrm{NH}_{3}$ \\
\hline \multirow[t]{2}{*}{$\mathrm{PH}$} & 1 & 0,219 & $-0,313$ & $-0,156$ & 0,036 & $-0,162$ & $-0,204$ & 0,134 & $-0,009$ & $-0,092$ & 0,212 & 0,133 \\
\hline & 0,000 & 0,282 & 0,137 & 0,447 & 0,862 & 0,429 & 0,329 & 0,513 & 0,966 & 0,668 & 0,298 & 0,517 \\
\hline \multirow[t]{2}{*}{ MSs } & 19 & 1 & 0,058 & 0,115 & 33 & 18 & 68 & 0,051 & $-0,671$ & 09 . & 16 & $-0,484$ \\
\hline & 0,282 & 0,000 & 0,787 & 0,576 & 0,252 & 0,001 & 0,421 & 0,805 & 0,000 & 0,965 & 0,573 & 0,012 \\
\hline \multirow[t]{2}{*}{ MMs } & $-0,313$ & 0,058 & 1 & 0,269 & 0,132 & 0,142 & 0,016 & 0,085 & 0,122 & $-0,166$ & 0,147 & $-0,278$ \\
\hline & 0,137 & 0,787 & 0,000 & 0,203 & 0,539 & 0,508 & 0,941 & 0,694 & 0,570 & 0,461 & 0,494 & 0,188 \\
\hline \multirow[t]{2}{*}{ PBs } & $-0,156$ & 0,115 & 0,269 & 1 & $-0,662$ & 373 & $-0,360$ & $-0,621$ & $-0,057$ & 0,426 & $-0,609$ & 0,219 \\
\hline & 0,447 & 0,576 & 0,203 & 0,000 & 0,000 & 0,060 & 0,077 & 0,001 & 0,784 & 0,038 & 0,001 & 0,283 \\
\hline \multirow[t]{2}{*}{ FDNs } & 0,036 & $-0,233$ & 0,132 & $-0,662$ & 1 & 0,628 & 0,317 & 0,902 & 0,443 & $-0,461$ & 0,540 & $-0,059$ \\
\hline & 0,862 & 0,252 & 0,539 & 0,000 & 0,000 & 0,001 & 0,123 & 0,000 & 0,024 & 0,023 & 0,004 & 0,776 \\
\hline \multirow[t]{2}{*}{ FDAs } & $-0,162$ & $-0,618$ & 0,142 & $-0,373$ & 0,628 & 1 & 0,357 & 0,232 & 0,746 & $-0,178$ & 0,369 & 0,288 \\
\hline & 0,429 & 0,001 & 0,508 & 0,060 & 0,001 & 0,000 & 0,080 & 0,255 & 0,000 & 0,406 & 0,063 & 0,153 \\
\hline \multirow[t]{2}{*}{ LIGs } & 204 & -0 & 0,016 & $-0,360$ & 0,317 & 0,357 & 1 & 99 & 52 & 51 & 0,284 & 0,088 \\
\hline & 0,329 & 0,421 & 0,941 & 0,077 & 0,123 & 0,080 & 0,000 & 0,341 & 0,468 & 0,237 & 0,169 & 0,677 \\
\hline \multirow[t]{2}{*}{ HEMs } & 0,134 & 0,051 & 0,085 & $-0,621$ & 0,902 & 0,232 & 0,199 & 1 & 0,140 & $-0,487$ & 0,471 & $-0,233$ \\
\hline & 0,513 & 0,805 & 0,694 & 0,001 & 0,000 & 0,255 & 0,341 & 0,000 & 0,494 & 0,016 & 0,015 & 0,253 \\
\hline \multirow[t]{2}{*}{ CELS } & $-0,009$ & 771 & 0,122 & $-0,057$ & 0,443 & 0,746 & $-0,152$ & 0,140 & 1 & $-0,053$ & 0,211 & 0,406 \\
\hline & 0,966 & 0,000 & 0,570 & 0,784 & 0,024 & 0,000 & 0,468 & 0,494 & 0,000 & 0,807 & 0,300 & 0,039 \\
\hline \multirow[t]{2}{*}{ CINs } & $-0,092$ & 09 & $-0,166$ & 0,426 & $-0,461$ & $-0,178$ & $-0,251$ & $-0,487$ & $-0,053$ & 1 & $-0,408$ & $-0,173$ \\
\hline & 0,668 & 0,965 & 0,461 & 0,038 & 0,023 & 0,406 & 0,237 & 0,016 & 0,807 & 0,000 & 0,048 & 0,420 \\
\hline \multirow[t]{2}{*}{ N-FDA } & 0,212 & $-0,116$ & 0,147 & $-0,609$ & 0,540 & 0,369 & 0,284 & 0,471 & 0,211 & $-0,408$ & 1 & $-0,061$ \\
\hline & 0,298 & 0,573 & 0,494 & 0,001 & 0,004 & 0,063 & 0,169 & 0,015 & 0,300 & 0,048 & 0,000 & 0,769 \\
\hline \multirow[t]{2}{*}{$\mathrm{N}-\mathrm{NH}_{3}$} & 0,133 & $-0,484$ & $-0,278$ & 0,219 & $-0,059$ & 0,288 & 0,088 & $-0,233$ & 0,406 & $-0,173$ & $-0,061$ & 1 \\
\hline & 0,517 & 0,012 & 0,188 & 0,283 & 0,776 & 0,153 & 0,677 & 0,253 & 0,039 & 0,420 & 0,769 & 0,000 \\
\hline
\end{tabular}


Tabela 40. Correlação entre a composição química das silagens e da fração volumosa de hibridos de milho de 1996.

\begin{tabular}{|c|c|c|c|c|c|c|c|c|c|c|c|c|}
\hline \multirow{2}{*}{$\begin{array}{l}\text { Porção } \\
\text { Fibrosa }\end{array}$} & \multicolumn{12}{|c|}{ Composição química das silagens } \\
\hline & $\mathrm{PH}$ & MSs & MMs & PBs & FDNs & FDAS & LIGs & HEMS & CELS & CINs & N-FDA & $\mathrm{N}-\mathrm{NH}_{3}$ \\
\hline \multirow[t]{2}{*}{ MS } & 42 & 0,749 & 0,199 & 0,348 & -0 & & -0 & & 23 & 0,266 & $-0,011$ & $=0$ \\
\hline & 0,491 & 0,000 & 0,352 & 0,082 & 0,122 & 0,012 & 0,424 & 0,561 & 0,031 & 0,209 & 0,958 & 0,034 \\
\hline \multirow[t]{2}{*}{ MM } & $-0,021$ & $-0,078$ & $-0,010$ & $-0,042$ & 0,116 & 0,062 & 0,090 & 0,110 & 0,014 & $-0,201$ & $-0,116$ & 0,174 \\
\hline & 0,919 & 0,705 & 0,964 & 0,839 & 0,574 & 63 & 0,668 & 0,594 & 0,946 & 0,346 & 0,571 & 0,394 \\
\hline \multirow[t]{2}{*}{ PB } & 0,060 & 0,375 & 0,087 & 0,291 & -0, & -0 & $-0,391$ & $-0,063$ & $-0,247$ & 82 & or & -0 \\
\hline & 0,772 & 0,059 & 0,685 & 0,149 & 0,251 & 0,036 & 0,054 & 0,761 & 0,225 & 0,705 & 0,674 & 0,754 \\
\hline \multirow[t]{2}{*}{ FDN } & $-0,289$ & $-0,262$ & 663 & $-0,050$ & 35 & 33 & 0,339 & 0,161 & 0,338 & 77 & 0,151 & 0,2 \\
\hline & 0,152 & 0,196 & 0,769 & 0,810 & 0,067 & 0,005 & 0,097 & 0,432 & 0,091 & 0,722 & 0,461 & 0,156 \\
\hline \multirow[t]{2}{*}{ FDA } & $-0,227$ & $-0,115$ & 0,285 & $-0,116$ & 0,401 & 0,445 & 0,210 & 0,255 & 0,328 & $-0,321$ & 0,265 & 0, \\
\hline & 0,264 & 0,576 & 0,177 & 0,571 & 0,042 & 0,023 & 0,314 & 0,209 & 0,102 & 0,127 & 0,190 & 0,659 \\
\hline \multirow[t]{2}{*}{ LIG } & $-0,188$ & $-0,439$ & $-0,036$ & 0,036 & 0,170 & 0,545 & 0,210 & $-0,089$ & 0,377 & 0,427 & 0,209 & 0,182 \\
\hline & 0,359 & 0,025 & 0,868 & 0,862 & 0,407 & 0,004 & 0,315 & 0,665 & 0,058 & 0,038 & 0,306 & 0,373 \\
\hline \multirow[t]{2}{*}{ CEL } & $-0,113$ & 0,073 & 0,293 & $-0,204$ & 0,370 & 0,191 & 0,096 & 0,356 & 0,185 & $-0,604$ & 0,201 & $-0,036$ \\
\hline & 0,584 & 0,723 & 0,164 & 0,317 & 0,063 & 0,349 & 646 & 074 & 0,365 & 0,002 & 0,324 & 0,861 \\
\hline \multirow[t]{2}{*}{ HEM } & $-0,221$ & -0 & -0 & 0,025 & 7 & 0 & 0,305 & 0,019 & 0,210 & 0,155 & $-0,003$ & 0,330 \\
\hline & 0,278 & 0,171 & 0,126 & 0,902 & 0,359 & 0,050 & 0,138 & 0,927 & 0,303 & 0,469 & 0,989 & \\
\hline \multirow[t]{2}{*}{ CELFDN } & 0,121 & 0,288 & 0,344 & $-0,175$ & 0,095 & $-0,223$ & $-0,176$ & 0,243 & $-0,079$ & $-0,530$ & 0,087 & $-0,262$ \\
\hline & 0,556 & 0,153 & 0,100 & 0,393 & 0,643 & 0,274 & 0,399 & 0,233 & 0,701 & 0,008 & 0,673 & 0,196 \\
\hline \multirow[t]{2}{*}{ LIGFDN } & $-0,147$ & $-0,440$ & $-0,020$ & 0,059 & 0,093 & 0,486 & 0,161 & $-0,153$ & 0,344 & 0,509 & 0,183 & 0,1 \\
\hline & 0,473 & 0,024 & 0,925 & 0,774 & 0,652 & 0,012 & 0,441 & 0,455 & 0,086 & 0,011 & ,370 & 0,496 \\
\hline \multirow[t]{2}{*}{ FDAFDN } & 0,088 & 0 , & 0,467 & $-0,094$ & 0 & & & & 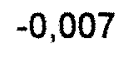 & & 8 & .08 \\
\hline & 0,668 & 0,332 & 0,022 & 0,647 & 0,779 & 0,609 & 0,418 & 0,525 & 0,973 & 0,114 & 0,471 & 0,203 \\
\hline
\end{tabular}

A porcentagem de espigas na MS se mostrou positivamente correlacionada com o teor de $\mathrm{N}-\mathrm{NH}_{3}(r=0,51$, tabela 41), resultado provável da correlação negativa entre a porcentagem de espigas na MS e o teor de MS da 
fração volumosa (tabela 26), indicando que o teor de MS da fração volumosa seria mais importante para o controle de fermentações indesejáveis do que 0 teor de MS da espiga.

Para ilustrar essa afirmação, vemos nas tabelas 40 e 41 que o teor de $\mathrm{N}$ $\mathrm{NH}_{3}$ se mostrou negativamente correlacionado com o teor de MS do fração volumosa (MSFIB, $r=-0,42$ ), e não se mostrou correlacionado com o teor de MS da espiga (MSESP) ou com o teor de MS da planta no momento da ensilagem (MSPL).

Tabela 41. Correlação entre a composição química das silagens de milho e as caracteristicas de produção dos hibridos de milho em 1996.

\begin{tabular}{|c|c|c|c|c|c|c|c|c|c|c|c|c|}
\hline & $\mathrm{PH}$ & MS & $\mathrm{MM}$ & $\mathrm{PB}$ & FDN & FDA & LIG & HEM & CEL & $\mathrm{CIN}$ & N-FDA & $\overline{\mathrm{N}-\mathrm{NH}_{3}}$ \\
\hline \multirow[t]{2}{*}{ MSESP } & 0,174 & 0,645 & 0,128 & 0,282 & $-0,277$ & $-0,673$ & $-0,111$ & 0,026 & $-0,477$ & 0,000 & $-0,257$ & $-0,268$ \\
\hline & 0,395 & 0,000 & 0,551 & 0,162 & 0,171 & 0,000 & 0,596 & 0,898 & 0,014 & 0,999 & 0,205 & 0,186 \\
\hline \multirow[t]{2}{*}{ PESP } & 0,262 & 0,160 & $-0,242$ & $-0,105$ & 0,237 & $-0,195$ & 0,045 & 0,404 & $-0,113$ & $-0,367$ & $-0,079$ & 0,257 \\
\hline & 0,196 & 0,435 & 0,255 & 0,609 & 0,244 & 0,340 & 0,830 & 0,041 & 0,584 & 0,077 & 0,700 & 0,205 \\
\hline \multirow[t]{2}{*}{ PFIB } & 0,162 & 0,702 & 0,130 & 0,234 & $-0,307$ & $-0,604$ & $-0,139$ & $-0,049$ & $-0,540$ & 0,035 & $-0,142$ & $-0,442$ \\
\hline & 0,429 & 0,000 & 0,544 & 0,251 & 0,127 & 0,001 & 0,509 & 0,811 & 0,004 & 0,873 & 0,490 & 0,024 \\
\hline \multirow[t]{2}{*}{ PTOT } & 0,265 & 0,651 & $-0,020$ & 0,125 & $-0,126$ & $-0,614$ & $-0,129$ & 0,182 & 00 & $-0,121$ & $-0,158$ & $-0,293$ \\
\hline & 0,190 & 0,000 & 0,927 & 0,543 & 0,539 & 0,001 & 0,540 & 0,374 & 0,009 & 0,574 & 0,440 & 0,147 \\
\hline \multirow[t]{2}{*}{$\%$ ESPIGA } & 0,084 & $-0,291$ & $-0,291$ & $-0,251$ & 0,410 & 0,271 & 0,195 & 0,363 & 0,265 & $-0,301$ & 0,023 & 0,510 \\
\hline & 0,684 & 0,149 & 0,168 & 0,216 & 0,037 & 0,181 & 0,351 & 0,068 & 0,191 & 0,153 & 0,910 & 0,008 \\
\hline \multirow[t]{2}{*}{ MSPL } & 0,274 & 0,681 & 0,035 & 0,300 & $-0,216$ & $-0,556$ & $-0,144$ & 0,038 & $-0,401$ & 0,133 & $-0,087$ & $-0,182$ \\
\hline & 0,175 & 0,000 & 0,872 & 0,136 & 0,289 & 0,003 & 0,493 & 0,854 & 0,043 & 0,534 & 0,674 & 0,375 \\
\hline \multirow[t]{2}{*}{ Dry-down } & 0,141 & 0,422 & 0,063 & 0,176 & $-0,186$ & $-0,572$ & $-0,054$ & 0,085 & $-0,370$ & $-0,128$ & $-0,297$ & $-0,128$ \\
\hline & 0,492 & 0,032 & 0,769 & 0,391 & 0,364 & 0,002 & 0,796 & 0,680 & 0,063 & 0,551 & 0,140 & 0,535 \\
\hline
\end{tabular}


Tabela 42. Correlação entre a composição química das silagens de milho e a digestibilidade da fração volumosa em 1996.

\begin{tabular}{|c|c|c|c|c|c|c|c|c|c|c|c|c|}
\hline & $\mathrm{Oh}$ & $3 h$ & $6 h$ & $12 \mathrm{~h}$ & $24 h$ & $48 h$ & $72 h$ & $\bar{A}$ & $B$ & c & Lag & Deg.ef \\
\hline \multirow[t]{2}{*}{$\mathrm{pH}$} & 0,192 & 0,130 & 0,157 & 0,021 & 0,202 & $-0,015$ & 0,261 & 0,199 & $-0,031$ & $-0,085$ & 0,210 & 0,132 \\
\hline & 0,346 & 0,526 & 0,443 & 0,919 & 0,321 & 0,941 & 0,197 & 0,331 & 0,882 & 0,681 & 0,304 & 0,521 \\
\hline \multirow[t]{2}{*}{ MS } & 0,156 & 0,096 & 0,065 & $-0,144$ & $-0,112$ & $-0,350$ & $-0,142$ & 0,170 & $-0,459$ & $-0,077$ & 0,228 & $-0,087$ \\
\hline & 0,446 & 0,642 & 0,753 & 0,482 & 0,587 & 0,079 & 0,490 & 0,406 & 0,018 & 0,707 & 0,263 & 0,671 \\
\hline \multirow[t]{2}{*}{ MM } & 0,021 & $-0,010$ & 0,031 & $-0,044=$ & $-0,198$ & $-0,180$ & $-0,101$ & 0,048 & 0,276 & 0,115 & $-0,104$ & 0,259 \\
\hline & 0,921 & 0,965 & 0,887 & 0,837 & 0,354 & 0,399 & 0,639 & 0,827 & 0,203 & 0,603 & 0,638 & 0,232 \\
\hline \multirow[t]{2}{*}{ PB } & 0,223 & 0,265 & 0,237 & 0,171 & 0,187 & 0,270 & 0,149 & 0,215 & $-0,113$ & 0,031 & 0,087 & 0,222 \\
\hline & 0,273 & 0,192 & 0,244 & 0,403 & 0,360 & 0,183 & 0,469 & 0,291 & 0,583 & 0,882 & 0,672 & 0,276 \\
\hline \multirow[t]{2}{*}{ FDN } & $-0,429$ & $-0,421$ & $-0,332$ & $-0,306$ & $-0,351$ & $-0,319$ & $-0,251$ & $-0,429$ & 0,372 & $-0,168$ & $-0,372$ & $-0,366$ \\
\hline & 0,029 & 0,032 & 0,097 & 0,128 & 0,079 & 0,112 & 0,216 & 0,029 & 0,061 & 0,412 & 0,061 & 0,066 \\
\hline \multirow[t]{2}{*}{ FDA } & $-0,544$ & $-0,517$ & $-0,435$ & $-0,323$ & $-0,326$ & $-0,276$ & $-0,298$ & $-0,574$ & 0,496 & $-0,041$ & $-0,467$ & $-0,408$ \\
\hline & 0,004 & 0,007 & 0,027 & 0,108 & 0,104 & 0,172 & 0,139 & 0,002 & 0,010 & 0,844 & 0,016 & 0,039 \\
\hline \multirow[t]{2}{*}{ LIG } & $-0,279$ & $-0,271$ & $-0,315$ & $-0,190$ & $-0,378$ & $-0,381$ & $-0,298$ & $-0,290$ & 0,084 & $-0,131$ & $-0,215$ & $-0,323$ \\
\hline & 0,176 & 0,190 & 0,125 & 0,363 & 0,063 & 0,060 & 0,148 & 0,159 & 0,692 & 0,534 & 0,302 & 0,115 \\
\hline \multirow[t]{2}{*}{ HEM } & $-0,235$ & $-0,240$ & $-0,175$ & $-0,204$ & $-0,258$ & $-0,246$ & $-0,149$ & $-0,218$ & 0,191 & $-0,187$ & $-0,207$ & $-0,231$ \\
\hline & 0,248 & 0,237 & 0,393 & 0,317 & 0,203 & 0,226 & 0,469 & 0,284 & 0,351 & 0,359 & 0,310 & 0,255 \\
\hline \multirow[t]{2}{*}{ CEL } & $-0,326$ & $-0,284$ & $-0,160$ & $-0,080$ & 0,042 & 0,012 & 0,049 & $-0,358$ & 0,539 & 0,049 & $-0,426$ & $-0,098$ \\
\hline & 0,105 & 0,159 & 0,435 & 0,699 & 0,837 & 0,953 & 0,811 & 0,073 & 0,005 & 0,812 & 0,030 & 0,635 \\
\hline \multirow[t]{2}{*}{ N-FDA } & $-0,290$ & $-0,291$ & $-0,220$ & $-0,256$ & $-0,262$ & $-0,350$ & $-0,125$ & $-0,305$ & 0,253 & $-0,266$ & $-0,351$ & $-0,284$ \\
\hline & 0,151 & 0,149 & 0,279 & 0,207 & 0,197 & 0,080 & 0,542 & 0,130 & 0,212 & 0,190 & 0,079 & 0,159 \\
\hline \multirow[t]{2}{*}{$\mathrm{N}-\mathrm{NH}_{3}$} & $-0,233$ & $-0,167$ & $-0,156$ & $-0,102$ & 0,052 & 0,149 & 0,036 & $-0,218$ & 0,362 & 0,142 & $-0,002$ & $-0,063$ \\
\hline & 0,253 & 0,415 & 0,447 & 0,620 & 0,801 & 0,467 & 0,862 & 0,286 & 0,070 & 0,489 & 0,990 & 0,761 \\
\hline
\end{tabular}

Não fai encontrada correlação entre os parâmetros de fermentação das 
silagens ( $\mathrm{pH}, \mathrm{N}-\mathrm{FDA}, \mathrm{N}-\mathrm{NH}_{3}$ ) e a digestibilidade da fração volumosa (tabela 42), indicando que os híbridos com maior digestibilidade da fração volumosa não interferiram no padrão de fermentação.

\subsection{Efeito do ambiente sobre as características agronômicas, composição química e digestibilidade da fração volumosa de híbridos de milho}

Os dois anos experimentais se mostraram bastante diversos quanto a precipitação hídrica. O ano experimental de 1996 se mostrou um ano seco com ocorrência de veranico nos meses de Novembro e Dezembro. Enquanto o ano de 1997 foi um ano caracterizado por chuvas abundantes durante toda a condução do experimento no campo (tabela 5).

Os resultados mostram que o ano experimental teve influência marcante sobre todos os parâmetros estudados, interagindo com o efeito dos híbridos de modo a provocar comportamentos diversos dos híbridos em cada ano experimental. Ou seja, as diferentes condições de crescimento levaram a existência de interações ano $x$ híbrido significativas.

Os híbridos de milho em 1997 apresentaram uma produção de MS total em média 62\% superior ao ano de 1996 (tabela 43), sendo o aumento na produção de espigas superior ao aumento na produção da fração volumosa (120 e $26,5 \%$ respectivamente) levando a um aumento médio de 13,8 unidades percentuais na proporção de espigas na MS total (tabela 43). O aumento na proporção de grãos na MS de plantas de milho quando submetidas a irrigação foi anteriormente demonstrado por Tiemann et al. (1990)

A interação significativa ano $x$ híbrido para os parâmetros agronômicos, indica que não houve consistência na classificação dos híbridos nos dois anos experimentais.

Observa-se na tabela 44 que o ano agrícola teve efeito significativo sobre a composição química da fração volumosa dos híbridos de milho. No ano de 
maior disponibilidade de água e maior produçăo de grãos (1997), os hibridos apresentavam um maior teor dos constituintes da parede celular (FDN, FDA e lignina) na fração volumosa.

Tabela 43. Efeito do ano agrícola sobre a composição bromatológica dos híbridos de milho.

\begin{tabular}{|c|c|c|c|c|c|c|c|c|}
\hline & MS & M.M. & P.B. & FDN & FDA & LIG & CEL & HEM \\
\hline Ano & \multicolumn{8}{|c|}{ média } \\
\hline 96 & 20,90 & 7,59 & 8,80 & 61,07 & 35,14 & 4,80 & 29,29 & 25,93 \\
\hline 97 & 22,32 & 7,98 & 7,63 & 66,23 & 41,26 & 6,20 & 32,93 & 24,96 \\
\hline Ano ${ }^{1}$ & 0,014 & 0,0035 & 0,0001 & 0,0001 & 0,0001 & 0,0009 & 0,0001 & 0,0614 \\
\hline Ano $x$ Híbrido ${ }^{2}$ & 0,0001 & 0,0097 & 0,3191 & 0,0001 & 0,0697 & 0,0121 & 0,0021 & 0,0136 \\
\hline
\end{tabular}

Probabilidade do efeito de ano ser nulo

${ }^{2}$ Probabilidade de não ocorrer interação ano $x$ híbrido

Tabela 44. Efeito do ano agrícola sobre as características agronômicas dos híbridos de milho.

\begin{tabular}{|c|c|c|c|c|c|c|c|}
\hline Ano & PESP & PFIB & PTOT & $\begin{array}{c}\text { Espigas } \\
\text { média }\end{array}$ & MSPL & MSESP & Dry-down \\
\hline 96 & 4584,68 & 7498,40 & 12083,36 & 37,92 & 0,27 & 37,26 & 16,36 \\
\hline 97 & 10096,08 & 9485,51 & 19581,60 & 51,68 & 0,34 & 52,33 & 30,01 \\
\hline $\mathrm{Ano}^{1}$ & 0,0001 & 0,0001 & 0,0001 & 0,0001 & 0,0001 & 0,0001 & 0,0001 \\
\hline Ano $\times$ Hibrido $^{2}$ & 0,0165 & 0,0003 & 0,0011 & 0,0455 & 0,0145 & 0,0001 & 0,0001 \\
\hline
\end{tabular}

Probabilidade do efeito de ano ser nulo

2 Probabilidade de não ocorrer interação ano $x$ híbrido

A interação ano $x$ híbrido não foi significativa para o teor de FDA e PB da fração volumosa, porém foi significativa para o teor de FDN e lignina (tabela 44), indicando que houve uma consistência no comportamento dos híbridos quanto aos teores de FDA e PB da fração volumosa, mesmo quando expostas 
a condições ambientais diversas.

Em 1997, os hibridos apresentaram menor digestibilidade da MS da fração volumosa (tabela 45) em todos os tempos de incubação, sendo a interação ano $\times$ híbrido significativa para todos os tempos de incubação. Esse resultado demonstra que o efeito ambiental sobre a digestibilidade da fração volumosa prevaleceu sobre o efeito genético na maioria dos híbridos, e, portanto, tornase difícil estabelecer parâmetros de qualidade dos híbridos para seleção genética.

Tabela 45. Efeito do ano agrícola sobre a digestibilidade da MS da fração volumosa dos híbridos de milho.

\begin{tabular}{|c|c|c|c|c|c|c|c|c|c|c|c|c|}
\hline \multirow[b]{2}{*}{ Ano } & oh & $3 h$ & $6 \mathrm{~h}$ & $12 \mathrm{~h}$ & $24 \mathrm{~h}$ & $48 \mathrm{~h}$ & $72 \mathrm{~h}$ & $\bar{A}$ & $B$ & c & lag & Deg.ef \\
\hline & \multicolumn{12}{|c|}{ média } \\
\hline 96 & 0,37 & 0,42 & 0,50 & 0,58 & 0,68 & 0,68 & 0,68 & 37,0 & 33,0 & 5,0 & 2,90 & 51,0 \\
\hline 97 & 0,33 & 0,34 & 0,36 & 0,41 & 0,47 & 0,55 & 0,61 & 32,0 & 34,0 & 3,0 & 2,33 & 42,0 \\
\hline $\mathrm{Ano}^{\mathrm{T}}$ & 0,001 & 0,001 & 0,001 & 0,001 & 0,001 & 0,001 & 0,001 & & & & & \\
\hline Ano*var ${ }^{2}$ & 0,001 & 0,001 & 0,001 & 0,001 & 0,001 & 0,001 & 0,001 & & & & & \\
\hline
\end{tabular}

Probabilidade do efeito de ano ser nulo

${ }^{2}$ Probabilidade de não ocorrer interação ano $x$ híbrido

Roth (1993) relata que a digestiblidade do colmo é menos consistente do que a digestibilidade da planta inteira, em diferentes ambientes, devido provavelmente aos efeitos do estresse sobre o nível de carboidratos do colmo. Lundvall et al. (1994) também encontraram interação significativa ano x híbrido para a digestibilidade e teor de FDN de hastes e folhas de híbridos de milho.

A menor digestibilidade da fração volumosa em 1997, foi devido principalmente ao maior teor de FDA da fração volumosa, demonstrado pela elevada correlação negativa desse item com a degradabilidade efetiva (Deg.ef) da MS quando os dados dos dois anos são analisados em conjunto (tabela 35 ).

$O$ teor de FDA da fração volumosa se mostrou fortemente correlacionado com a produção de espigas dos híbridos ( $r=0,75$, tabela 28 ), levando a uma 
correlação negativa $(r=-0,79)$ entre a produção de espigas e a degradabilidade efetiva da fração volumosa quando os dados foram analisados em conjunto(tabela 46).

Tabela 46. Correlação entre as características agronômicas e a digestibilidade "in situ" da MS da fração volumosa (1996 e 1997).

\begin{tabular}{lccccc}
\hline & PESP & PFIB & PTOT & $\%$ ESPIGA & MSPL \\
\hline Oh & $-0,507$ & $-0,047$ & $-0,368$ & $-0,607$ & $-0,378$ \\
& 0,000 & 0,750 & 0,009 & 0,000 & 0,007 \\
3h & $-0,606$ & $-0,148$ & $-0,480$ & $-0,672$ & $-0,476$ \\
& 0,000 & 0,310 & 0,001 & 0,000 & 0,001 \\
6h & $-0,667$ & $-0,217$ & $-0,550$ & $-0,705$ & $-0,535$ \\
& 0,000 & 0,135 & 0,000 & 0,000 & 0,000 \\
12h & $-0,788$ & $-0,373$ & $-0,697$ & $-0,771$ & $-0,703$ \\
& 0,000 & 0,008 & 0,000 & 0,000 & 0,000 \\
24h & $-0,844$ & $-0,470$ & $-0,777$ & $-0,777$ & $-0,750$ \\
& 0,000 & 0,001 & 0,000 & 0,000 & 0,000 \\
48h & $-0,846$ & $-0,512$ & $-0,794$ & $-0,765$ & $-0,787$ \\
& 0,000 & 0,000 & 0,000 & 0,000 & 0,000 \\
72h & $-0,746$ & $-0,369$ & $-0,669$ & $-0,727$ & $-0,682$ \\
& 0,000 & 0,009 & 0,000 & 0,000 & 0,000 \\
& $-0,508$ & $-0,045$ & $-0,368$ & $-0,606$ & $-0,383$ \\
A & 0,000 & 0,760 & 0,009 & 0,000 & 0,007 \\
& 0,184 & $-0,173$ & 0,055 & 0,294 & $-0,002$ \\
B & 0,206 & 0,234 & 0,707 & 0,040 & 0,991 \\
& 0,206 & $-0,613$ & $-0,851$ & $-0,711$ & $-0,788$ \\
C & $-0,870$ & $-0,61$ & \\
& 0,000 & 0,000 & 0,000 & 0,000 & 0,000 \\
Lag & $-0,222$ & $-0,167$ & $-0,219$ & $-0,157$ & $-0,192$ \\
& 0,125 & 0,251 & 0,131 & 0,282 & 0,187 \\
Deg.ef & $-0,792$ & $-0,383$ & $-0,704$ & $-0,767$ & $-0,696$ \\
& 0,000 & 0,007 & 0,000 & 0,000 & 0,000 \\
\hline A & 0,007 & &
\end{tabular}

$A=$ fração solúvel

$B=$ fração insolúvel potencialmente degradável

$C=$ taxa de degradação da fração $B$

Lag = tempo de colonização

Deg.ef. = degradação efetiva supondo-se $5 \% \cdot \mathrm{h}^{-1}$ como taxa de passagem ruminal 
A menor digestibilidade da MS em 1997 poderia estar relacionada com o maior teor de MS das plantas no momento da colheita (tabela 44), porém não houve grande variação no teor de MS da fração volumosa dos híbridos em 1996 e 1997 (tabela 43).

Na tabela 47, vemos a média de degradação da MS nos três períodos do feno de aveia utilizado como padrão nos 2 anos experimentais. Não ocorreu efeito do ano experimental sobre a digestibilidade do padrão utilizado.

Tabela 47. Degradabilidade da MS do feno de aveia (padrão) nos dois anos experimentais.

\begin{tabular}{rrrrrrrr}
\hline & Oh & $3 h$ & $6 h$ & $12 h$ & $24 h$ & $48 h$ & $72 h$ \\
& & & & & & \\
\hline 1996 & 26,1 & 27,8 & 33,2 & 40,9 & 51,0 & 52,9 & 59,9 \\
1997 & 24,2 & 26,7 & 30,8 & 39,3 & 48,4 & 58,7 & 63,4 \\
\hline
\end{tabular}

Analisando-se os dados da digestibilidade do FDN, vemos que no ano de 1997 tivemos uma maior degradação do FDN nos períodos iniciais (0, 3 e 6 horas), sendo que após 6 horas, os híbridos apresentaram menor degradabilidade do FDN do que em 1996 (tabela 48). A interação ano x híbrido foi significativa para todos os tempos de incubação (tabela 48).

A menor digestibilidade do FDN nos tempos mais avançados de incubação no ano de 1997 pode ser explicado pelo maior teor de FDA e lignina da fração volumosa dos híbridos neste ano (tabela 43). Vemos na tabela 50 que o teor de FDA e lignina se mostraram negativamente correlacionados com a digestibilidade do FDN após 6 horas quando os dados dos dois anos foram analisados em conjunto. 
Tabela 48. Efeito do ano agrícola sobre a digestibilidade do FDN da fração volumosa dos híbridos de milho.

\begin{tabular}{|c|c|c|c|c|c|c|c|c|c|c|}
\hline & Oh & $3 \mathrm{~h}$ & $6 \mathrm{~h}$ & $12 \mathrm{~h}$ & $24 h$ & $48 \mathrm{~h}$ & $72 h$ & $B$ & $\bar{U}$ & Lag Fill \\
\hline Ano & \multicolumn{10}{|c|}{ média } \\
\hline 96 & 0,11 & 0,13 & 0,18 & 0,31 & 0,44 & 0,58 & 0,56 & 47,6 & $6,9 \quad 40,7$ & $4,15 \quad 16,39$ \\
\hline 97 & 0,15 & 0,17 & 0,20 & 0,27 & 0,36 & 0,46 & 0,53 & 44,0 & $2,941,4$ & $2,1216,01$ \\
\hline Ano $^{\prime}$ & 0,0001 & 0,0001 & 0,0015 & 0,0001 & 0,0001 & 0,0001 & 0,0056 & & & \\
\hline Ano*var ${ }^{2}$ & 0,0001 & 0,0001 & 0,0001 & 0,0001 & 0,0001 & 0,0001 & 0,0001 & & & \\
\hline
\end{tabular}

Probabilidade do efeito de ano ser nulo

${ }^{2}$ Probabilidade de não ocorrer interação ano $x$ híbrido

No entanto, nenhuma análise química realizada ou características agronômicas dos híbridos, explicaram a variação do efeito de enchimento do FDN (Fill) entre os dois anos experimentais (tabelas 49 e 50 ).

Tabela 49. Correlação entre a digestibilidade "in situ" do FDN e as características agronômicas de híbridos de milho dos dois anos experimentais (1996 e 1997).

\begin{tabular}{|c|c|c|c|c|c|c|c|c|c|c|c|c|}
\hline & Oh & $3 h$ & $6 \mathrm{~h}$ & $12 \mathrm{~h}$ & $24 h$ & $48 \mathrm{~h}$ & $72 h$ & $B$ & C & LAG & $\mathrm{U}$ & Fill \\
\hline PESP & $\begin{array}{l}0,395 \\
0,005\end{array}$ & $\begin{array}{l}0,319 \\
0,026\end{array}$ & $\begin{array}{l}0,164 \\
0,262\end{array}$ & $\begin{array}{c}-0,480 \\
0,001\end{array}$ & $\begin{array}{c}-0,717 \\
0,000\end{array}$ & $\begin{array}{c}-0,776 \\
0,000\end{array}$ & $\begin{array}{c}-0,450 \\
0,001\end{array}$ & $\begin{array}{c}-0,383 \\
0,007\end{array}$ & $\begin{array}{c}-0,763 \\
0,000\end{array}$ & $\begin{array}{l}-0,496 \\
0,000\end{array}$ & $\begin{array}{l}0,075 \\
0,610\end{array}$ & $\begin{array}{r}-0,138 \\
0,345\end{array}$ \\
\hline PFIB & $\begin{array}{l}0,183 \\
0,208\end{array}$ & $\begin{array}{l}0,142 \\
0,330\end{array}$ & $\begin{array}{l}0,021 \\
0,889\end{array}$ & $\begin{array}{c}-0,380 \\
0,007\end{array}$ & $\begin{array}{c}-0,514 \\
0,000\end{array}$ & $\begin{array}{c}-0,568 \\
0,000\end{array}$ & $\begin{array}{c}-0,403 \\
0,004\end{array}$ & $\begin{array}{c}-0,368 \\
0,009\end{array}$ & $\begin{array}{c}-0,532 \\
0,000\end{array}$ & $\begin{array}{c}-0,292 \\
0,042\end{array}$ & $\begin{array}{l}0,270 \\
0,060\end{array}$ & $\begin{array}{r}-0,003 \\
0,986\end{array}$ \\
\hline PTOT & $\begin{array}{l}0,353 \\
0,013\end{array}$ & $\begin{array}{l}0,284 \\
0,048\end{array}$ & $\begin{array}{l}0,125 \\
0,391\end{array}$ & $\begin{array}{c}-0,483 \\
0,000\end{array}$ & $\begin{array}{c}-0,706 \\
0,000\end{array}$ & $\begin{array}{r}-0,767 \\
0,000\end{array}$ & $\begin{array}{c}-0,474 \\
0,001\end{array}$ & $\begin{array}{c}-0,412 \\
0,003\end{array}$ & $\begin{array}{r}-0,749 \\
0,000\end{array}$ & $\begin{array}{r}-0,471 \\
0,001\end{array}$ & $\begin{array}{l}0,155 \\
0,288\end{array}$ & $\begin{array}{r}-0,106 \\
0,469\end{array}$ \\
\hline$\%$ ESPIGA & $\begin{array}{l}0,384 \\
0,006\end{array}$ & $\begin{array}{l}0,314 \\
0,028\end{array}$ & $\begin{array}{l}0,177 \\
0,224\end{array}$ & $\begin{array}{r}-0,403 \\
0,004\end{array}$ & $\begin{array}{c}-0,590 \\
0,000\end{array}$ & $\begin{array}{r}-0,650 \\
0,000\end{array}$ & $\begin{array}{c}-0,354 \\
0,013\end{array}$ & $\begin{array}{c}-0,310 \\
0,030\end{array}$ & $\begin{array}{c}-0,621 \\
0,000\end{array}$ & $\begin{array}{c}-0,405 \\
0,004\end{array}$ & $\begin{array}{c}-0,024 \\
0,871\end{array}$ & $\begin{array}{r}-0,121 \\
0,409\end{array}$ \\
\hline MSPL & $\begin{array}{l}0,253 \\
0,080\end{array}$ & $\begin{array}{l}0,198 \\
0,172\end{array}$ & $\begin{array}{l}0,066 \\
0,650\end{array}$ & $\begin{array}{c}-0,540 \\
0,000\end{array}$ & $\begin{array}{c}-0,714 \\
0,000\end{array}$ & $\begin{array}{c}-0,796 \\
0,000\end{array}$ & $\begin{array}{c}-0,516 \\
0,000\end{array}$ & $\begin{array}{c}-0,372 \\
0,009\end{array}$ & $\begin{array}{c}-0,731 \\
0,000\end{array}$ & $\begin{array}{c}-0,466 \\
0,001\end{array}$ & $\begin{array}{l}0,188 \\
0,197\end{array}$ & $\begin{array}{c}-0,076 \\
0,605\end{array}$ \\
\hline
\end{tabular}


Tabela 50. Correlação entre a digestibilidade "in situ" do FDN e composição bromatológica da fração volumosa dos dois anos experimentais (1996 e 1997).

\begin{tabular}{|c|c|c|c|c|c|c|c|c|c|c|c|c|}
\hline & Oh & $3 h$ & $6 h$ & $12 \mathrm{~h}$ & $24 h$ & $48 \mathrm{~h}$ & $72 h$ & $B$ & $C$ & LAG & $\mathrm{U}$ & Fill \\
\hline MS & $\begin{array}{c}-0,016 \\
0,913\end{array}$ & $\begin{array}{c}-0,009 \\
0,951\end{array}$ & $\begin{array}{r}-0,095 \\
0,515\end{array}$ & $\begin{array}{r}-0,373 \\
0,008\end{array}$ & $\begin{array}{c}-0,424 \\
0,002\end{array}$ & $\begin{array}{c}-0,486 \\
0,000\end{array}$ & $\begin{array}{r}-0,403 \\
0,004\end{array}$ & $\begin{array}{c}-0,273 \\
0,058\end{array}$ & $\begin{array}{c}-0,374 \\
0,008\end{array}$ & $\begin{array}{c}-0,231 \\
0,110\end{array}$ & $\begin{array}{l}0,349 \\
0,014\end{array}$ & $\begin{array}{l}0,036 \\
0,808\end{array}$ \\
\hline PB & $\begin{array}{r}-0,367 \\
0,010\end{array}$ & $\begin{array}{c}-0,358 \\
0,011\end{array}$ & $\begin{array}{c}-0,236 \\
0,102\end{array}$ & $\begin{array}{l}0,273 \\
0,058\end{array}$ & $\begin{array}{l}0,492 \\
0,000\end{array}$ & $\begin{array}{l}0,530 \\
0,000\end{array}$ & $\begin{array}{l}0,225 \\
0,120\end{array}$ & $\begin{array}{l}0,216 \\
0,137\end{array}$ & $\begin{array}{l}0,596 \\
0,000\end{array}$ & $\begin{array}{l}0,401 \\
0,004\end{array}$ & $\begin{array}{l}0,103 \\
0,480\end{array}$ & $\begin{array}{l}0,178 \\
0,220\end{array}$ \\
\hline FDN & $\begin{array}{l}0,265 \\
0,065\end{array}$ & $\begin{array}{l}0,253 \\
0,079\end{array}$ & $\begin{array}{l}0,169 \\
0,247\end{array}$ & $\begin{array}{r}-0,306 \\
0,032\end{array}$ & $\begin{array}{c}-0,532 \\
0,000\end{array}$ & $\begin{array}{c}-0,543 \\
0,000\end{array}$ & $\begin{array}{r}-0,379 \\
0,007\end{array}$ & $\begin{array}{r}-0,390 \\
0,006\end{array}$ & $\begin{array}{r}-0,461 \\
0,001\end{array}$ & $\begin{array}{r}-0,307 \\
0,032\end{array}$ & $\begin{array}{l}0,121 \\
0,406\end{array}$ & $\begin{array}{r}-0,077 \\
0,600\end{array}$ \\
\hline FDA & $\begin{array}{l}0,305 \\
0,033\end{array}$ & $\begin{array}{l}0,220 \\
0,129\end{array}$ & $\begin{array}{l}0,074 \\
0,612\end{array}$ & $\begin{array}{c}-0,481 \\
0,001\end{array}$ & $\begin{array}{c}-0,732 \\
0,000\end{array}$ & $\begin{array}{c}-0,763 \\
0,000\end{array}$ & $\begin{array}{c}-0,542 \\
0,000\end{array}$ & $\begin{array}{l}-0,507 \\
0,000\end{array}$ & $\begin{array}{c}-0,654 \\
0,000\end{array}$ & $\begin{array}{c}-0,373 \\
0,008\end{array}$ & $\begin{array}{l}0,271 \\
0,060\end{array}$ & $\begin{array}{c}-0,010 \\
0,944\end{array}$ \\
\hline LIG & $\begin{array}{l}0,421 \\
0,003\end{array}$ & $\begin{array}{l}0,387 \\
0,006\end{array}$ & $\begin{array}{l}0,287 \\
0,046\end{array}$ & $\begin{array}{r}-0,197 \\
0,175\end{array}$ & $\begin{array}{c}-0,404 \\
0,004\end{array}$ & $\begin{array}{c}-0,505 \\
0,000\end{array}$ & $\begin{array}{c}-0,283 \\
0,049\end{array}$ & $\begin{array}{c}-0,485 \\
0,000\end{array}$ & $\begin{array}{c}-0,419 \\
0,003\end{array}$ & $\begin{array}{r}-0,241 \\
0,096\end{array}$ & $\begin{array}{l}0,094 \\
0,521\end{array}$ & $\begin{array}{c}-0,070 \\
0,630\end{array}$ \\
\hline CEL & $\begin{array}{l}0,197 \\
0,176\end{array}$ & $\begin{array}{l}0,112 \\
0,443\end{array}$ & $\begin{array}{l}0,002 \\
0,991\end{array}$ & $\begin{array}{r}-0,439 \\
0,002\end{array}$ & $\begin{array}{c}-0,653 \\
0,000\end{array}$ & $\begin{array}{c}-0,644 \\
0,000\end{array}$ & $\begin{array}{c}-0,494 \\
0,000\end{array}$ & $\begin{array}{c}-0,416 \\
0,003\end{array}$ & $\begin{array}{r}-0,570 \\
0,000\end{array}$ & $\begin{array}{c}-0,343 \\
0,016\end{array}$ & $\begin{array}{l}0,282 \\
0,050\end{array}$ & $\begin{array}{c}-0,013 \\
0,929\end{array}$ \\
\hline HEM & $\begin{array}{c}-0,036 \\
0,808\end{array}$ & $\begin{array}{l}0,090 \\
0,538\end{array}$ & $\begin{array}{l}0,186 \\
0,201\end{array}$ & $\begin{array}{l}0,265 \\
0,066\end{array}$ & $\begin{array}{l}0,281 \\
0,051\end{array}$ & $\begin{array}{l}0,314 \\
0,028\end{array}$ & $\begin{array}{l}0,235 \\
0,104\end{array}$ & $\begin{array}{l}0,155 \\
0,288\end{array}$ & $\begin{array}{l}0,277 \\
0,054\end{array}$ & $\begin{array}{l}0,077 \\
0,601\end{array}$ & $\begin{array}{c}-0,244 \\
0,091\end{array}$ & $\begin{array}{c}-0,126 \\
0,389\end{array}$ \\
\hline CELFDN & $\begin{array}{c}-0,005 \\
0,971\end{array}$ & $\begin{array}{r}-0,123 \\
0,399\end{array}$ & $\begin{array}{c}-0,193 \\
0,185\end{array}$ & $\begin{array}{r}-0,341 \\
0,016\end{array}$ & $\begin{array}{r}-0,402 \\
0,004\end{array}$ & $\begin{array}{c}-0,376 \\
0,008\end{array}$ & $\begin{array}{c}-0,336 \\
0,018\end{array}$ & $\begin{array}{c}-0,203 \\
0,161\end{array}$ & $\begin{array}{r}-0,349 \\
0,014\end{array}$ & $\begin{array}{c}-0,169 \\
0,247\end{array}$ & $\begin{array}{l}0,303 \\
0,034\end{array}$ & $\begin{array}{l}0,080 \\
0,585\end{array}$ \\
\hline LIGFDN & $\begin{array}{l}0,357 \\
0,012\end{array}$ & $\begin{array}{l}0,314 \\
0,028\end{array}$ & $\begin{array}{l}0,260 \\
0,072\end{array}$ & $\begin{array}{r}-0,047 \\
0,749\end{array}$ & $\begin{array}{c}-0,231 \\
0,110\end{array}$ & $\begin{array}{c}-0,344 \\
0,016\end{array}$ & $\begin{array}{r}-0,177 \\
0,223\end{array}$ & $\begin{array}{c}-0,466 \\
0,001\end{array}$ & $\begin{array}{r}-0,261 \\
0,071\end{array}$ & $\begin{array}{c}-0,212 \\
0,145\end{array}$ & $\begin{array}{l}0,164 \\
0,259\end{array}$ & $\begin{array}{c}-0,125 \\
0,393\end{array}$ \\
\hline FDAFDN & $\begin{array}{l}0,234 \\
0,105 \\
\end{array}$ & $\begin{array}{l}0,097 \\
0,506 \\
\end{array}$ & $\begin{array}{c}-0,059 \\
0,688 \\
\end{array}$ & $\begin{array}{c}-0,504 \\
0,000\end{array}$ & $\begin{array}{c}-0,688 \\
0,000\end{array}$ & $\begin{array}{c}-0,728 \\
0,000\end{array}$ & $\begin{array}{r}-0,527 \\
0,000\end{array}$ & $\begin{array}{c}-0,450 \\
0,001\end{array}$ & $\begin{array}{c}-0,629 \\
0,000\end{array}$ & $\begin{array}{c}-0,312 \\
0,029\end{array}$ & $\begin{array}{l}0,338 \\
0,018\end{array}$ & $\begin{array}{l}0,067 \\
0,647\end{array}$ \\
\hline $\begin{array}{l}c=\text { taxa } \\
L A G=t \\
U=\text { fraç }\end{array}$ & o nã & $\begin{array}{l}\text { ivel do } \\
\text { adação } \\
\text { coloni } \\
\text { legrada }\end{array}$ & $\begin{array}{l}\text { FDN p } \\
\text { do B } \\
\text { ação }\end{array}$ & encia & & grad & & & & & & \\
\hline
\end{tabular}




\section{CONCLUSÕES}

1) A produção total de $M S$ e a porcentagem de grãos na $M S$ não se mostram correlacionadas com a digestibilidade da MS e do FDN da fração volumosa de híbridos de milho, possibilitando um trabalho de seleção conjunto para produção e digestibilidade da porção volumosa.

2) Dentre os constituintes da parede celular, o teor de FDA da porção volumosa apresenta a maior relação com a degradabilidade efetiva da MS.

Como esta variável é relativamente fácil de se determinar, sugere-se que seja utilizado, doravante, como indicador da digestibilidade, usando-se a equação:

\section{Deg.ef $=100,6077-1,4085 *$ FDA}

3) A porcentagem de espigas na MS se mostra positivamente correlacionada com o teor de FDA da porção volumosa

4) Nenhuma análise química é capaz de explicar a variação na digestibilidade "in situ" do FDN medida por seu efeito de enchimento (Fill).

5) Híbridos com maior digestibilidade da fração volumosa não alteram o padrão de fermentação na ensilagem ( $\mathrm{pH}, \mathrm{N}-\mathrm{NH}_{3}$ e N-FDA).

6) A porcentagem de espigas na MS se mostra positivamente relacionada com a diferença de umidade entre as espigas e a fração volumosa, e com o teor de $\mathrm{N}-\mathrm{NH}_{3}$ das silagens.

7) O ambiente exerce grande influência sobre a expressão genética dos hibridos, porém não influi no teor de FDA da fração volumosa de híbridos de milho. 
8) A ocorrência de estresse hídrico (1996) diminui a produção total de MS e a participação das espigas na MS, porém aumenta a digestibilidade "in situ" da MS da fração volumosa dos híbridos. No entanto, pouco altera a digestibilidade do FDN.

9) Estes resultados destacam a necessidade de se realizar ensaios de desempenho de híbridos por vários anos experimentais, e em várias localidades, uma vez que de pouca valia é o resultado de um híbrido em um único ambiente, tanto para o pecuarista, quanto para o melhorista.

10) Dada a importância do assunto, novos experimentos devem ser realizados para se estudar a influência das características ambientais sobre a qualidade da planta de milho e a expressão genética dos híbridos. 


\section{REFERÊNCIAS BIBLIOGRÁFICAS}

ALLEN, M.S. Troubleshooting silage-based ration problems:Ruminal fermentation of fiber and starch. In: Silage production: From seed to animal National Silage Production Conference, Syracuse, New York, 1993. Proceedings. Ithaca: Northeast Regional Agricultural Engineering Service, 1993. p.186-195.

ALLEN, M.S. Physical constraints on voluntary intake of forages by ruminants. Journal of Animal Science, v.74, p.3063-3075, 1996.

ALLEN, M.S.; MAIN, D.G.; O'NEIL, K.A.; BECK, J. Variations in fiber fractions and in vitro true and cell wall digestibility of corn silage hybrids. Journal of Dairy Science, v.73, Suplemento 1, p.129, 1990.

ALLEN, M.S.; OBA, M. Increasing fiber digestibility may increase energy density, dry matter intake. Feedstuffs, p.12-17, Nov. 1996.

ALLEN, M.S.; OBA, M.; CHOI, B.R. Nutritionist's perspective on corn hybrids for silage. In: Silage: Field to Feedbunk North American Conference, Hershey, Pennsylvania, 1997. Proceedings. Ithaca: Northeast Regional Agricultural Engineering Service, 1997. p.25-36. 
ANIL, M.H.; MBANYA, J.N.; SYMONDS, H.W.; FORBES, J.M. Responses in the voluntary intake of hay or silage by lactating cows to intraruminal infusions of sodium acetate or sodium propionate, the tonicity of rumen fluid or rumen distension. British Journal of Nutrition, v.69, p.699-712, 1993.

ASSOCIATION OF OFFICIAL ANALYTICAL CHEMISTS. Official methods of analysis of the association of official chemists. 14ed. Washington, 1984. $1141 p$.

BALCH, C.C.; CAMPLING, R.C. Regulation of voluntary intake in ruminants. Nutrition Abstracts Review, v.32, p.669, 1962.

BAILE, C.A.; FORBES, J.M. Control of feed intake and regulation of energy balance in ruminants. Physiology Review, v.54, p.161, 1974.

BERGEN, W.G. Protein conservation in silage management. In: McCULLOUGH, M.E.; BOLSEN, K.K. (Ed) Silage management. West Des Moines: Silage Technology Division. National Feed Ingredients Association, 1990. cap.6, p.113-140.

BRATZLER, J.W.; KING, T.B.; THOMAS, W.I. Nutritive value of high-sugar corn silage. Journal of Animal Science, v.21, p.1218, 1965. /Abstract/

BUXTON, D.R.; CASLER, M.D. Environmental and genetic effects on cell-wall composition and digestibility. In: JUNG, H.G.; BUXTON, D.R.; HATFIELD, R.D.; RALPH, J. (Ed) Forage Cell Wall Structure and Digestibility. Madison: American Society of Agronomy, Crop Science Society of America, Soil Science Society of America, 1993. cap.25, p.685-714. 
CASTRO, F.B.de. Avaliação do processo de digestão do bagaço de cana-deaçucar (Saccharum sp. L) auto-hidrolisado em bovinos. Piracicaba, 1989. 123p. Dissertação (M.S.) - Escola Superior de Argicultura "Luiz de Queiroz".

CHENOST, M.; GRENET, E.; DEMARQUILLY, C.; JARRIGE, R. The use of the nylon bag technique for the study of forage digestion in the rumen and for predicting feed value. In: International Grassland Congress, 11th, Surfers Paradise, 1970. Proceedings. St.Lucia: University of Queensland Press, 1970. p.697-710.

COORS, J.G.; TOELKE, K.; ALBRECHT, K.A.; CARTER, P.R.; UNDERSANDER, D.J. Nutritive value of corn hybrids used as silage. Agronomy Abstracts, p.180, 1992.

COORS, J.G. Findings of the Wisconsin corn silage consortium. In: Seeds of Animal Nutrition Symposium, Rochester, New York, 1996. Proceedings. Rochester, 1996.

COX, W.J.; CHERNEY, D.J.; PARDEE, W.D. Forage quality index of corn hybrids under different growing conditions. Agronomy Journal, v.86, p.277282, 1994.

DAYNARD, T.B.; HUNTER, R.B. Relationships among whole-plant moisture, grain moisture, dry matters yield and quality of whole-plant corn silage. Canadian Journal Plant Science, v.55, p.77-84, 1975.

DEINUM, B. Genetic and environmental variation in quality of forage maize in Europe. Netherlands Journal of Agricultural Science, v.36, p.400-403, 1988. 
DEINUM, B; BAKKER, J.J. Genetic differences in digestibility of forage maize hybrids. Netherlands Journal Agricultural Science, v.29, p.93-98, 1981.

FAIREY, N.A. Hybrid maturity and the relative importance of grain and stover for the assessment of the forage potential of maize genotypes grown in marginal and non-marginal environments. Canadian Journal Plant Science, v.60, p.539-545, 1980.

FANCELLI, A.L.; LIMA, U.A. Millho - Produção, pré-processamento e transformação agro-industrial. Piracicaba:FEALQ, 1990. 112p.

FERRET, A.; GASA, J.; PLAIXATS, J.; CASAÑAS, F.; BOSCH, L.; NUEZ, F. Prediction of voluntary intake and digestibility of maize silages given to sheep from morphological and chemical composition, in vitro digestibility or rumen degradation characteristics. Animal Science, v.64, p.493-501, 1997.

FISCHER, L.J.; LOGAN, V.S.; DONOVAN, L.S.; CARSON, R.B. Factors influencing the dry matter intake and utilization of corn silage by lactating cows. Canadian Journal of Animal Science, v.48, p.207-214, 1968.

FLACHOWSKY, G.; PEYKER, W.; SCHNEIDE, S.; HENKEL, K. Fiber analyses and in sacco degradability of plant fractions of two corn varieties harvested at various times. Animal Feed Science and Technology, v.43, p.41-50, 1993.

GOERING, H.K.; VAN SOEST, P.J. Forage fiber analyses ( Apparatus, reagents, procedures and some applications ). Washington, D.C.: Agricultural Research Service USDA, 1970. 379p 
GORDON, C.H.; DERBYSHIRE, J.C.; VAN SOEST, P.J. Normal and late harvesting of corn for silage. Journal of Dairy Science, v.51, n.8, p.1258$1263,1968$.

GORDON, W.B.; RANEY, R.J.; STONE, L.R. Irrigation management practices for corn production in north central Kansas. Journal of Soil and Water Conservation, v.50, n.4, p.395-98, 1995.

HINTZ, R.W.; MERTENS, D.R.; BUXTON, D.R.; JUNG, H.G. Diversity among maize inbred lines for In Vitro digestion kinetics. Agronomy Abstracts, p.181, 1992.

HOVELL, F.D.DeB.; NGAMBI, J.W.W.; BARBER, W.P.; KYLE, D.J. The voluntary intake of hay by sheep in relation to its degradability in the rumen as measured in nylon bags. Animal Production, v.42, p.111-118, 1986.

HUBER, J.T.; GRAF, G.C.; ENGEL, R.W. Effect of maturity on nutritive value of corn silage for lactating cows. Journal of Dairy Science, v.48, p.1121$1123,1965$.

HUNT, C.W.; KEZAR, W.; HINMAN, D.D.; COMBS, J.J.; LOESCHE, J.A.; MOEN, T. Effects of hybrid and ensiling with and without a microbial inoculant on the nutritional characteristics of whole-plant corn. Journal of Animal Science, v.71, p.38-43, 1993.

HUNTER, R.B. Selection and evaluation procedures for whole-plant corn silage. Canadian Journal Plant Science, v.58, p.661-678, 1978.

JAMA, A.O.; OTTMAN, M.J. Timing of the first irrigation in corn and water stress conditioning. Agronomy Journal, v.85, n.6, p.1159-64, 1993. 
JOHNSON, J.C.; MONSON, W.G.; PETTIGREW, W.T. Variation in nutritive value of corn hybrids for silage. Nutrition Reports International, v.32, n.4, p.953-958, 1985.

JOHNSON, R.R.; MCCLURE, K.E. Corn plant maturity. IV. Effects on digestibility of corn silage in sheep. Journal Animal Science, v.27, n.2, 1968.

JUNG, H.G. Identification of cell wall traits that can be manipulated to improve forage digestibility. In. Dairy Forage Industry Conference, Madison, 1996. Proceedings. Madison: US Dairy Forage Research Center, 1996.

JUNG, H.G.; ALLEN, M.S. Characteristics of plant cell walls affecting intake and digestibility of forage by ruminants. Journal of Animal Science, v.73, p.2774-2790, 1995.

KEYSERLINGK, M.A.G.VOM; MATHISON, G.W. Use of the in situ technique and passage rate constants in predicting voluntary intake and apparent digestibility of forages by steers. Canadian Journal Animal Science, v.69, p.973-987, 1989.

LEASK, W.C.; DAYNARD, T.B. Dry matter yield, in vitro grain digestibility, percent protein, and moisture of corn stover following grain maturity. Canadian Journal of Plant Science, v.53, p.515-522, 1973.

LECHTENBERG, V.L.; COLENBRANDER, V.F.; BAUMAN, L.F.; RHYKERD, C.L. Effect of lignin on rate of in vitro cell wall and cellulose disappearance in corn. Journal of Animal Science, v.39, n.6, p.1165-1169, 1974. 
LOOMIS, W.E. The chemical composition of drought injured corn plants. Journal American Society of Agronomy, v.29, p.697, 1937.

LUNDVALL, J.P.; BUXTON, D.R.; HALLAUER, A.R.; GEORGE, J.R. Forage quality variation among maize inbreeds: in vitro digestibility and cell wall components. Crop Science, v.34, p.1672-1678, 1994.

MAHANNA, W.C. Genetic selection for forage nutritional quality. In: Ontario Ministry of Agriculture and Food "Quality Forage and Ruminants", Guelph \& Brockville, 1994. Proceedings. , Ontario, 1994.

MADSEN, J.; STENSIG, T.; WEISBJERG, M.R.; HVELPLUND, T. Estimation of the physical fill of feedstuffs in rumen by the in sacco degradation characteristics. Livestock Production Science, v.39,n.1, p.43-47,1994.

MARTEN, G.C.; GOODRICH, R.D.; JORDAN, R.M.; SCHMID, A.R.; MEISKE, J.C. Evaluation of laboratory methods for determining quality of corn and sorghum silages: III Biological and Chemical Methods for predicting Animal Intake. Agronomy Journal, v.68, p.289-291, 1976.

Mc CULLOUGH, M.E.; SICK, L.R.; SELL, O.E. Influence of silage dry matter intake on efficiency of milk production. Journal of Dairy Science, v.47, p.650$52,1964$.

MC DONALD, I. A revised model for the estimation of protein degradability in the rumen. Journal of Agricultural Science, v.96, n.1, p.251-252, 1981. 
MEDEIROS, S.R.de. Efeito da substituição do bagaço de cana de açucar auto hidrolisado por sorgo na fermentação ruminal em bovinos, digestibilidade in vivo em ovinos e desempenho animal em bovinos em acabamento. Piracicaba, 1992. 104p. Dissertação (M.S.) - Escola Superior de Argicultura "Luiz de Queiroz".

MERTENS, D.R. Application of theoretical mathematical models to cell wall digestion and forage intake in ruminants. Ithaca, 1973. Tese (Ph.D.) - Cornell University.

MERTENS, D.R. Regulation of forage intake. In: FAHEY, G.C.Jr.; COLLINS, M.; MERTENS, D.R.; MOSER, L.E. (Ed) Forage Quality, Evaluation, and Utilization. Madison: American Society of Agronomy, Crop Science Society of America, Soil Science Society of America, 1994. cap.11, p.450-493.

MERTENS, D.R. Predicting intake and digestibility using mathematical models of ruminal function. Journal of Animal Science, v.64, p.1548-1558, 1987.

MERTENS, D.R.; LOFTEN, J.R. The effect of starch on forage fiber digestion kinetics in vitro. Journal of Dairy Science, v.63, p.1437-1446, 1980.

MINSON, D.J. The effect of pelleting and wafering on the feeding value of roughage-A review. Journal British Grassland Society, v.18, p.39, 1963.

MOE, A.J.; CARR, S.B. Laboratory assays and Near-Infrared reflectance spectroscopy for estimates of feeding value of corn silage. Journal Dairy Science, v.68, p.2220-2226, 1985. 
MOORE, L.A. Symposium on forage utilization: Nutritive values of forage as affected by physical form. Part I. General principles involved with ruminants and effect of feeding pelleted or wafered forage to dairy cattle. Journal of Animal Science, v.23, p.230, 1964.

MORRISON, F.B. Feeds and Feeding. 22a.ed. Clinton: The Morrison Publishing Co, 1959. 1165p.

MULLER, L.D.; LECHTENBERG, V.L.; BAUMAN, L.F; BARNES, R.F.; RHYKERD, C.L. In vivo evaluation of a brown midrib mutant of Zea mays L. Journal of Animal Science, v.35, p.883-889, 1972.

NOCEK, J.E. Evaluation of specific variables affecting in situ estimates of ruminal dry matter and protein digestion. Journal of Animal Science, v.60, n.5, p.1347-58, 1985.

NUSSIO, L.G.; PENATI, M.A.; CORSI, M.; BOSE, M.L.V.; BARBEIRO, V.E.S.; ROSSI, P.; PEREIRA, J.R.A. Avaliação de parâmetros nutricionais de hibrido de milho para a produção de silagem. In: Reunião Anual da Sociedade Brasileira de Zootecnia, Lavras, 1992. Anais. Lavras: SBZ, 1992, p.58.

NUSSIO, L.C. Avaliação de cultivares de milho (Zea mays L.) para ensilagem através da composição química e digestibilidade "in situ". Piracicaba, 1997. 58p. Dissertação (M.S.) - Escola Superior de Argicultura "Luiz de Queiroz".

OLIVEIRA, J.S.; BRAGA, R.A.N.; LOPES, F.C.F; VITTORI, A.; RESENDE, H. Avaliação da qualidade da planta de milho para silagem. In: Reunião Anual da Sociedade Brasileira de Zootecnia, Juiz de Fora, 1997. Anais. Juiz de Fora: SBZ, 1997. v.1, p.161-163. 
OWEN, F.G. Factors affecting nutritive value of corn and sorghum silage. Journal of Dairy Science, v.50, p.404-416, 1967.

PENATI, M.A. Relação de alguns parâmetros agronômicos e bromatológicos de híbridos de milho ( Zea mays L.) com a produção, digestibilidade e teor de matéria seca da planta. Piracicaba, 1994. 97p. Dissertação (M.S.) Escola Superior de Agricultura "Luiz de Queiroz".

POPPI, D.P.; MINSON, D.J.; TERNOUTH, J.H. Studies of cattle and sheep eating leaf and stem fractions of grasses. I. The voluntary intake, digestibility and retention time in the reticulo-rumen. Australian Journal Agricultural Research, v.32, p.99-108, 1981.

ROSSI JUNIOR, P. Degradabilidade ruminal dos componentes da fração nitrogenada e de carboidratos de silagem de milho, farelo de soja e sorgo grão, em bovinos da raça nelore. Piracicaba, 1994. 100p. Dissertação (M.S.) - Escola Superior de Agricultura "Luiz de Queiroz".

ROTH, G.W. Forage quality differences and stability for corn hybrids in Pennsylvania. Agronomy Abstracts, p.184, 1992.

ROTH, G.W. Consistency of corn hybrid quality differences for silage in the northeast U.S. In: Silage production: From seed to animal National Silage Production Conference, Syracuse, New York, 1993. Proceedings. Ithaca: Northeast Regional Agricultural Engineering Service, 1993. p.28-37.

ROTH, G.W.; LAUER, J.G. Agronomist's perspective of corn hybrids for silage. In: Silage: Field to Feedbunk North American Conference, Hershey, Pennsylvania, 1997. Proceedings. Ithaca: Northeast Regional Agricultural Engineering Service, 1997. p.15-24. 
ROTH, L.S.; MARTEN, G.C.; COMPTON, W.A.; STUTHMAN, D.D. Genetic variations of quality traits in maize (Zea Mays L.) forage. Crop Science, v.10, p.365-367, 1970.

RUSSEL, J.R.; IRLBECK, N.A.; HALLAUER, A.R.; BUXTON, D.R. Nutritive value and ensiling characteristics of maize herbage as influenced by agronomic factors. Animal Feed Science and Technology, v.38, p.11-24, 1992.

SANDERSON, M.A.; JONES, R.M.; READ, J.C.; LIPPKE, H. Digestibility and lignocellulose composition of forage corn morphological components. Journal of Production Agriculture, v.8, n.2, p.169-174, 1995.

SAS. SASISTAT User's guide: Version 6. 4ed. Cary, 1990.

SCHMID, A.R.; GOODRICH, R.D.; JORDAN, R.M.; MARTEN, G.C.; MEISKE, J.C. Relationships among agronomic characteristics of corn and sorghum cultivars and silage quality. Agronomy Journal, v.68, p.403-406, 1976.

SNAYDON, R.W. The effect of total water supply, and of frequency of application, upon Lucerne. II. Chemical composition. Australian Journal of Agricultural Research, v.23, p.253-256, 1972.

SONON, R.N.; DALKE, B.S.; BOLSEN, K.K.; BOYER, J.E. Effect of grain content on nutritive value of whole-plant corn silage. Journal of Animal Science, v.71, Suplemento 1, p.266, 1993.

SUSMEL, P.; STEFANON, B.; MILLS, C.R.; SPANGHERO, M. Rumen degradability of organic matter, nitrogen and fiber fractions in forages. Animal Production, v.51, p.515-526, 1990. 
TIEMANN, D.G.; BOLSEN, K.K.; JOHNSON, D. An evaluation of seven Pioneer corn hybrids for silage and a comparison of irrigated vs. dryland silages. Journal of Animal Science, v.68, Suplemento 1, p.557, 1990.

UNDERSANDER, D. Perspectives on forage sampling, handling, and analysis. In: Silage: Field to Feedbunk North American Conference, Hershey, Pennsylvania, 1997. Proceedings. Ithaca: Northeast Regional Agricultural Engineering Service, 1997. p.262-267.

VAN SOEST, P.J. Symposium on factors influencing the voluntary intake of herbage by ruminants: voluntary intake in relation to chemical composition and digestibility. Journal of Animal Science, v.24, p.834-843, 1965.

VAN SOEST, P.J.; MERTENS, D.R.; DEINUM, B. Preharvest factors influencing quality of conserved forage. Joumal of Animal Science, v.47, n.3, p.712-720, 1978.

VAN SOEST, P.J.; ROBERTSON, J.B.; LEWIS, B.A. Methods for dietary fiber, neutral detergent fiber and nonstarch polysaccharides in relation to animal nutrition. Journal of Dairy Science, v.74, n.9, p.1-15, 1991.

VAN SOEST, P.J.; ALLEN, M.S. Limitations of prediction systems for digestibility and ration balancing. In: Silage production: From seed to animal National Silage Production Conference, Syracuse, New York, 1993. Proceedings. Ithaca: Northeast Regional Agricultural Engineering Service, 1993. p.196-209.

VAN SOEST, P.J. Nutritional ecology of the ruminant. 2.ed. Cornell: Cornell University Press, 1994. 476p. 
VARGA, G.A.; HOOVER, W.H. Rate and extend of neutral detergent fiber degradation of feedstuffs in situ. Journal of Dairy Science, v.66, n.10, p.2109-2115, 1983.

VATTIKONDA, M.R.; HUNTER, R.B. Comparison of grain yield and wholeplant silage production of recommended corn hybrids. Canadian Journal of Plant Science, v.63, p.601-609, 1983.

WALDO, D.R.; SMITH, L.W.; COX, E.L. Model of cellulose disappearance from the rumen. Journal of Dairy Science, v.55, p.125-129, 1972.

WEAKLEY, D.C.; STERN, M.D.; SATTER, L.D. Factors affecting disappearance of feedstuffs from bags suspended in the rumen. Journal of Animal Science, v.56, n.2, p.493-507, 1983.

WILKERSON, V. ${ }^{a}$; KLOPFENSTEIN, T.J.; STROUP, W.W. A collaborative study of In Situ forage protein degradation. Journal of Animal Science, v.73, p.583-588, 1995.

WILKINS, R.J.; HUTCHINSON, K.J.; WILSON, R.F.; HARRIS, C.E. The voluntary intake of silage by sheep. I. Interrelationships between silage composition and intake. Journal of Agricultural Science, v.77, p.531-537, 1971.

WOLF, D.P.; COORS, J.G.; ALBRECHT, K.A.; UNDERSANDER, D.J.; CARTER, P.R. Forage quality of maize genotypes selected for extreme fiber concentrations. Crop Science, v.33, p.1353-1359, 1993. 